\section{Pacific Northwest}

National Laboratory

Operated by Battelle for the

U.S. Department of Energy

\title{
Evaluation of PFP Furnace Systems for Thermal Stabilization of Washed High Chloride Plutonium Oxide Items
}

\author{
C. M. Fischer \\ D. S. Muzatko \\ M. R. Elmore \\ S. R. Gano \\ A. J. Schmidt \\ B. M. Thornton
}

M. A. Gerber

December 17, 2002

Prepared for Fluor Hanford by

Pacific Northwest National Laboratory

Richland, Washington 99352 


\title{
DISCLAIMER
}

This report was prepared as an account of work sponsored by an agency of the United States Government. Neither the United States Government nor any agency thereof, nor Battelle Memorial Institute, nor any of their employees, makes any warranty, express or implied, or assumes any legal liability or responsibility for the accuracy, completeness, or usefulness of any information, apparatus, product, or process disclosed, or represents that its use would not infringe privately owned rights. Reference herein to any specific commercial product, process, or service by trade name, trademark, manufacturer, or otherwise does not necessarily constitute or imply its endorsement, recommendation, or favoring by the United States Government or any agency thereof, or Battelle Memorial Institute. The views and opinions of authors expressed herein do not necessarily state or reflect those of the United States Government or any agency thereof.

\author{
PACIFIC NORTHWEST NATIONAL LABORATORY \\ operated by \\ BATTELLE \\ for the \\ UNITED STATES DEPARTMENT OF ENERGY \\ under Contract DE-AC06-76RL01830
}

This document was printed on recycled paper. 


\section{Evaluation of PFP Furnace Systems for Thermal Stabilization of Washed High Chloride Plutonium Oxide Items}

C. M. Fischer

M. R. Elmore

A. J. Schmidt

M. A. Gerber

D. S. Muzatko

S. R. Gano

B. M. Thornton

December 17, 2002

Prepared for Fluor Hanford

Work Supported by

the U.S. Department of Energy

under Contract DE-AC06-76RL01830

Pacific Northwest National Laboratory

Richland, Washington 99352 


\section{Summary}

Currently at the Plutonium Finishing Plant (PFP), there are 939 items, weighing nearly 1.1 metric tons, that consist of impure plutonium oxides, referred to as high chloride content plutonium (HCP) oxides. These HCP oxides, which were generated at the Rocky Flats Environmental Technology Site in various molten salt processes (electrorefining, molten salt extraction, and direct oxide reduction), contain $\mathrm{NaCl}$, $\mathrm{KCl}, \mathrm{MgCl}_{2}$ and/or $\mathrm{CaCl}_{2}$ salts at potentially high concentrations. These materials pose special challenges to stabilization, because volatile chloride salts can corrode furnace heating elements and downstream ventilation components. In the cooler zones of the ventilation system, the chloride salts can condense and blind filters or plug the vent line. Also, some of the chloride salt impurities are hygroscopic and those remaining in the calcined solids can make it difficult to meet the DOE standard for moisture content prior to sealing the stabilized product in 3013 canisters.

In an evaluation conducted for PFP, Pacific Northwest National Laboratory (PNNL) recommended converting PFP's existing solutions precipitation equipment to a washing process as the preferred option for treating the HCP oxides, as well as using the existing PFP RMC furnaces to thermally stabilize the washed material. As further requested by PFP, PNNL performed testing to validate the recommended use of existing furnaces for thermal stabilization. The results of this testing are summarized here.

For evaluating the use of the existing furnace systems, a prototypical high-temperature furnace (same make and model as used at RMC at PFP) and the associated offgas system were set up and operated at PNNL to identify system vulnerabilities and to investigate alternative materials and operating conditions that would mitigate corrosion and plugging. The furnace system evaluation focused on 1) furnace heating element longevity, 2) corrosion and plugging of the internal and external offgas lines, 3) salt collection efficiency and plugging of the filter cartridges or knockout pot, and 4) corrosion of the system components and coupon specimens (Inconel 690, Haynes HR-160, Haynes 214, and Hastelloy X). Fifty test cycles were attempted using the standard PFP thermal stabilization protocol (a 5.5-hr controlled ramp from room temperature to $1000^{\circ} \mathrm{C}$, a $2-\mathrm{hr}$ hold at $1000^{\circ} \mathrm{C}$, and cooling from $1000^{\circ} \mathrm{C}$ to room temperature); 47 cycles were completed successfully. For each cycle, the furnace was charged with a $\mathrm{CeO}_{2}$ simulant impregnated with either $16 \mathrm{~g}$ or $20 \mathrm{~g}$ of chloride salts $(45 \mathrm{~mole} \% \mathrm{NaCl}, 45 \mathrm{~mole} \% \mathrm{KCl}$, and $10 \mathrm{~mole} \% \mathrm{MgCl}_{2}$ ). Each simulant charge represented $1600 \mathrm{~g}$ or $2000 \mathrm{~g}$ of washed $\mathrm{PuO}_{2}$ containing a residual of $1 \mathrm{wt} \%$ chloride salts.

During the 50 furnace test cycles, only one furnace element failed (during the $16^{\text {th }}$ cycle). This failure is believed to be the result of arcing caused by contact between a side furnace element and the Hastelloy X sample boat. As a result of the thermal cycling, the width of the sample boat had increased to about 5.25 in. (from 5.0 in.). Further furnace element failures were avoided by monitoring the boat width and adjusting it back to 5.0 in. between cycles. Consequently, during actual operations, sample boats should be examined for evidence of bowing after every cycle and the boats should be accurately centered between the side heating elements when being loaded into the furnace.

After the $5^{\text {th }}$ furnace cycle, the internal Inconel 600 tube failed as a result of severe corrosion, which was apparently caused by a zone of condensed molten chloride salts. The susceptibility of the Inconel 600 tube to chloride salts at high temperature was confirmed by a subsequent near failure of a second internal tube after three cycles and by coupon testing in the sample boat. Coupon testing also identified Inconel 690 as exhibiting a lower corrosion rate than other materials tested. Therefore, the internal offgas line was replaced with a heavy-walled Inconel 690 line, and an acceptable service life was obtained (i.e., greater than 12 cycles). While the internal offgas line underwent significant corrosive attack (with both 
Inconel 600 and Inconel 690), the cooler external offgas line (Inconel 600) was structurally sound even after 46 cycles.

Plugging in the internal and external (between furnace and filter) offgas lines was determined to be the most frequent means of operational failure. Routine line cleaning was found to prevent further failures. Partially failed offgas lines were provided to PFP pipe fitters for development and testing of cleaning tools. Also, evidence of significant offgas line plugging was detected in some cases by observing the pressure drop through the offgas line.

A number of knockout pot and filter cartridge configurations, all rated for high-temperature operation, were tested to identify a system that provided good particulate collection efficiency and that could be operated for multiple cycles before cleaning or cartridge replacement. While packed knockout pots provided reasonable operability, they did not efficiently remove salt particles. Both depth filters and absolute filters, rated from 5 to $100 \mu \mathrm{m}$, were tested and removed essentially all of the salt particulate. Service life depended on the available filter surface area, and therefore, pleated stainless steel filters, which exhibit three to five times more surface area per unit volume, are recommended for PFP. Under the conditions investigated, a 20-in.-long, 2.6-in.-diameter pleated stainless steel cartridge, which roughly fits within the current PFP filter footprint, could be operated for five cycles before blinding.

During the furnace testing, information on corrosion rates was collected by monitoring the appearance and weight loss of system components (furnace vent baffle plate, sample boat, offgas tubes) and corrosion coupons placed in the sample boat. These data showed that in the high-temperature chloride salt environment, the coupons tested exhibited high corrosion rates (400 to 700 mils per year), but the mechanism was predominantly uniform corrosion as compared to localized corrosion (pitting). The corrosion rate exhibited by Hastelloy X (the current material of construction for the boats) was significantly higher than that of the other materials. However, a Hastelloy X sample boat survived 40 cycles before being retired without any failures, including welds. Inconel 690 and Haynes HR-160 displayed the lowest relative corrosion rates.

From the results of this evaluation, along with the modifications recommended below, reasonable process operability should be achieved using the existing PFP furnaces. The $1 \%$ chloride salt content in the simulant represents the expected residual salt level in a moderately efficient washing process. More efficient washing will reduce the mass of chloride salts charged to the furnaces and improve the overall thermal stabilization operability. 
Furnace System Vulnerabilities and Recommended Mitigation Approaches

\begin{tabular}{|c|c|c|}
\hline $\begin{array}{c}\text { Identified } \\
\text { Vulnerability }\end{array}$ & Failure Mode & Recommended Mitigation Approach \\
\hline $\begin{array}{l}\text { Furnace element } \\
\text { failure }\end{array}$ & Arcing through boat & $\begin{array}{l}\text { - } \begin{array}{l}\text { Do not allow boat to contact furnace } \\
\text { element }\end{array} \\
\text { - Monitor and maintain appropriate boat } \\
\text { width } \\
\text { - } \quad \text { Consider using a boat alignment tool for } \\
\text { proper placement of boat in furnace }\end{array}$ \\
\hline $\begin{array}{l}\text { Internal offgas line } \\
\text { failure }\end{array}$ & Corrosion & $\begin{array}{l}\text { - Change Inconel } 600 \text { tube to heavy-wall } \\
\text { Inconel } 690 \text { tube/pipe. } \\
\text { - Bore-out bulkhead to eliminate fittings } \\
\text { and simplify cleaning/line replacement }\end{array}$ \\
\hline $\begin{array}{l}\text { Internal and External } \\
\text { offgas line plugging }\end{array}$ & $\begin{array}{l}\text { Chloride salt } \\
\text { condensation }\end{array}$ & $\begin{array}{l}\text { - Maximize salt removal during HCP item } \\
\text { washing } \\
\text { Bore-out bulkhead to eliminate fittings } \\
\text { and simplify cleaning/line replacement } \\
\text { - Plan for routine/frequent line clean out } \\
\text { and/or plan for routine/frequent line } \\
\text { replacement } \\
\text { - Consider larger pipe diameter } \\
\text { - Monitor pressure drop to assess salt build } \\
\text { up in lines }\end{array}$ \\
\hline Filter failure & $\begin{array}{l}\text { Blinding from } \\
\text { chloride salt } \\
\text { accumulation }\end{array}$ & $\begin{array}{l}\text { - Maximize salt removal during HCP item } \\
\text { washing } \\
\text { - Use pleated stainless steel filters to } \\
\text { increase filter surface area. }\end{array}$ \\
\hline $\begin{array}{l}\text { Boat distortion } \\
\quad \text { (bowing) }\end{array}$ & $\begin{array}{l}\text { Thermal cycling and } \\
\text { corrosion }\end{array}$ & $\begin{array}{l}\text { - Consider fabricating Hastelloy X boats } \\
\text { with width reduced by } \sim 1 / 4 \text { in. }\end{array}$ \\
\hline
\end{tabular}




\section{Contents}

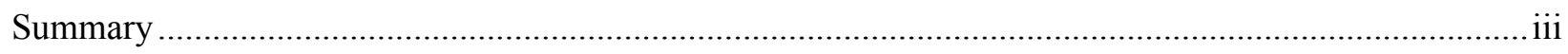

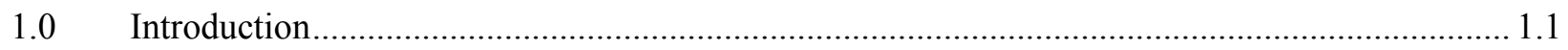

$2.0 \quad$ Test Approach, Equipment, and Methods........................................................................ 2.1

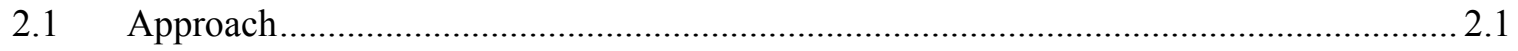

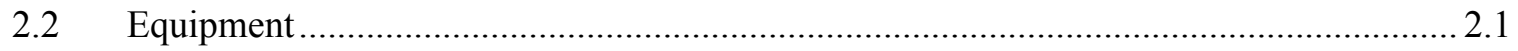

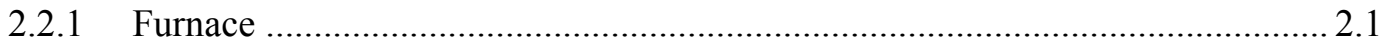

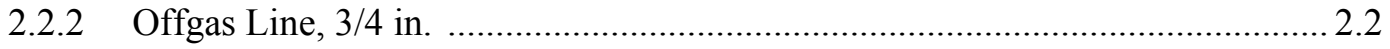

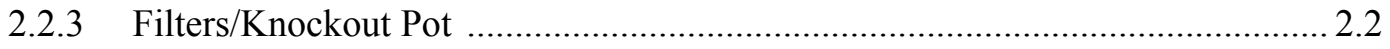

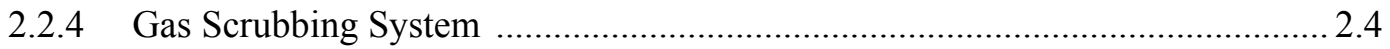

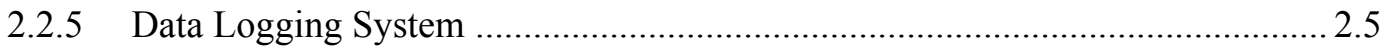

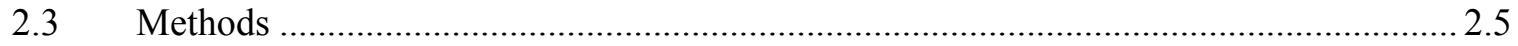

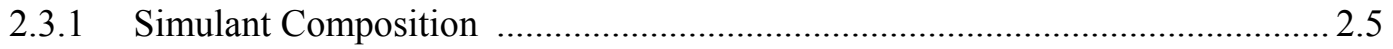

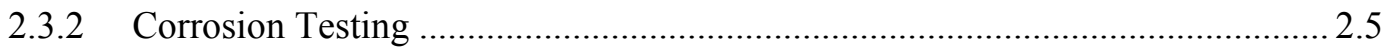

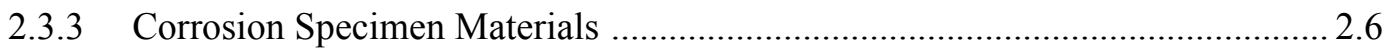

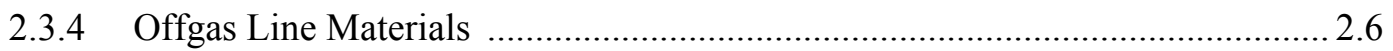

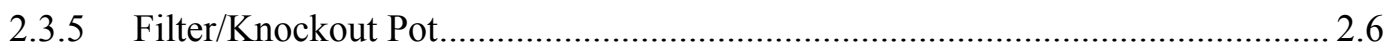

2.3.6 Furnace Operation/Process Variables ............................................................ 2.6

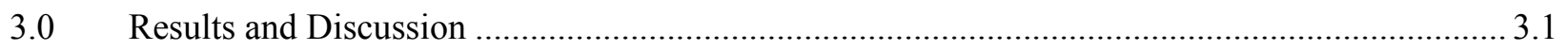

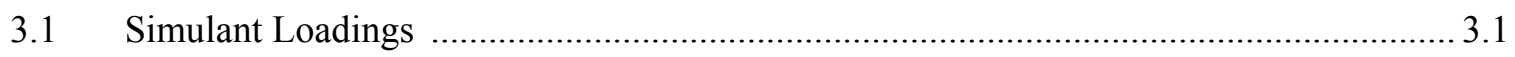

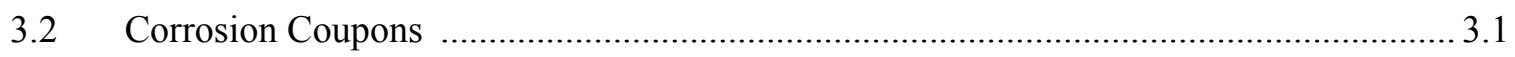

3.2.1 Inconel 690, Haynes HR-160, Haynes 214, and Hastelloy X Coupons .............. 3.1

3.2.2 Other Coupon Specimens …....................................................................... 3.2

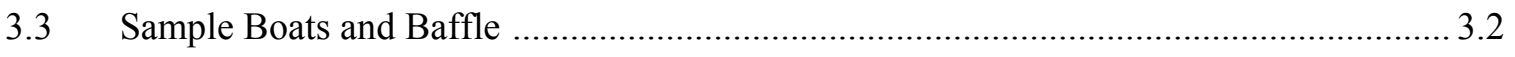

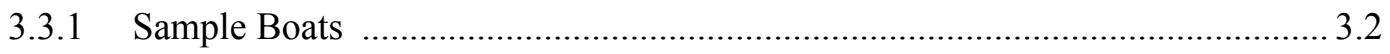

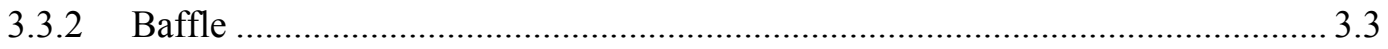

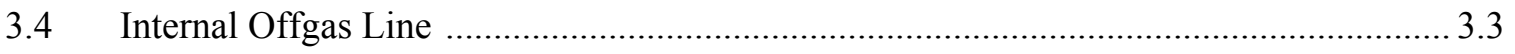

3.4.1 Inconel 600 Offgas Line, 3/4-in.-OD Tubing (6-in. long) ................................ 3.3

3.4.2 Inconel 690 Offgas Line, 3/4-in.-OD Pipe (6-in. long)...................................... 3.4

3.4.3 High Temperature Ceramic Offgas Line, 3/4-in.-OD Tubing (11-in. long) ....... 3.4

3.4.4 Inconel 690 Offgas Line, 3/4-in.-OD Pipe (11-in. long)...................................... 3.4 


\section{Contents (continued)}

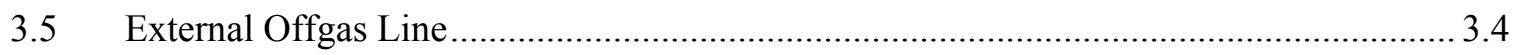

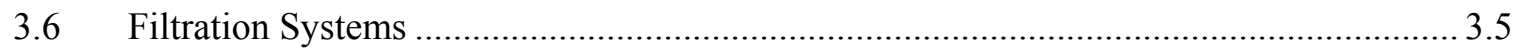

3.6.1 Purlator Cartridge with Shelco Housing .............................................................. 3.6

3.6.2 Nowata Filtration System (Glass-Wound Cartridges) ….................................. 3.6

3.6.3 Rosedale Filtration System (Pleated Metal Filters) .......................................... 3.6

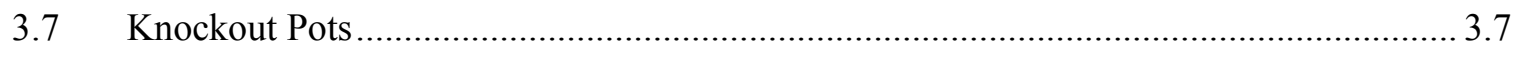

3.7.1 2-in. Schedule 40 Stainless Steel Pipe …...................................................... 3.7

3.7.2 Nowata Filter Housing Conversion............................................................ 3.7

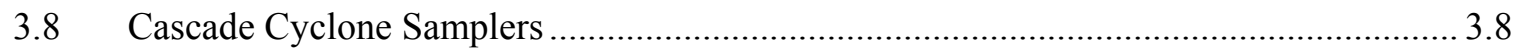

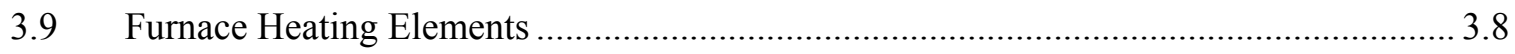

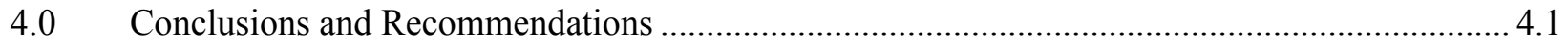

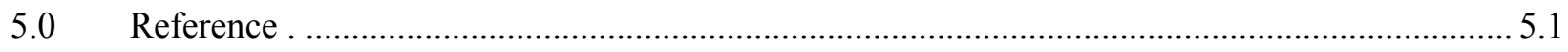

Appendix A, Basis for Simulant Composition ................................................................................ A.1

Appendix B, Furnace Operation using Heating Cycle Planned for High-Chloride Pu Oxide

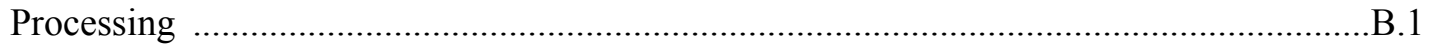

Appendix C, Cycle-by-Cycle Summary for HCP Oxides Furnace Corrosion Tests ................................1

Appendix D, Analysis of Deposits in Inconel Furnace Offgas Tube (Inside Furnace) ......................... D.1

\section{Tables}

3.1 Total Number of Test Cycles for Each Equipment Configuration Material Used....................... 3.9

3.2 Performance Summary for Inconel 690, Haynes HR-160, Haynes 214, and Hastelloy X

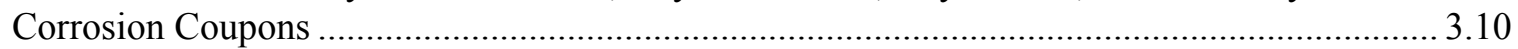

3.3 Performance Summary for Boats \#1 and \#2, and Baffle \#1 .................................................... 3.10

3.4 Performance Summary for Internal Offgas Line Configurations ........................................... 3.11

3.5 Performance Summary for Filter Systems Tested .............................................................. 3.11

3.6 Performance Summary for Knockout Pot Systems Tested ..................................................... 3.12

4.1 Furnace System Vulnerabilities and Recommended Mitigation Approaches............................ 4.1 


\section{Figures}

2.1 Test Stand for PFP Furnace and Offgas System Evaluation...................................................... 2.7

2.2 Furnace, 3/4-in. Offgas Lines, and Filter/Knockout Pot Configuration ................................... 2.8

2.3 Front View of the Furnace Chamber to Show the Arrangement of the Baffle and

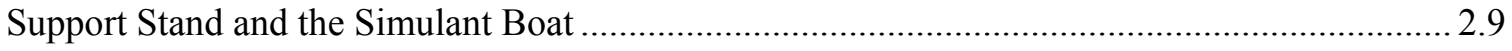

2.4 Internal Offgas Line Inlet and Controller Thermocouple as Installed in the Furnace ............... 2.10

2.5 Bulkhead Used to Connect the External Offgas Line to a 6-in.-long Internal Offgas Line........ 2.10

2.6 Bored-Out Bulkhead for Supporting 11-in.-long Internal Offgas Lines .................................. 2.11

2.7 Schematic of a Purlator Cartridge Filter Installed in a Shelco Housing ................................... 2.12

2.8 Shelco Housing and Purlator Cartridge Before a Test Cycle.................................................. 2.13

2.9 Schematic of the Nowata Filtration System Implementing Woven Glass Filter Cartridges....... 2.14

2.10 Nowata Filter Housing and Cartridges Before Installation................................................... 2.15

2.11 Schematic of the Rosedale Filtration System Implementing Pleated Metal Filter Cartridges.... 2.16

2.12 Rosedale Filter Housing and Cartridge Before Installation ................................................... 2.17

2.13 Schematic of the 2-in. Schedule 40 Stainless Steel Knockout Pot .......................................... 2.18

2.14 2-in. Schedule 40 Stainless Steel Knockout Pot Housing and Intalox Ceramic Packing

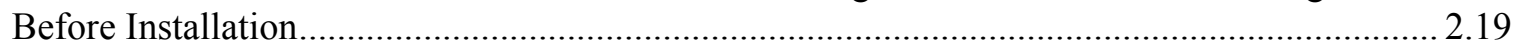

2.15 Schematic of the Nowata Filter Housing Converted to a Knockout Pot .................................. 2.20

2.16 Nowata Knockout Pot Conversion and 10-mm Nominal Interpack Stainless Steel Packing

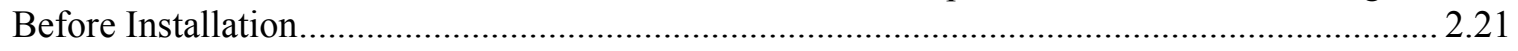

2.17 Series 280 In-Stack Cascade Cyclone Samplers ................................................................. 2.22

2.18 Blower and Control Valve Used to Draw Offgas from Furnace............................................2.23

3.1 New Coupon Specimens Loaded in the Simulant Boat ........................................................ 3.13

3.2 Percent Weight Loss Versus Number of Cycles Completed for Coupon Set \#1 ...................... 3.14

3.3 Percent Weight Loss Versus Number of Cycles Completed for Coupon Set \#2 ...................... 3.14

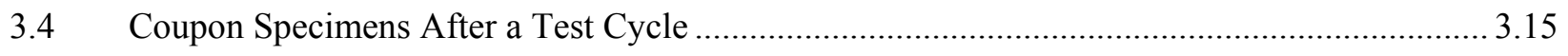

3.5 Haynes HR-160 Coupon with Scale Buildup …................................................................... 3.15

3.6 Haynes 214 Coupon with a Broken Corner ....................................................................... 3.16

3.7 Wedge-Shaped Coupons from Set \#1 After 19 Consecutive Test Cycles ................................ 3.16

3.8 Inconel 690-1 (Inc-690-1) and Haynes 214-1(HA-214-1) Coupons at the Front

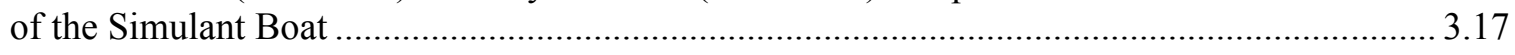

3.9 Zircaloy Tubing Used as a Corrosion Coupon.................................................................... 3.18

3.10 Zircaloy Tubing Residue After One Test Cycle ................................................................... 3.18

3.11 Inconel 600 Tubing Used as a Corrosion Coupon. Condition after one test cycle................... 3.19 


\section{Figures (continued)}

3.12 Inconel 600 Tubing Used as a Corrosion Coupon. Condition after three test cycles.

3.13 Percent Weight Loss Versus Number of Cycles Completed for Simulant Boats \#1 and \#2, and Baffle \#1

3.14 Corrosion at the Bottom of Simulant Boat \#2 After Five Test Cycles .................................... 3.20

3.15 Scale Buildup on Baffle After 50 Test Cycles....................................................................... 3.21

3.16 Inconel 600 Internal Offgas Line After Five Test Cycles ...................................................... 3.21

3.17 Approximate Location of Hard Deposits that Formed in the Inconel 600 Internal

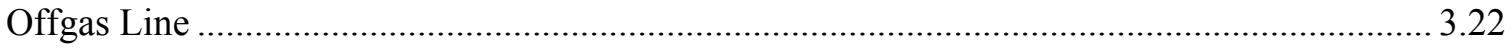

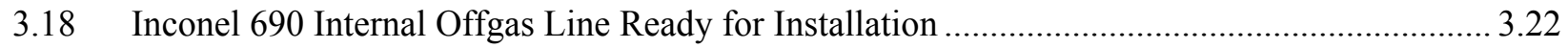

3.19 Salt Deposits and Corrosion Products Removed from Inconel 690 Internal Offgas Line .......... 3.23

3.20 Approximate Location of Hard Deposits Removed from Inconel 690 Internal Offgas Line...... 3.23

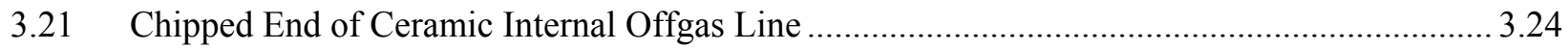

3.22 Final Bend on Inconel 600 External Offgas Line Plugged with Salt Deposits ......................... 3.24

3.23 Purlator Sintered Metal Cartridge Blinded by Salt Deposits ..................................................... 3.25

3.24 New Cartridge Initial Pressure Drop and Final Pressure Drop at the End of Each Completed Cycle for Nowata Woven Glass Filter Cartridges ................................................... 3.26

3.25 Woven Glass Fiber Cartridge Blinded by Salts Compared to New Cartridge ............................ 3.27

3.26 Darkened Area of 100- $\mu \mathrm{m}$ Woven Glass Filter Cartridge After Three Test Cycles ................... 3.28

3.27 New Cartridge Pressure Drop and Final Pressure Drop at the End of Each Completed Cycle for Rosedale Pleated Metal Filters....................................................................................... 3.29

3.28 Salt Deposits on Outer Shell (pleated protector) of 20-micron Rosedale Pleated Metal Filter Cartridge After Five Test Cycles........................................................................................ 3.29

3.29 20-micron Rosedale Pleated Metal Filter Cartridge Blinded by Salt Deposits After

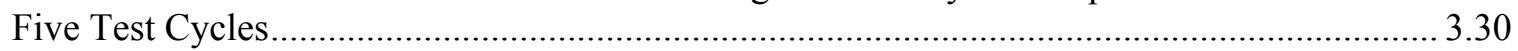

3.30 Intalox Ceramic Packing and Wire Mesh in 2-in. Schedule 40 Stainless Steel Knockout Pot ... 3.31

3.31 Inlet Port of the Nowata Housing that Filled with Packing and Plugged During the

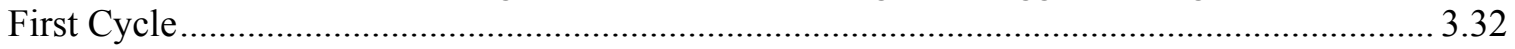

3.32 Interpack 10-mm Nominal Packing After Two Test Cycles.................................................. 3.32

3.33 Salt Deposits on Internal Walls of In-Stack Cascade Cyclone Samplers .................................. 3.33

3.34 Typical Furnace Voltage/Current Profile During a Test Cycle ................................................ 3.33

3.35 Hole Caused by the Side-Heating Element Arcing to the Boat ................................................3.34

3.36 Area Where Side-Heating Element Failed and Arced Across to the Simulant Boat ................. 3.34

3.37 Top Heating Element After 31 Test Cycles ........................................................................ 3.35 


\subsection{Introduction}

At the Hanford Plutonium Finishing Plant (PFP), 939 items, weighing nearly 1.1 metric tons, consist of impure plutonium oxides, referred to as high chloride content plutonium (HCP) oxides. The HCP oxides, which were generated at the Rocky Flats Environmental Technology Site in various molten salt processes (electrorefining, molten salt extraction, and direct oxide reduction), contain $\mathrm{NaCl}, \mathrm{KCl}, \mathrm{MgCl}_{2}$ and/or $\mathrm{CaCl}_{2}$ salts at potentially high concentrations. Because volatile chloride salts can corrode furnace heating elements and downstream ventilation components, the HCP oxides pose special challenges to stabilization. In the cooler zones of the ventilation system, for example, the chloride salts can condense and blind filters or plug the vent line. Also, some of the chloride salt impurities are hygroscopic, and those remaining in the calcined solids can make it difficult to meet the DOE standard for moisture content prior to sealing the stabilized product in 3013 canisters.

An evaluation of alternative solids washing processes conducted by the Pacific Northwest National Laboratory (PNNL) for Fluor Hanford (FH), in the spring of 2002, concluded that using the existing solutions precipitation system at PFP to wash the HCP solids appeared to be the simplest and most costeffective method for meeting DOE standards and for addressing treatment and process development issues (Letter Report PNNL 43925-L01, "Technical Evaluation of Candidate Alternatives for Treating High Chloride Content Plutonium Oxides at the Plutonium Finishing Plant"). The study concluded that it may be necessary to reach a target salt concentration of $0.25 \%$ or less to ensure that most washed batches of HCP solids would meet the $0.5 \%$ moisture limit established by the DOE Standard, Stabilization, Packaging, and Storage of Plutonium-bearing Materials (DOE-STD-3013-2000) and to minimize corrosion to furnace components during thermal stabilization. Modeling used in the study suggested that three or four stages of washing would be required to meet this limit. ${ }^{(a)}$ The study also recommended that the existing PFP RMC furnaces be used to thermally stabilize the washed material to prevent corrosion problems with the SPE furnace systems, since the RMC furnaces would be easier to maintain if corrosion became an issue.

Based in part on the recommendations from Letter Report 43925-L01, PFP contracted with PNNL to conduct the necessary testing to validate the conversion of existing precipitation equipment for washing and the use of existing furnaces for thermal stabilization of the washed material. Results from testing a modified precipitation vessel for HCP item washing are given in Letter Report 44820-RPT02, "Results of FY 2003 Testing of PFP Prototype Washing System." Results from the evaluation of PFP furnaces for thermal stabilization are provided within this document.

A high-temperature furnace (same make and model as used at the RMC at PFP) and the associated offgas system were set up at PNNL to identify system vulnerabilities and to investigate alternative materials and operating conditions that would mitigate any corrosion and plugging of furnace and offgas components. The key areas of interest for this testing were the furnace heating elements, the offgas line located inside the furnace, the offgas line between the furnace and the filter/knockout pot, the filter/knockout pot, the sample boat, and corrosion coupons to evaluate alternative materials of construction. The evaluation was conducted by charging the furnace with $\mathrm{CeO}_{2}$ that had been impregnated with a mixture of chloride salts

(a) Subsequent laboratory testing with simulants and modeling was performed to further examine HCP oxide washing strategies and to examine subsequent moisture uptake of the washed material (Letter Report 41921-RPT02, "Evaluation of Solids Rinsing to Treat PFP High Chloride Plutonium Solids"). This evaluation showed that a three-stage countercurrent washing strategy could be used to achieve the required chloride salt removal. 
(selected to represent the expected residual chloride salt level in washed high chloride items) and heated in the furnace in accordance with the temperature ramp rates and hold times used at PFP. The simulant charge loaded into the furnace for each cycle represented 1600 to $2000 \mathrm{~g}$ of $\mathrm{PuO}_{2}$ containing $1 \mathrm{wt} \%$ chloride salts. The chloride salt mixture consisted of $45 \mathrm{~mole} \% \mathrm{NaCl}, 45 \mathrm{~mole} \% \mathrm{KCl}$, and $10 \mathrm{~mole} \%$ $\mathrm{MgCl}_{2}$.

Section 2.0 of this report describes the test equipment, materials, and test procedures. The results of the evaluation are discussed in Section 3.0, and summarized in Section 4.0. Appendix A describes the technical basis for the simulant used in the tests. Appendix B summarizes the procedure used to conduct each test cycle. A summary of each of the 50 test cycles is provided in Appendix C. Appendix D provides the results of electron dispersion spectroscopy analyses of deposits that formed in the furnace offgas line. 


\subsection{Test Approach, Equipment, and Methods}

This section describes the test approach, as well as the furnace system equipment (furnace, offgas line, knockout pot/filters), test materials, and testing methods.

\subsection{Approach}

The furnace system evaluation was conducted by setting up a prototype PFP furnace and the associated offgas system and evaluating the performance of the system components as a function of processing cycles. For each cycle, a $\mathrm{CeO}_{2}$-salt simulant containing the expected residual chloride salt level in washed HCP items was loaded into a sample boat (also referred to as "simulant boat"); the boat was placed in the furnace chamber; and the furnace was heated in accordance with the standard PFP thermal stabilization protocol:

1. Room temperature at $500^{\circ} \mathrm{C} @ 300^{\circ} \mathrm{C} / \mathrm{hr}$

2.500 $50{ }^{\circ}$ to $700^{\circ} \mathrm{C} @ 200^{\circ} \mathrm{C} / \mathrm{hr}$

3. $700^{\circ} \mathrm{C}$ to $900^{\circ} \mathrm{C} @ 125^{\circ} \mathrm{C} / \mathrm{hr}$

4.900 90 to $1000^{\circ} \mathrm{C} @ 75^{\circ} \mathrm{C} / \mathrm{hr}$

5. Hold at $1000^{\circ} \mathrm{C}$ for $2 \mathrm{hr}$, then shut off and cool.

The furnace performance was evaluated by monitoring current and voltage to the furnace heating elements, and temperature in the furnace chamber. The offgas system performance was monitored by measuring temperature, pressure drop, and flow rate. Between cycles, furnace and offgas system components and metal coupons were examined, photographed, and weighed to evaluate corrosion.

\subsection{Equipment}

The test stand used for the furnace system evaluation is shown in Figure 2.1. A detailed schematic of the furnace, 3/4-in. offgas lines, and the filter/knockout pot is shown in Figure 2.2.

\subsubsection{Furnace}

The furnace used for this testing was a Thermolyne Model FA-1630-1 muffle furnace, identical to that used by PFP for materials stabilization. Four 240 VAC, 17.0 A heating elements, wired in series, lined the top, bottom, and side walls of the furnace. Actual dimensions of the furnace cavity with heating elements installed were 5.5 in. wide x 5 in. high x 13 in. deep (total chamber volume: 357.5 in. ${ }^{3}$ ). Maximum short-term and continuous operating temperatures recommended by the manufacturer were $1177^{\circ} \mathrm{C}$ and $1066^{\circ} \mathrm{C}$, respectively. A ceramic stand was placed inside the furnace directly on the bottom heating element to support a Hastelloy X sample boat, which was 11 in. long x 5.0 in. wide x 2.5 in. high. The boat was used to hold simulant and any corrosion coupons to be tested. A baffle constructed of Haynes HR-160 alloy was located at the back wall of the furnace chamber behind the boat, directly in front of where the gases exited the furnace. The arrangement of the baffle, support stand, and sample boat in the furnace is shown in Figure 2.3.

Temperature was controlled with a proportional-integral-derivative (PID) controller coupled with a silicon-controlled rectifier (SCR). The PID controller was a Eurotherm Model 818 process controller capable of running temperature ramp/dwell sequences was used. The SCR was a Control Concepts, Inc., 
Model 1039 power controller rated for $30 \mathrm{~A}$ at $208 \mathrm{VAC}$ (P/N 1039-V-208V-30A-F30-4/20MA). Both the process controller and the SCR were properly fused and grounded. Temperature input to the controller was provided by an Omega 1/4-in.-outer diameter (OD), 7-in.-long type K thermocouple (I-600 sheathed, P/N TJ48-CAIN-14U-7-SB-OSTW-M). Figures 2.2 and 2.4 show the location of the controller thermocouple. An Omega 1/8-in.-OD, 24-in.-long type K thermocouple (I-600 sheathed, $\mathrm{P} / \mathrm{N} \mathrm{KQIN-18U-24)}$ was inserted through the front of the furnace between the door and the furnace housing with the tip submerged into the simulant.

The available power supply in the lab was $208 \mathrm{VAC}$, not $240 \mathrm{VAC}$ as rated by the heating elements. However, this did not stop the furnace from reaching the required $1000^{\circ} \mathrm{C}$ dwell temperature.

\subsubsection{Offgas Line, $3 / 4$ in.}

The 3/4-in.-OD offgas line was divided into an internal and external section, as shown in Figure 2.2. The internal offgas line began inside the furnace with the inlet mounted flush with the back wall of the furnace (Figure 2.4). It extended out the back wall of the furnace and was supported by a bracket/bulkhead assembly mounted to the back of the furnace. Inconel 600 tubing is currently used for both internal and external offgas lines at PFP. The following materials/configurations were used for the internal offgas line:

- Inconel 600 tubing, 3/4-in. OD, 6-in. long, 0.028-in. wall thickness

- 1/2-in. Schedule 80 Inconel 690 pipe (0.840-in. OD), turned to 3/4-in. OD, 6-in. long, 0.102-in. wall thickness

- 1/2-in. Schedule 80 Inconel 690 pipe (0.840-in. OD), turned to 3/4-in. OD, 11-in. long, 0.102-in. wall thickness

- high-temperature ceramic, turned to 3/4-in. OD, 11 in. long, 0.109-in. wall thickness.

The internal offgas line was secured to the bracket by two methods. If the offgas line was 6 in. long, the end of the line outside of the furnace was connected to one end of the bulkhead fitting mounted to the bracket (Figure 2.5). Offgas lines 11 in. long were inserted completely through a bored-out bulkhead fitting (Figure 2.6).

The external offgas line was connected to the other end of the bulkhead (6-in. lines) or directly to the internal offgas line with a union (11-in. lines). The external line was 3/4-in.-OD Inconel 600 tubing, 0.028 -in. wall thickness. There were four 90 -degree bends to better represent the current system used by PFP. Three of the bends were 90-degree elbows and the fourth was a tee (one end of the branch was plugged; Figure 2.2). The tee and elbows were 316L stainless steel. Two Omega 1/8-in.-OD, 12-in.-long type $\mathrm{K}$ thermocouples (I-600 sheathed, P/N KQIN-18U-12) were inserted into the offgas line (see Figure 2.2 for locations).

\subsubsection{Filters/Knockout Pot}

A filter or knockout pot was connected downstream of the external offgas line for salt removal (Figure 2.1). The following filtration systems were evaluated during furnace testing: 
- Purlator (Greensboro, NC) fitted in a Shelco (West Hartford, Connecticut) filter housing

- Shelco Housing:

- MicroGuardian

- Model \# FOS-806-316

- Housing designed to accept one 20-in.-long filter cartridge (modified to accept one 10-in.-long filter cartridge)

- $212^{\circ} \mathrm{C}$ maximum temperature (at $250 \mathrm{psi} \max$ )

- Purlator Filter:

- Poroplate 10- $\mu \mathrm{m}$ 316L stainless steel sintered metal cartridge filter, Model PP10DOE10

- 10 in. long, 2.4-in. OD

- $\mathrm{P} / \mathrm{N} 1755058-10$

- $427^{\circ} \mathrm{C}$ maximum temperature

- Filter surface area (for one cartridge): 75 in. $^{2}$

- Nowata Filtration System (Nowata, Oklahoma)

- Housing:

- 1UY Series 316 stainless steel, 3.5-in. OD (body), 4.6-in. OD (head), 24.5-in. overall length, $36 \mathrm{lb}$ shipping weight

- $\mathrm{P} / \mathrm{N} 1 \mathrm{UY} 2 \mathrm{~N} 15 \mathrm{~N} 15 \mathrm{KT}$

- Holds two 9.75-in.-long filter cartridges

- $316^{\circ} \mathrm{C}$ maximum temperature (at 150 psi max)

- Filters:

- 10- $\mu \mathrm{m}$ (P/N 1WVS100), 20- $\mu \mathrm{m}$ (P/N 1WVS20), 50- $\mu \mathrm{m}$ (P/N 1WVS50), and $100-\mu \mathrm{m}(\mathrm{P} / \mathrm{N} 1 \mathrm{WVS} 100)$ nominal opening rating

- WF series glass fiber cartridges

- 9.75 in. long, 2.5-in. OD (per cartridge)

- $400^{\circ} \mathrm{C}$ maximum temperature

- Filter surface area (for two cartridges): $\sim 153$ in. $^{2}$ (actual surface area may be greater due to glass winding construction)

- Rosedale Products of California, Inc. (Coarsegold, California)

- Housing:

- Model 4, 304 stainless steel, 4.5-in. OD (body), 10-in. OD (flange), 30-in. overall length (including flange thickness and outlet port), $91 \mathrm{lb}$ shipping weight

- $\quad \mathrm{P} / \mathrm{N}$ 4-1-20-3/4P-2-50-S-(SP)-N-NPT (NPT = National Pipe Taper Thread)

- Holds one 20-in.-long filter cartridge

- $593^{\circ} \mathrm{C}$ maximum temperature (at 50 psi max)

- Filters:

- 5- $\mu \mathrm{m}$ (P/N 20-5-P-S-1NPTF-SP), 10- $\mu \mathrm{m}$ (P/N 20-10-P-S-1NPTF-SP), and $20-\mu \mathrm{m}(\mathrm{P} / \mathrm{N} 20-20-\mathrm{P}-\mathrm{S}-1 \mathrm{NPTF}-\mathrm{SP})$ nominal opening rating

- 304 stainless steel pleated cartridges 
- 20 in. long, 2.6-in. OD (per cartridge)

- $260^{\circ} \mathrm{C}$ maximum temperature

- Filter surface area (for one cartridge): $500 \mathrm{in.}^{2}$

Figures 2.7 through 2.12 show photos and installation schematics of the above filtration systems. The following knockout pot/packing configurations were also tested:

\section{- $\quad$ 2-in. Schedule 40 Stainless Steel Pipe}

- Housing:

- 2-in. Schedule 40 stainless steel pipe, 10 in. long

- Threaded piece of pipe with machined end caps

- Wire screens inserted into both end caps to hold packing in place

- Packing:

- 1/2-in. nominal ceramic Intalox saddle rings

- Stainless steel wire mesh with 1/8-in. x 3/16-in. and 1/8-in. x 5/16-in. openings

- Packing surface area (Intalox saddles): $141 \mathrm{ft}^{2} / \mathrm{ft}^{3}, 62 \%$ void space (Perry and Green 1984)

- Nowata Filtration housing modified to hold packing from Jaeger Products, Inc. (Houston, Texas)

- Housing:

- 1UY Series 316 stainless steel, 3.5-in. OD (body), 4.6-in. OD (head), 24.5-in. overall length, $36 \mathrm{lb}$ shipping weight

- P/N 1UY2N15N15KT

- End of housing tapped and plugged with a 1.5-in. NPT plug

- $316^{\circ} \mathrm{C}$ maximum temperature (at 150 psi max pressure)

- Packing:

- Interpack 10-mm nominal 316 stainless metal random packing

- Packing surface area: $189 \mathrm{ft}^{2} / \mathrm{ft}^{3}, 90 \%$ void space

Figures 2.13 through 2.16 show photos and installation schematics of the knockout pots.

Series 280 Cyclade In-Stack Cascade Cyclone Samplers from Anderson Instruments, Inc., were also tested for salt removal (Figure 2.17). The pressure drop across a filter or knockout pot was measured with a Dwyer 0-1.0 or 0-15 in. $\mathrm{H}_{2} \mathrm{O} 2000$ Series Magnehelic $\Delta \mathrm{P}$ gauge (Model 2001 or 2015, respectively). The particular gauge used was selected by the magnitude of the pressure drop.

\subsubsection{Gas Scrubbing System}

The layout of the complete scrubbing system is shown in Figure 2.1. All tubing was 1/2-in.-OD 304 stainless steel. The offgas exiting the filter or knockout pot was directed through a sparge tube located inside a 12 5/8-in. OD x 24 5/8-in.-high 304 stainless steel tank. The sparge tube was $\sim 10$ in. long with $101 / 8$-in. holes and is submerged in 8 to 11 in. of water. A sight glass was installed onto the side of the tank to monitor water height. There was also a plug on top of the tank to allow additions of sodium bicarbonate for acid neutralization. 
The offgas exited the top of the scrubber tank and entered a 1-L condenser pot (304L stainless steel) to remove water from the saturated offgas stream. The offgas was heated to $\sim 30^{\circ} \mathrm{C}$ with a heat tape, and then flowed through a Dwyer Model RMA 0-100 or 0-200 SCFH flowmeter (Models RMA-8-TMV or RMA-10-TMV, respectively). An Omega 1/8-in.-OD, 12-in.-long type K thermocouple (I-600 sheathed, $\mathrm{P} / \mathrm{N}$ KQIN-18U-12) and a Dwyer 0-30 in. $-\mathrm{H}_{2} \mathrm{O} 2000$ Series Magnehelic $\Delta \mathrm{P}$ gauge (Model 2030) were located on the 1/2-in. stainless steel line between the heat tape and the flowmeter. Directly below the flowmeter was a section of $1 / 2$-in.-OD tubing that served as a drop leg to catch any condensation that may have passed through the condenser.

The offgas flow was provided by a Model R2103 Gast Regenair blower (P/N LTD139) capable of $42 \mathrm{CFM}$ free air flow $\left(20^{\circ} \mathrm{C}, 14.7\right.$ PSIA $)$ or 35 in. $-\mathrm{H}_{2} \mathrm{O}$ vacuum. Due to the high capacity of the blower, the majority of gas flow was pulled directly from the room, while the target 1.0 SCFM offgas flow from the furnace was maintained with a valve located on the room air inlet (Figure 2.18). The room air inlet and the blower exhaust lines were 1-in. NPT.

\subsubsection{Data Logging System}

An Iotech Personal Daq/56 data logging system was used to record process data. Temperatures were recorded from the process controller thermocouple and others located in the simulant boat, Inconel 600 offgas line, and just upstream of the flowmeter. Furnace voltage and current data from the SCR were also recorded. At the end of a furnace test cycle, the data were downloaded to an Excel worksheet for analysis.

\subsection{Methods}

\subsubsection{Simulant Composition}

Each furnace charge consisted of $\sim 1000 \mathrm{~g} \mathrm{CeO}_{2}+16 \mathrm{~g}$ salts (nominally equivalent to $1600 \mathrm{~g} \mathrm{PuO}_{2}$ ) or $\sim 1249 \mathrm{~g} \mathrm{CeO}_{2}+20 \mathrm{~g}$ salts (nominally equivalent to $2000 \mathrm{~g} \mathrm{PuO}_{2}$ ). The mixed chloride salts in each charge were equivalent to a full boat containing $1 \mathrm{wt} \%$ chloride salts on $\mathrm{PuO}_{2}$ basis (i.e, $1.6 \mathrm{wt} \%$ chloride salts on $\mathrm{CeO}_{2}$ basis). The chloride salts were a mixture of sodium chloride, potassium chloride, and magnesium chloride at a mole ratio of $0.45: 0.45: 0.1$, respectively. The simulant was prepared in $\sim 6.5-\mathrm{kg}$ batches by dissolving the salts in a small quantity of water, and mixing the salt solution with $\mathrm{CeO}_{2}$ in a series of additions. After each addition, the simulant was thoroughly mixed. After the last salt solution addition and thorough mixing, the mixture was placed into shallow pans and dried overnight at $\sim 100^{\circ} \mathrm{C}$. The technical basis for the simulant composition can be found in Appendix A.

\subsubsection{Corrosion Testing}

A combination of standard coupon corrosion tests (based on ASTM methods) and in-service testing of system components (e.g., heaters, boats, baffles, offgas tubing, etc.) was used for corrosion and materials evaluations. Coupon corrosion tests utilized rectangular specimens of candidate metal alloy materials. Initial specimens were prepared from standard mill-finish plate. Tests consisted of initially characterizing all specimens, followed by exposing the specimens to furnace/offgas conditions for 15 to 19 exposures. The corrosion specimens were characterized initially by carefully weighing (nearest $0.0001 \mathrm{mg}$ ) and measuring dimensions (nearest $0.01 \mathrm{in}$.). Coupons were placed in the powder boats $(\sim 1 / 2$ submerged in the powder). After exposure, the coupons were evaluated for corrosion types and penetration rates. Evaluation included observations of the condition "as is" upon removal and chemical cleaning to remove 
corrosion products, followed by weighing and visual/microscopic examination. Similar post-test examinations were conducted for the heaters and offgas system components to evaluate the nature and degree of chloride attack during operation.

\subsubsection{Corrosion Specimen Materials}

The following alloys were used for corrosion specimen materials:

Mill-finish plate (1/8-in. thickness)

- Inconel 690

- Haynes HR-160

- Haynes 214

- Hastelloy X

Tubing

- Inconel 600, 3/4-in. OD, 0.028-in. wall thickness

- Zircaloy, 0.442-in. OD, 0.031-in. wall thickness

Foil

- Tantalum, 0.010-in. thickness

Before the tests were conducted, the corrosion specimens were cleaned, dried, and characterized to establish their initial conditions. The specimens were washed in warm water with mild detergent and rinsed with deionized water, alcohol, or acetone, and air-dried. The specimens were handled with appropriate gloves and instruments. Photographs were taken of the corrosion specimens with the alloy and specimen number identified in the picture.

\subsubsection{Offgas Line Materials}

The internal offgas line was initially cleaned, photographed, weighed and measured in the same manner as the corrosion specimens. The external offgas line was cleaned before the first furnace cycle and when the pressure drop across the entire system became high (ranged between 16.0 and 20.0 in. $-\mathrm{H}_{2} \mathrm{O}$, depending on the pressure drop across the filter/knockout pot).

\subsubsection{Filter/Knockout Pot}

Filter and knockout pot configurations were tested until the pressure drop increased significantly (approximately 3 to 8 in.- $\mathrm{H}_{2} \mathrm{O}$ ). Before installation, the filter or knockout pot was brushed clean and weighed. Any plugging was documented with the measured pressure drop across the collection device and photographs of any internal components that blinded with salt deposits. Thermal and chemical corrosion was also monitored and documented. Salt removal efficiency was determined by the mass of salts collected by the filter/knockout pot, final pressure drop measured at the end of a furnace cycle, and visual inspection of the downstream offgas lines.

\subsubsection{Furnace Operation/Process Variables}

The complete furnace operation procedure and a list of the measured process variables with sampling frequencies can be found in Appendix B. 


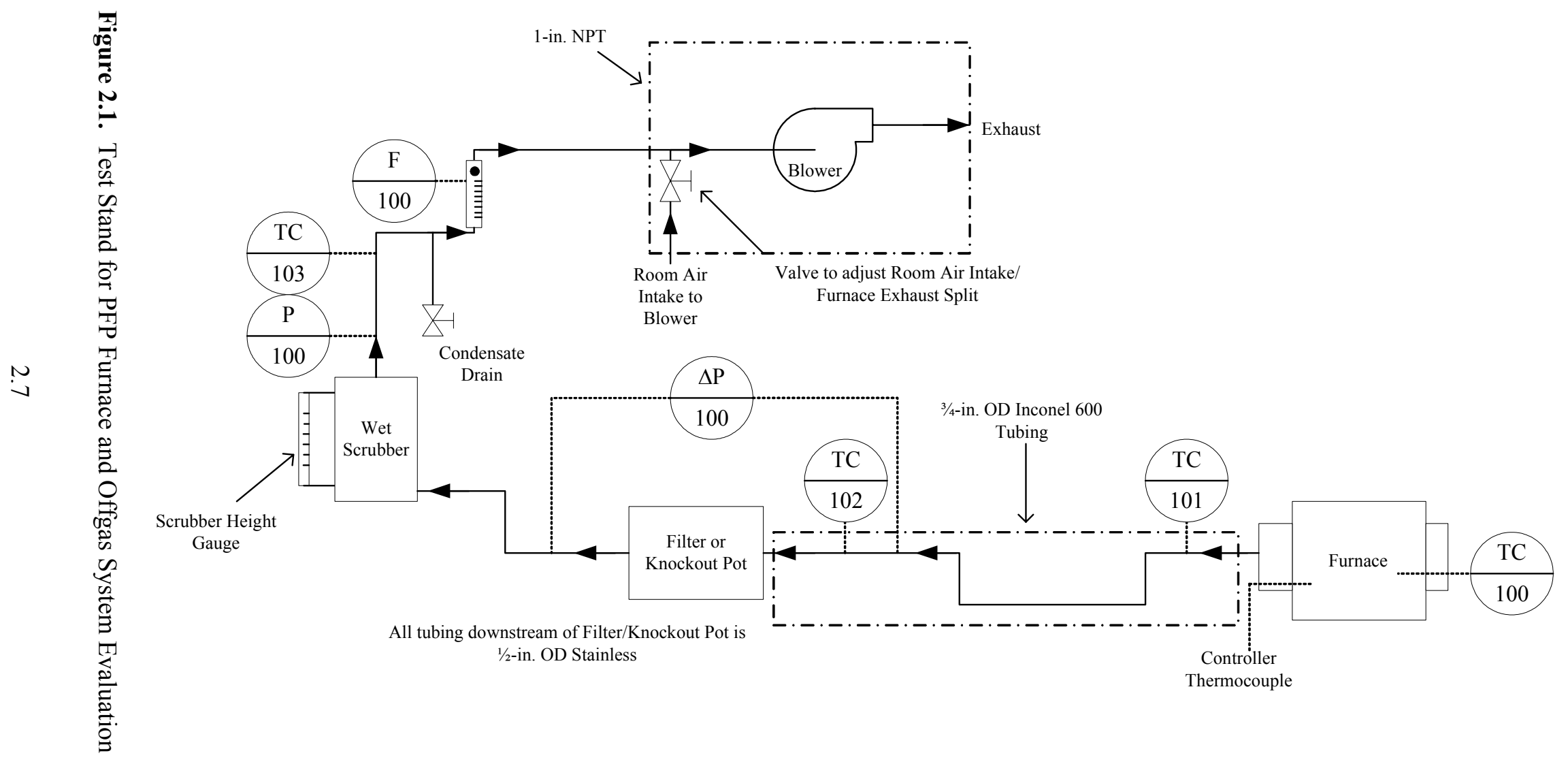




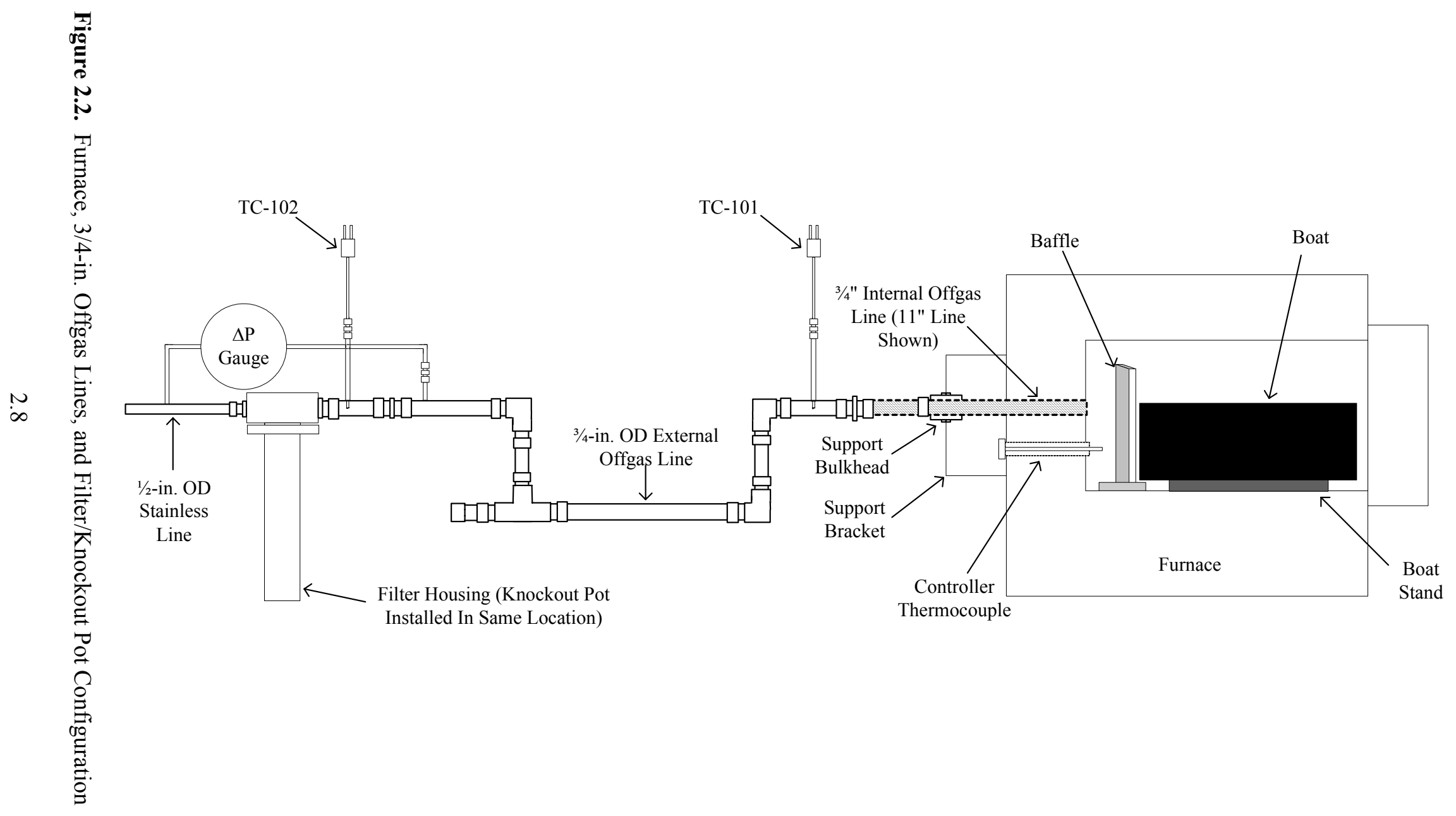




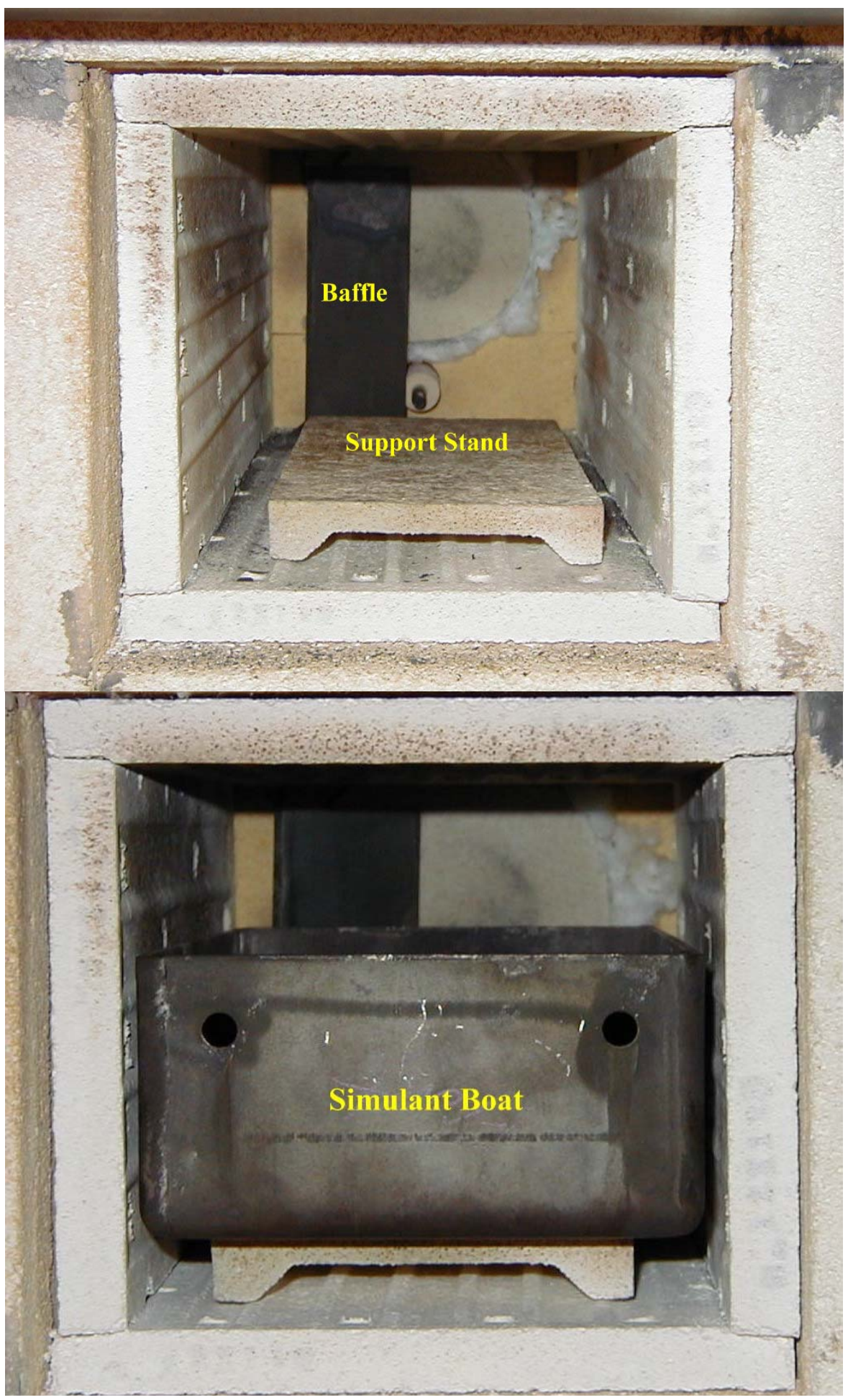

Figure 2.3. Front View of the Furnace Chamber to Show the Arrangement of the Baffle and Support Stand (above) and the Simulant Boat (below). Note that the furnace chamber was just wide enough for the simulant boat to fit. 


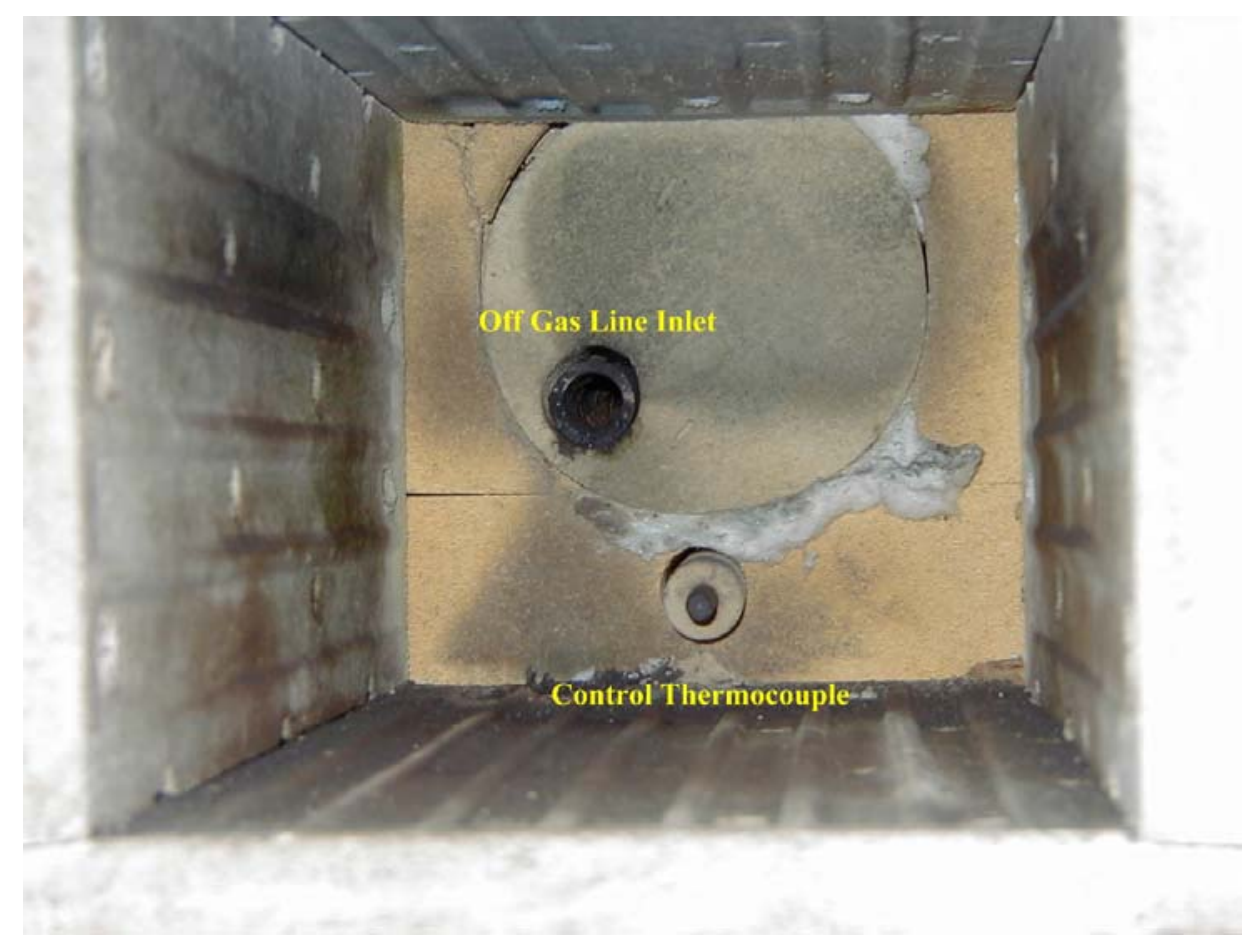

Figure 2.4. Internal Offgas Line Inlet and Controller Thermocouple as Installed in the Furnace

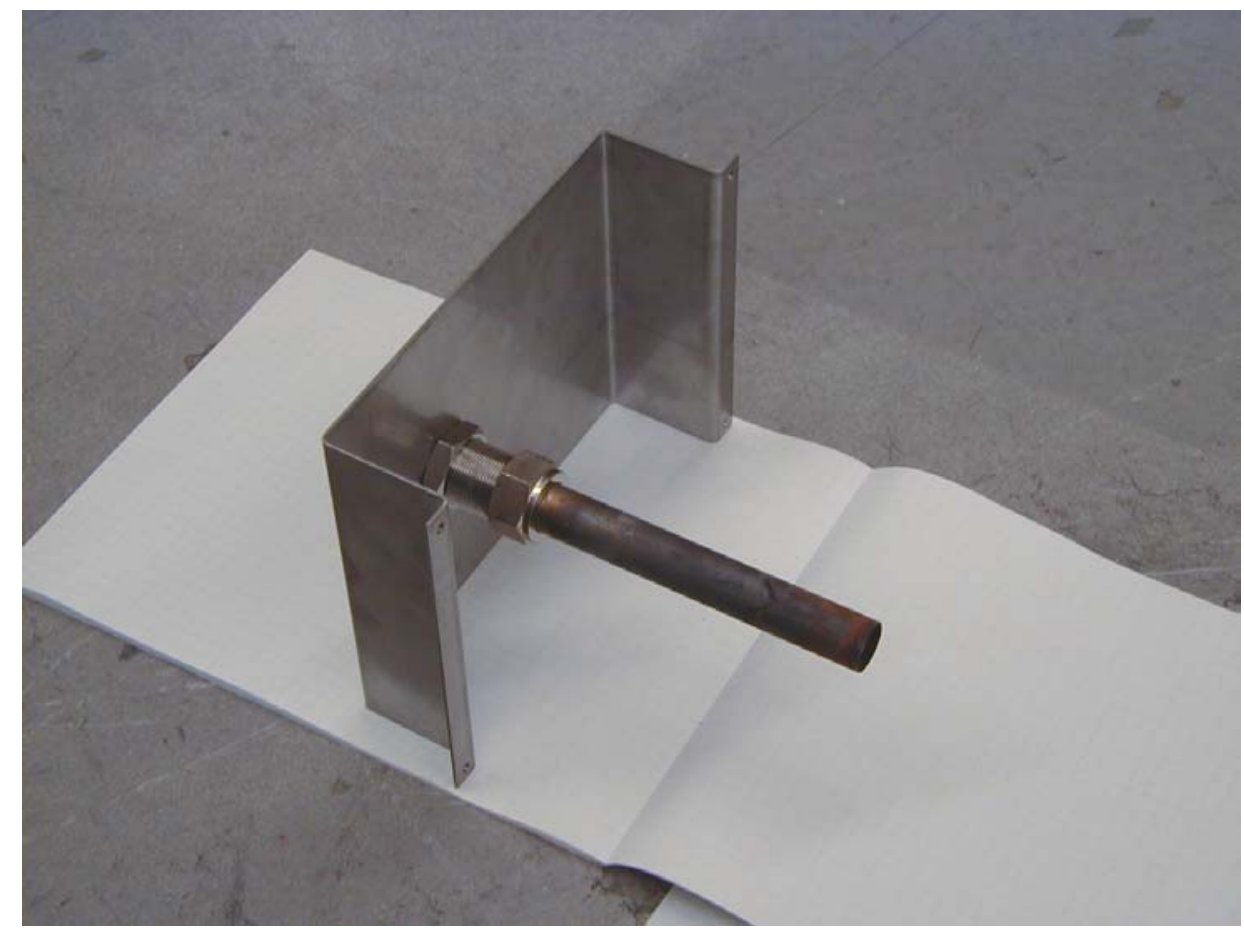

Figure 2.5. Bulkhead Used to Connect the External Offgas Line to a 6-in.-long Internal Offgas Line 


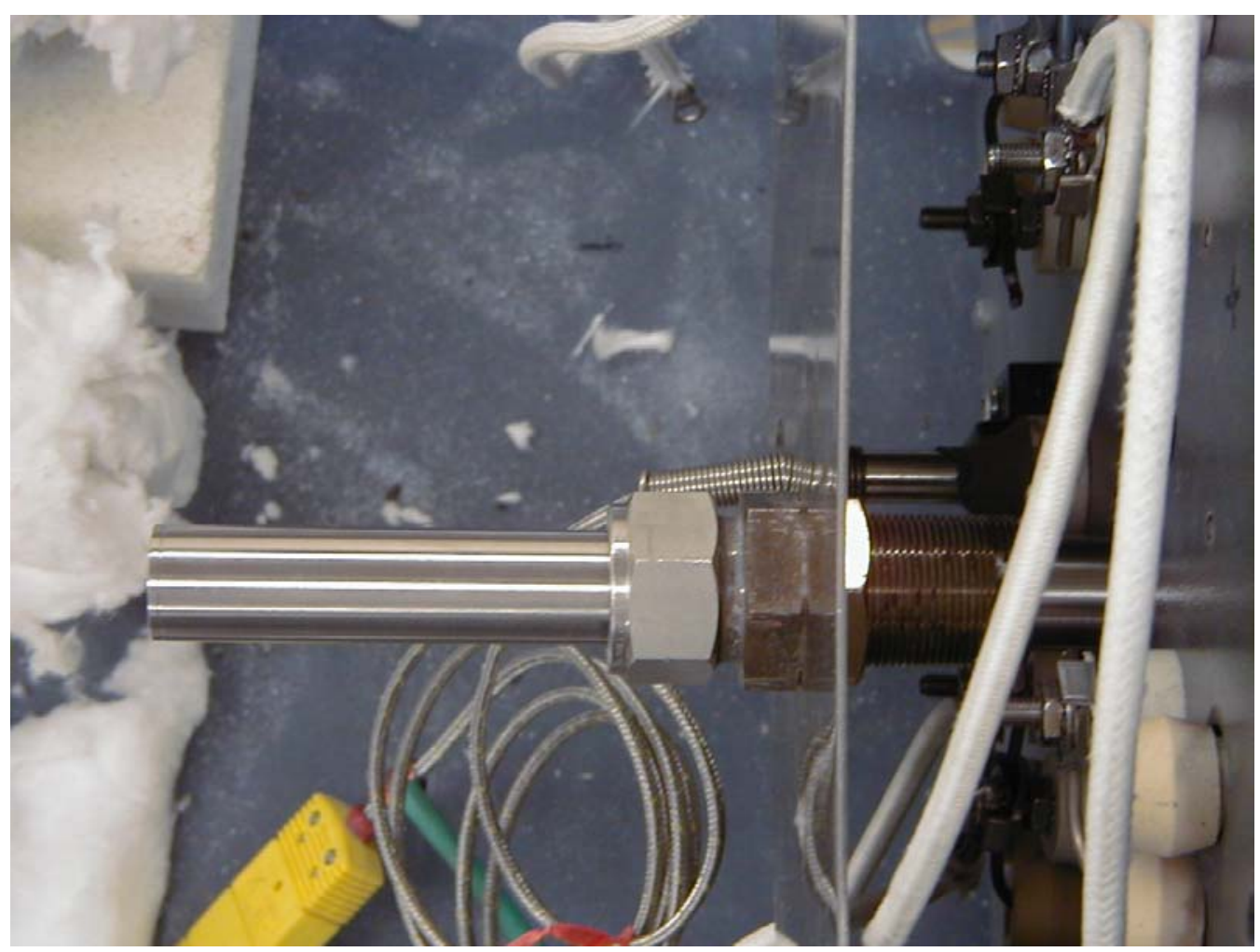

Figure 2.6. Bored-Out Bulkhead for Supporting 11-in.-long Internal Offgas Lines 


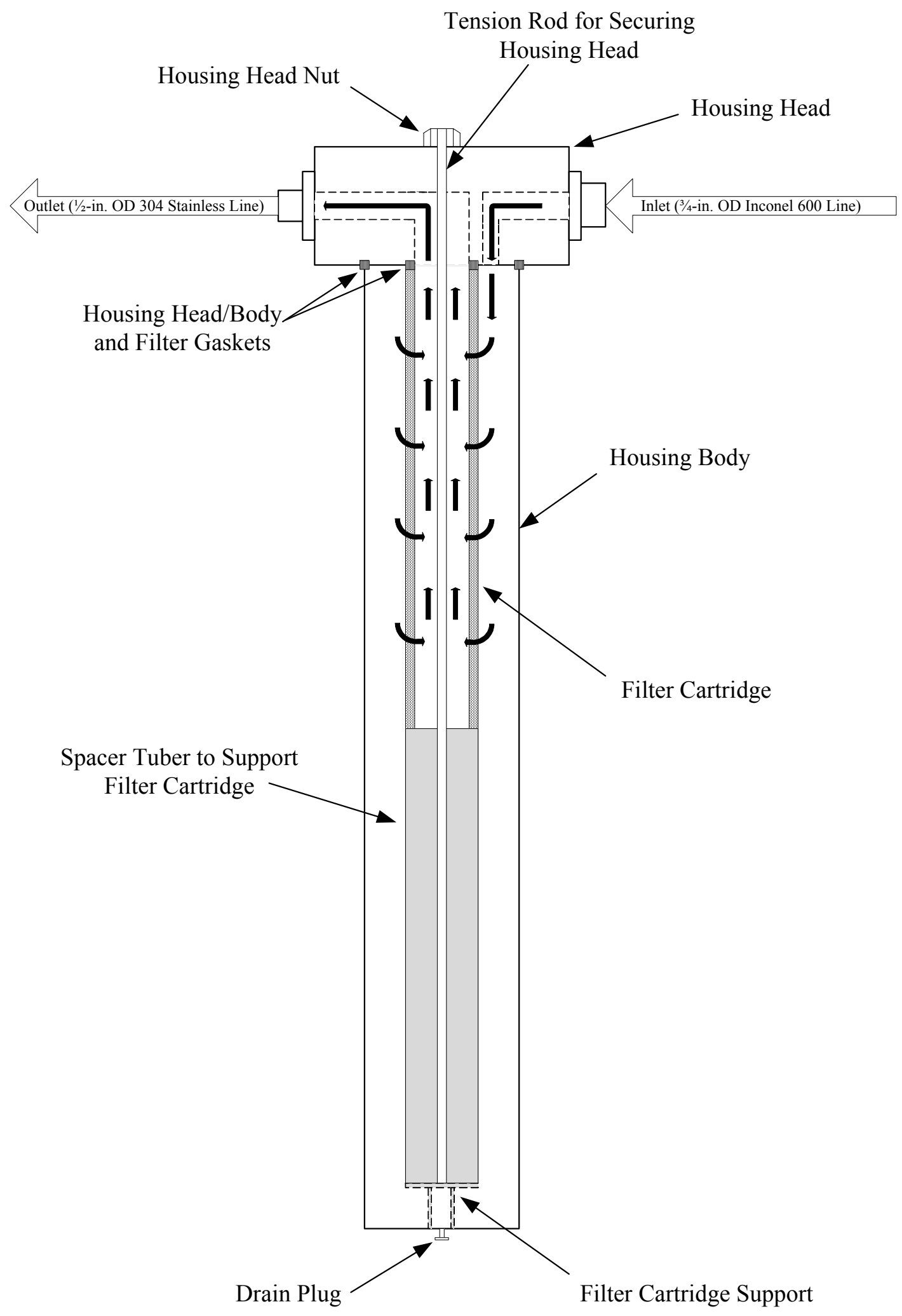

Figure 2.7. Schematic of a Purlator Cartridge Filter Installed in a Shelco Housing 


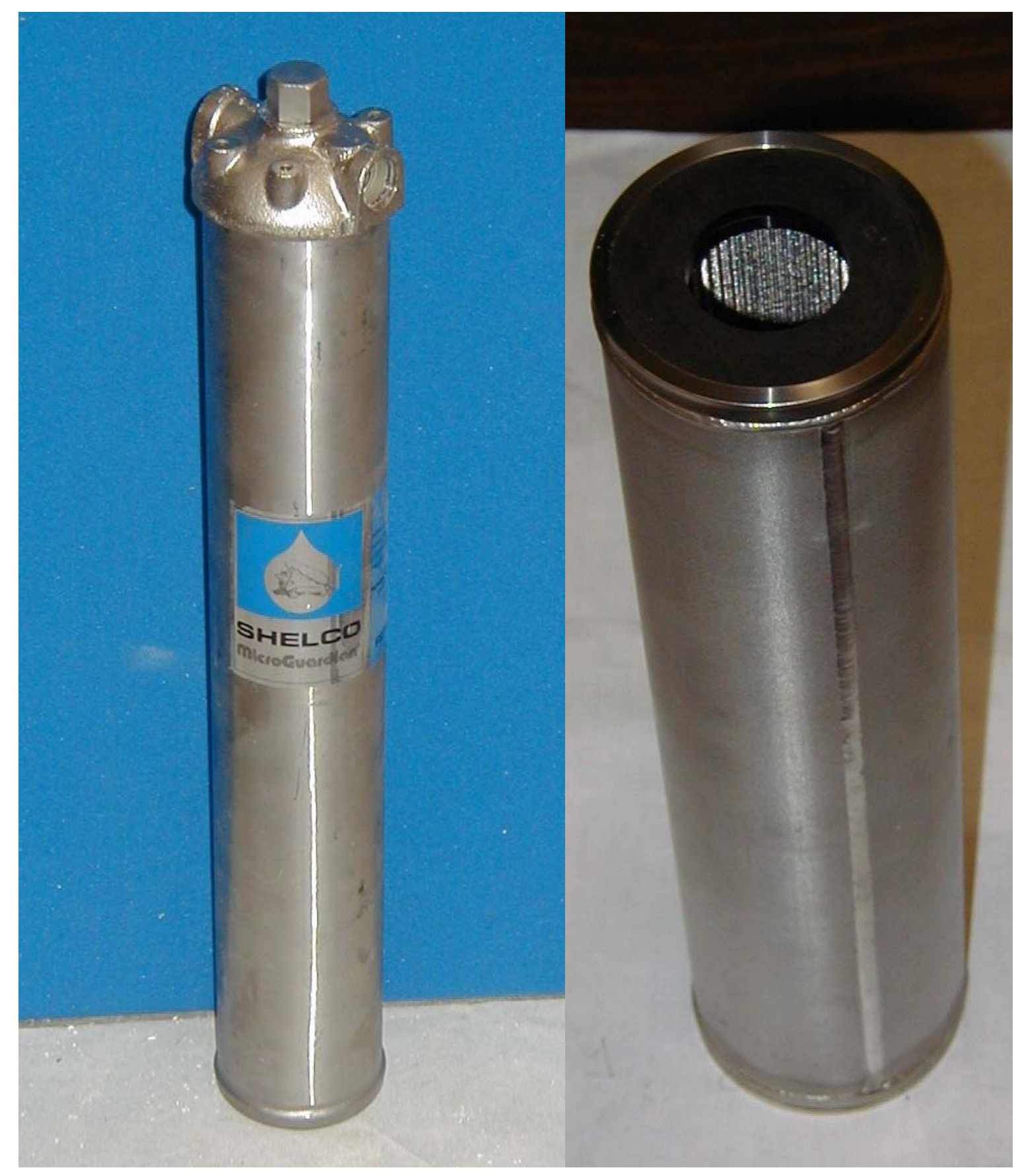

Figure 2.8. Shelco Housing and Purlator Cartridge Before a Test Cycle 


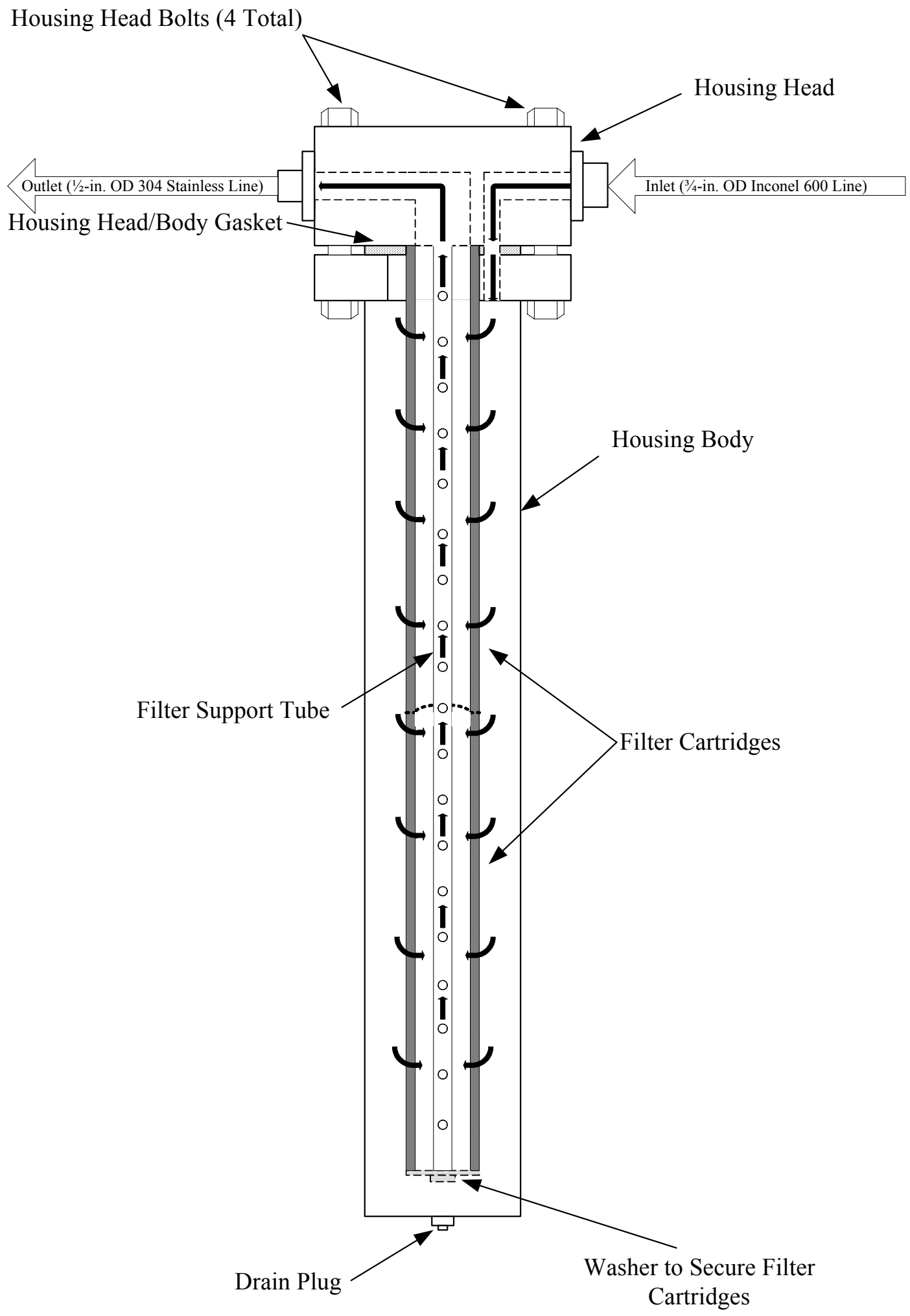

Figure 2.9. Schematic of the Nowata Filtration System Implementing Woven Glass Filter Cartridges 


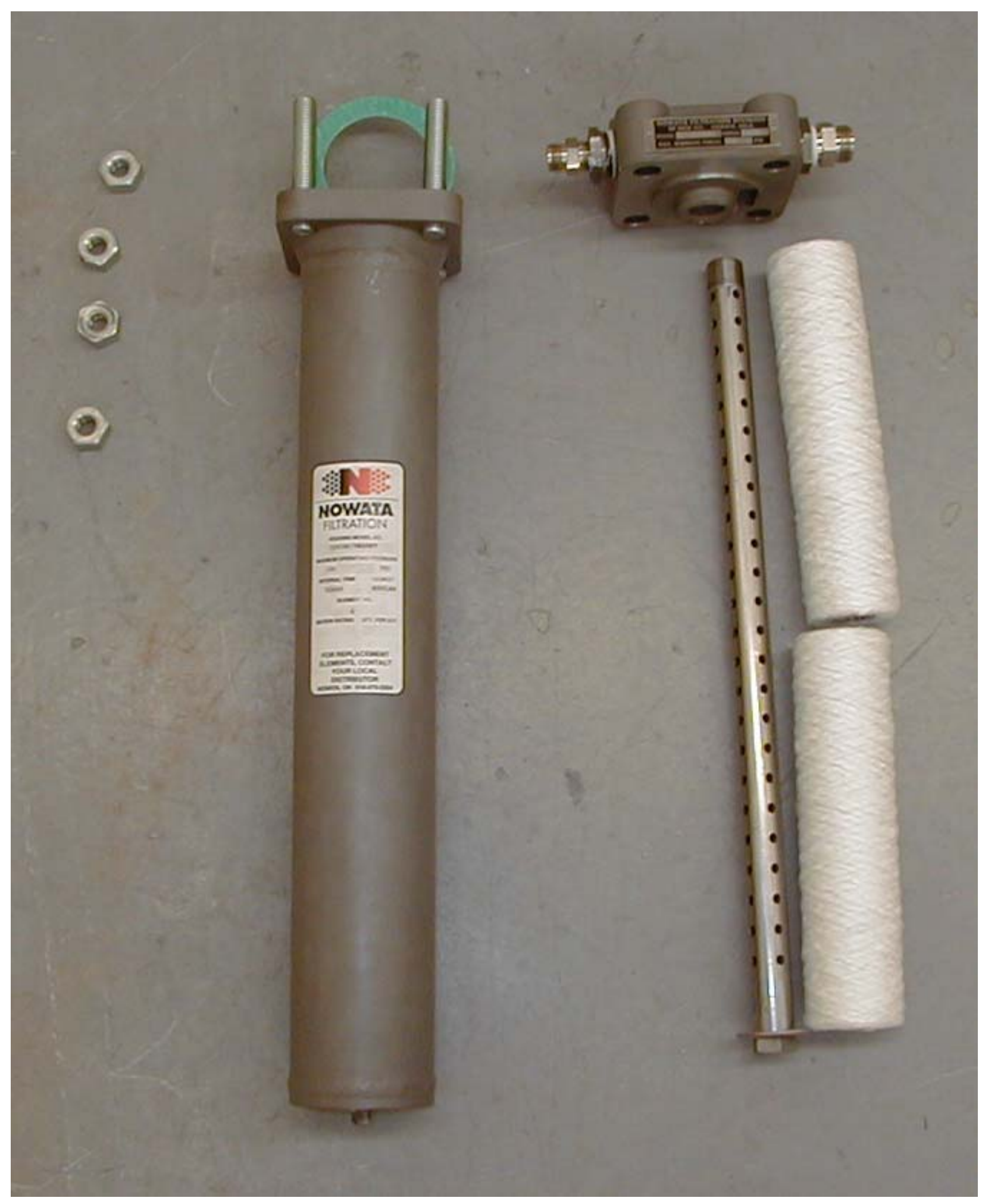

Figure 2.10. Nowata Filter Housing and Cartridges Before Installation. Housing outer diameter was $3.5 \mathrm{in}$. and shipped at $36 \mathrm{lb}$. Each filter cartridge was 2.5-in. OD and 9.75-in. long. 


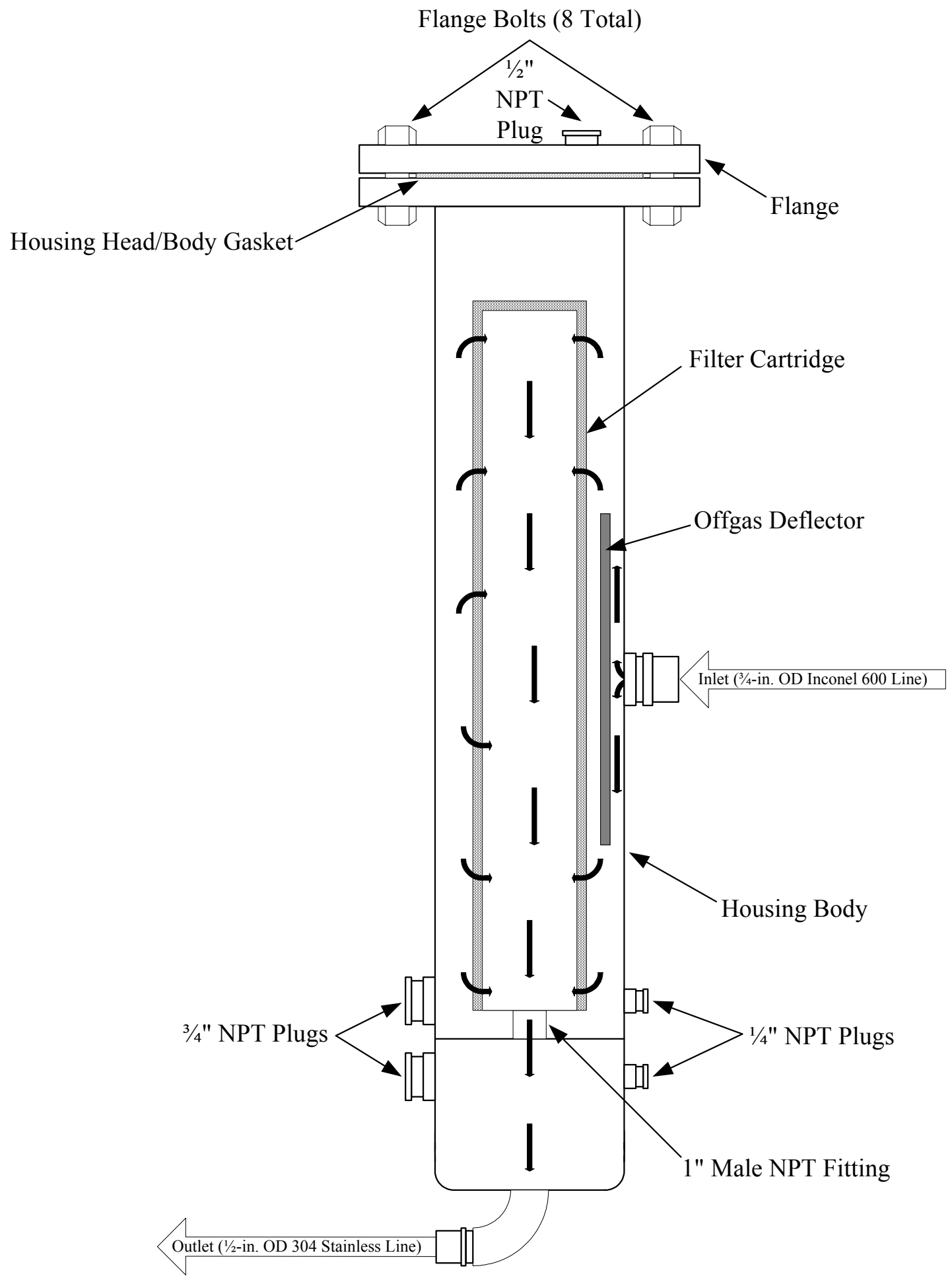

Figure 2.11. Schematic of the Rosedale Filtration System Implementing Pleated Metal Filter Cartridges 


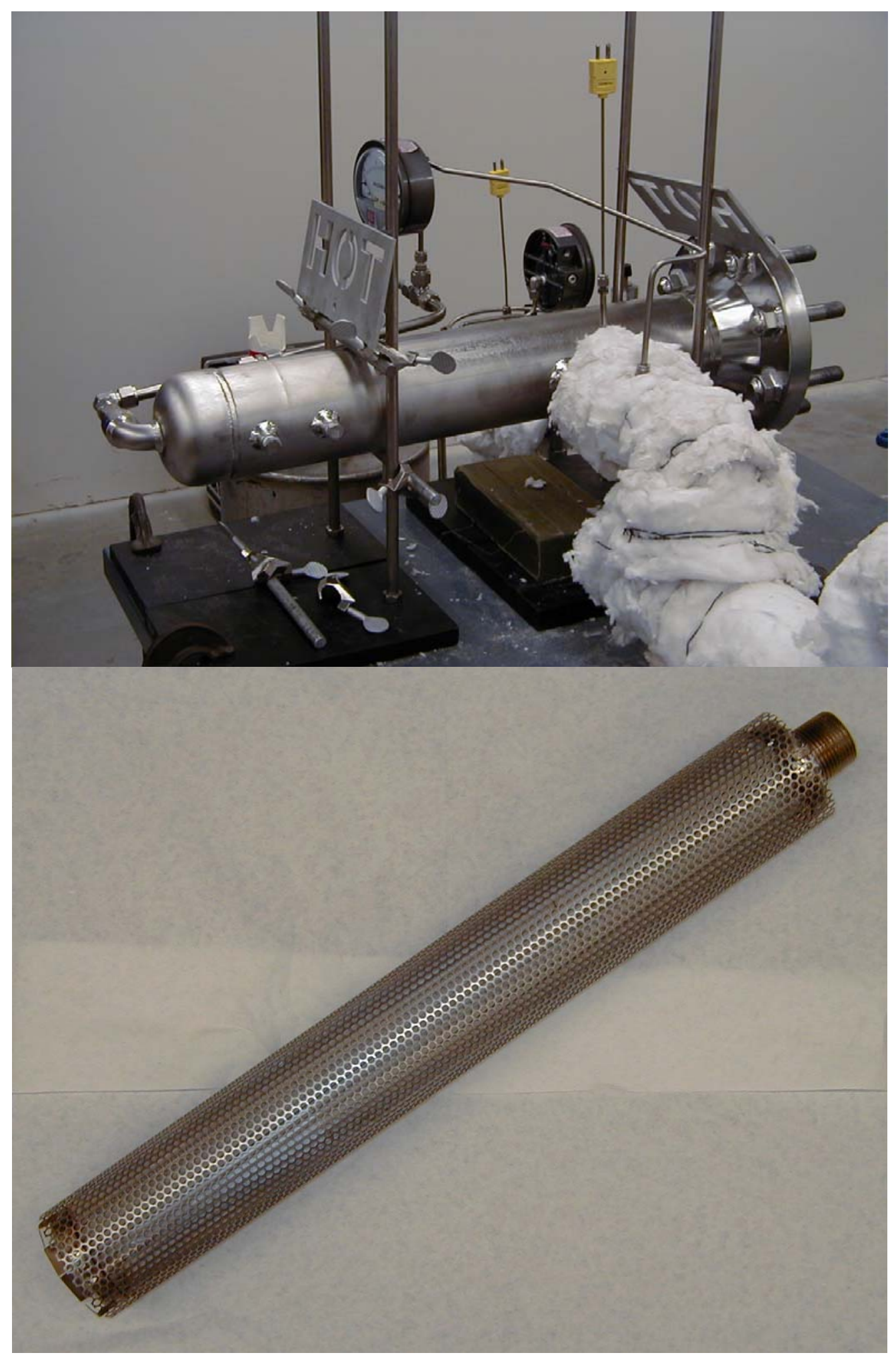

Figure 2.12. Rosedale Filter Housing and Cartridge Before Installation. Housing outer diameter was 4.5 in. and shipped at $91 \mathrm{lb}$. Each filter cartridge was 2.6-in. OD and 20-in. long. 


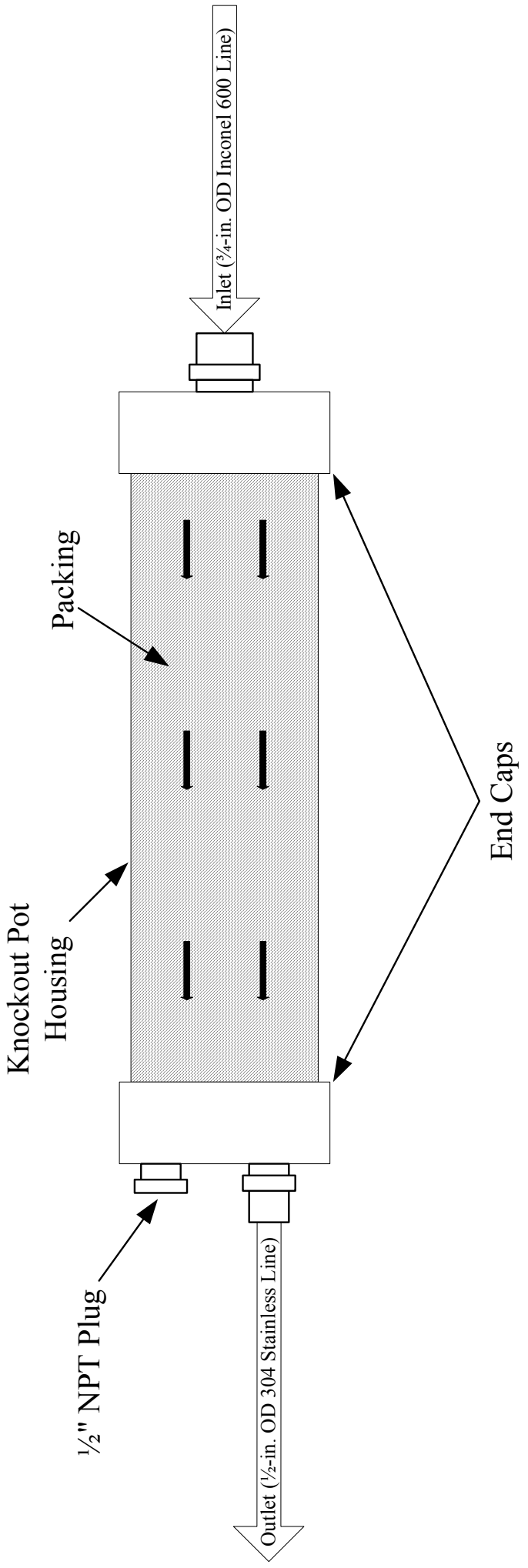

Figure 2.13. Schematic of the 2 -in. Schedule 40 Stainless Steel Knockout Pot 


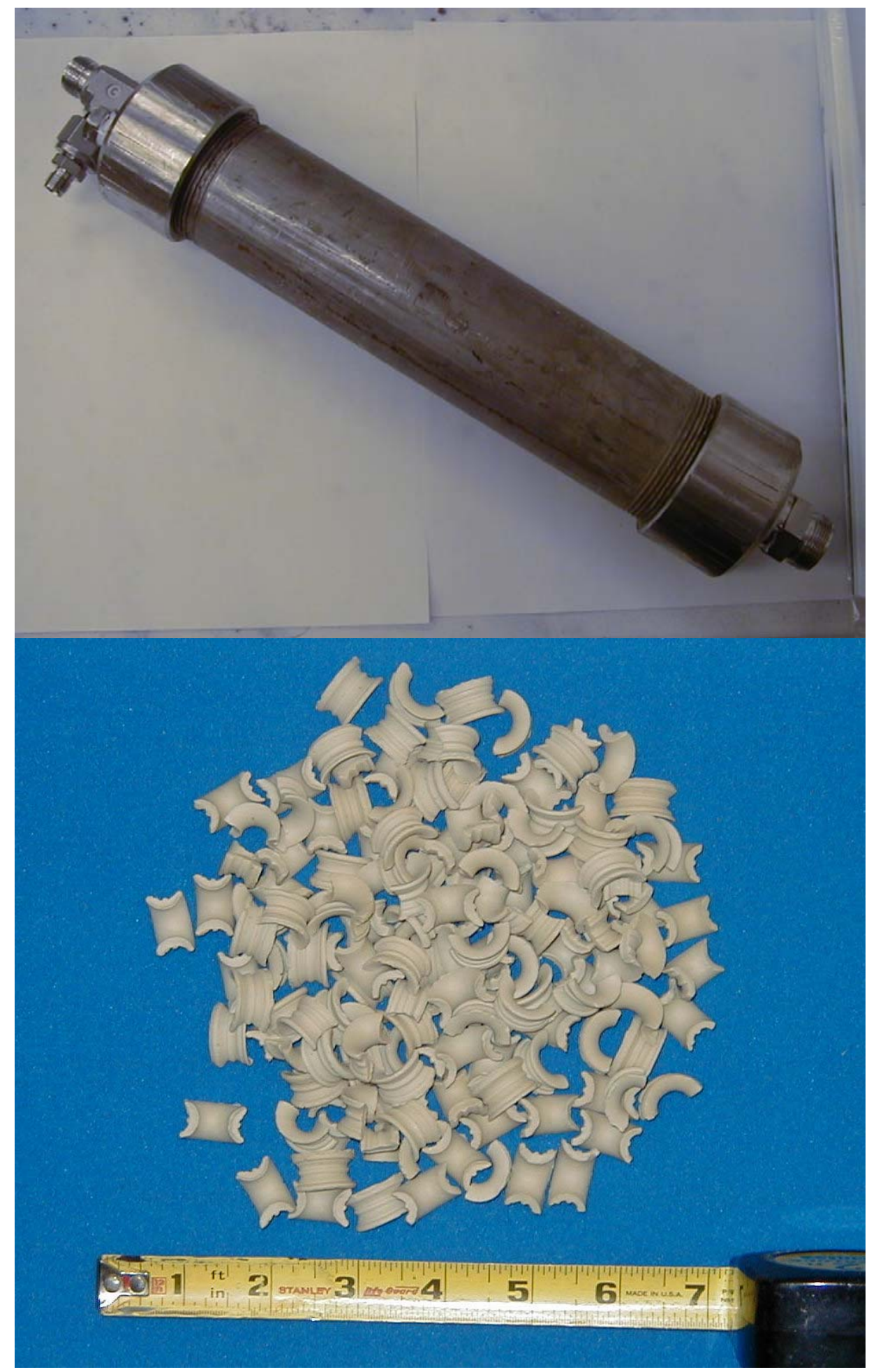

Figure 2.14. 2-in. Schedule 40 Stainless Steel Knockout Pot Housing and Intalox Ceramic Packing Before Installation 


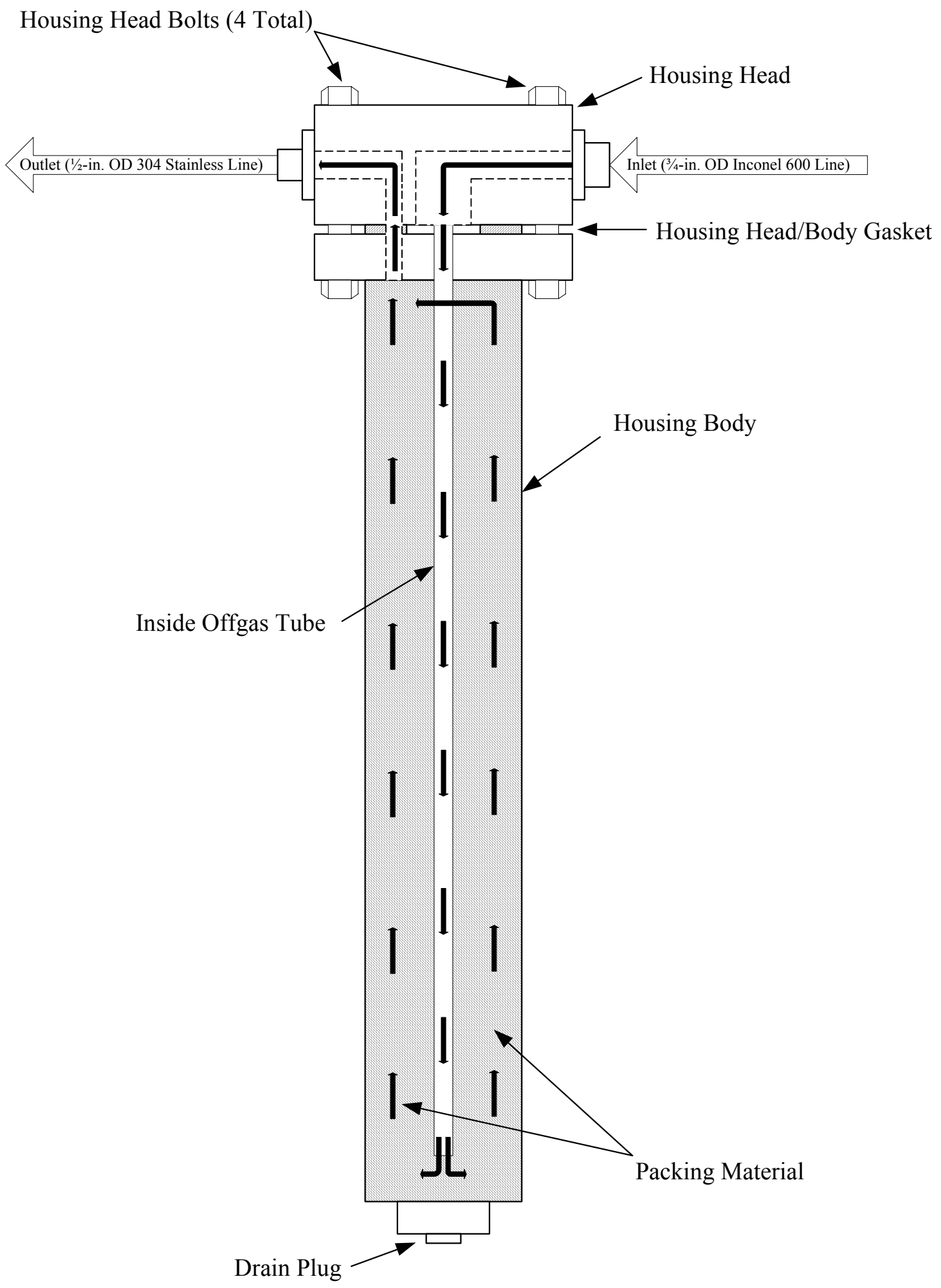

Figure 2.15. Schematic of the Nowata Filter Housing Converted to a Knockout Pot 


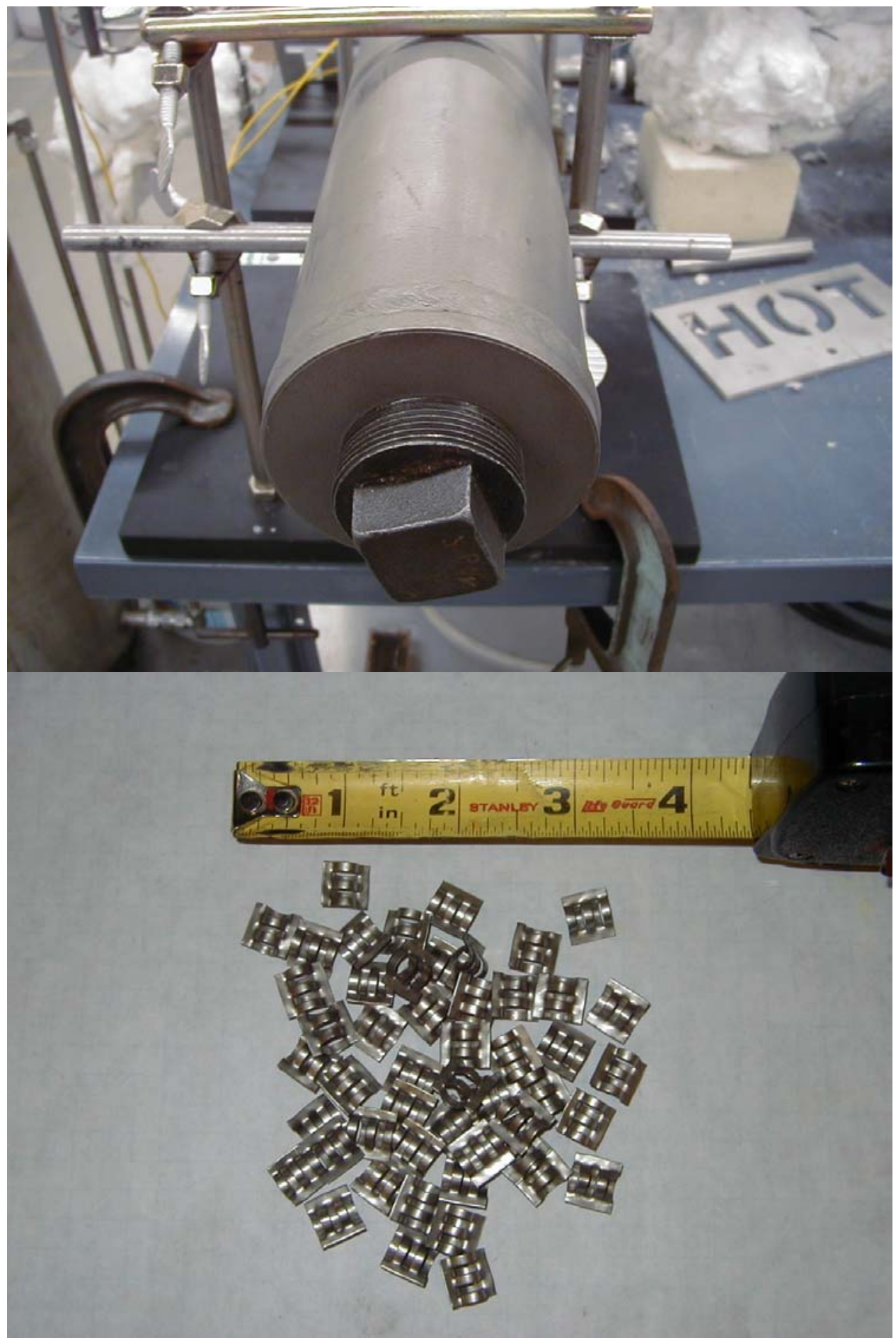

Figure 2.16. Nowata Knockout Pot Conversion and 10-mm Nominal Interpack Stainless Steel Packing Before Installation 


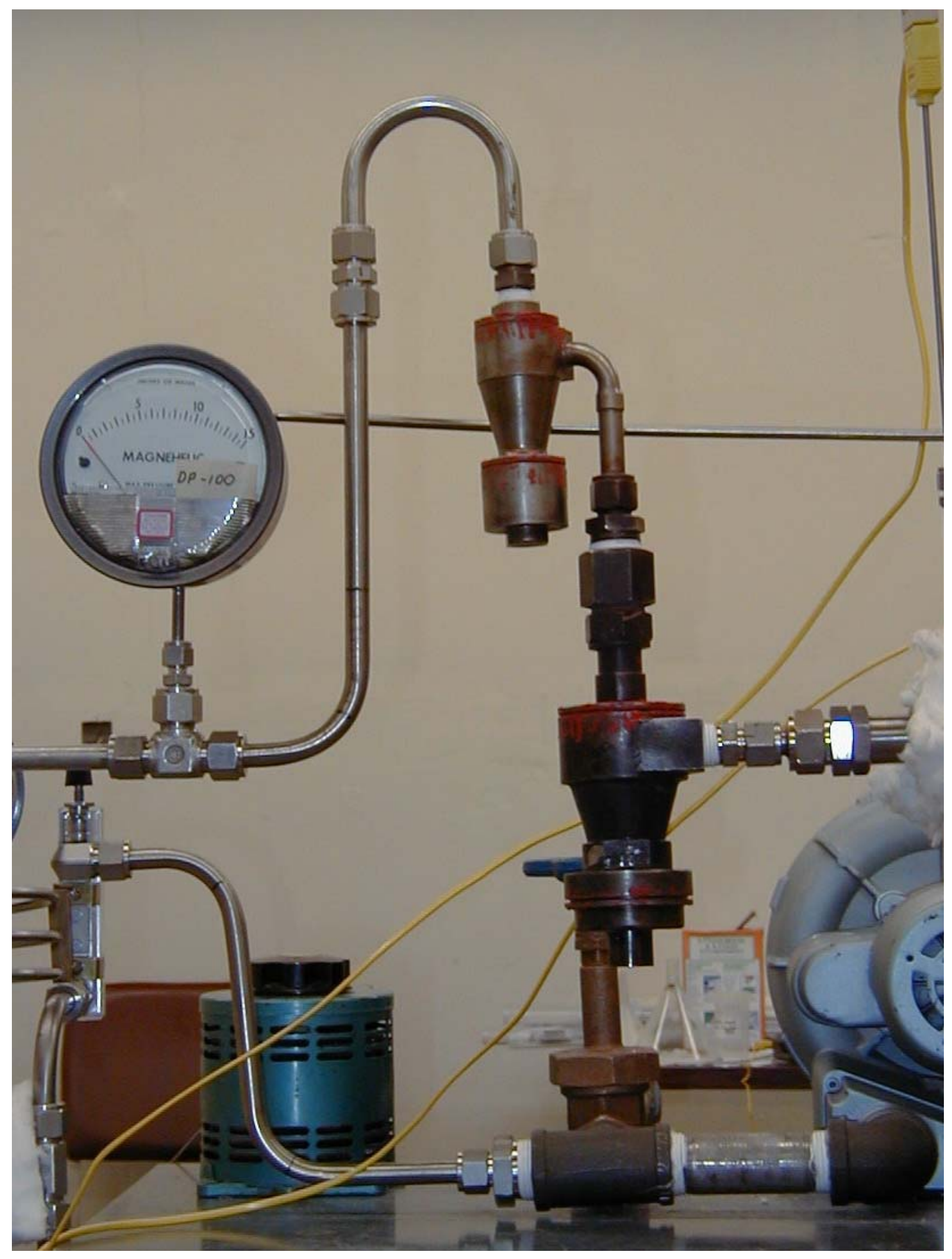

Figure 2.17. Series 280 In-Stack Cascade Cyclone Samplers 


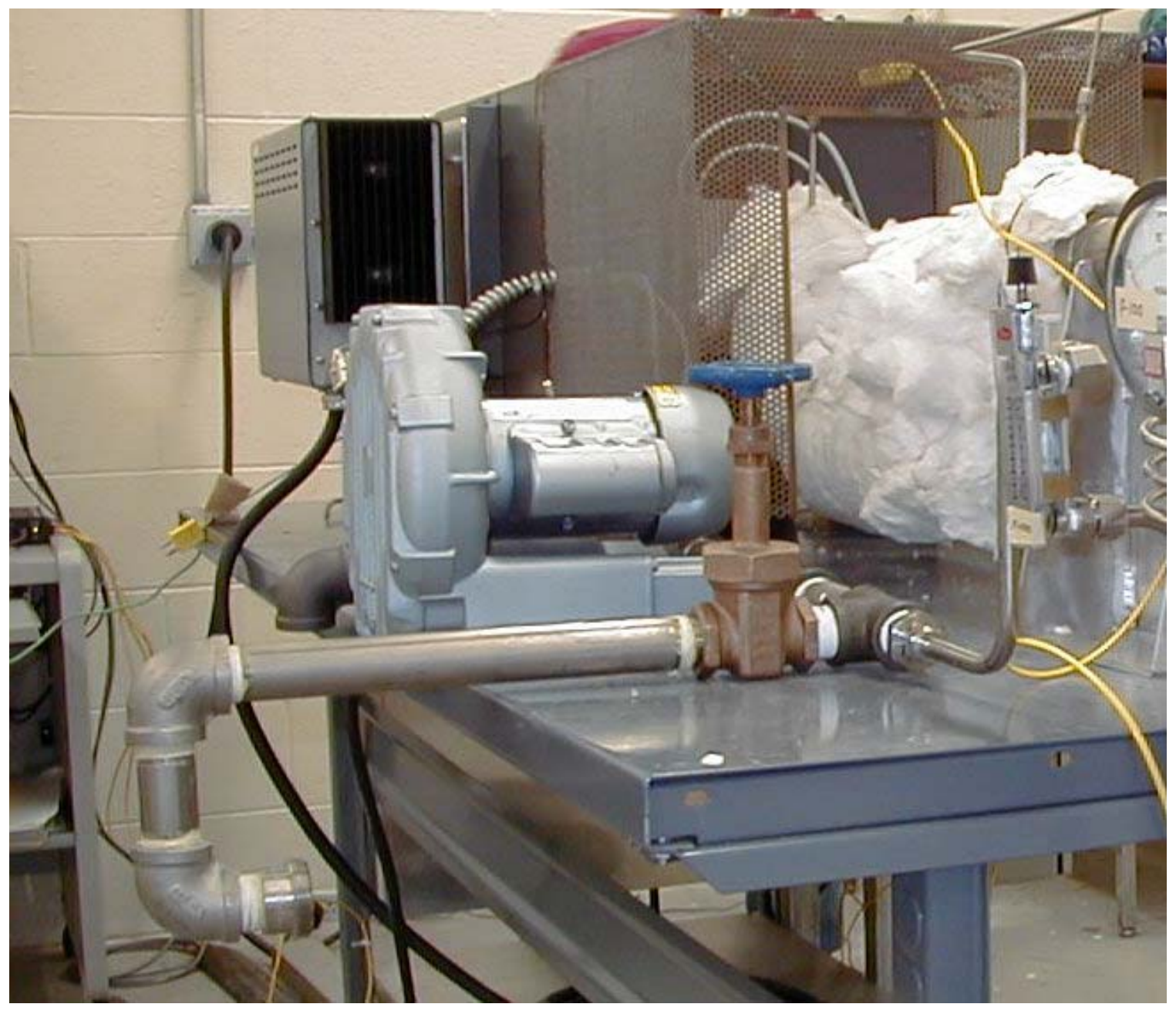

Figure 2.18. Blower and Control Valve Used to Draw Offgas from Furnace 


\subsection{Results and Discussion}

The corrosion testing consisted of 50 furnace cycles. Of these cycles, 47 were successfully completed and 3 failed due to plugging or furnace element failure. Table 3.1 shows the different equipment configurations tested, including number of cycles used per configuration. Appendix $\mathrm{C}$ contains a cycle-by-cycle summary.

\subsection{Simulant Loadings}

The first 31 test cycles used $1015 \mathrm{~g}$ of $\mathrm{CeO}_{2}$-salt simulant ( $\sim 16 \mathrm{~g}$ chloride salts). After Cycle 31 had been completed, new guidance from PFP suggested that the nominal $\mathrm{PuO}_{2}$ boat loading to be simulated should be increased from $1600 \mathrm{~g}$ to $2000 \mathrm{~g}$ per thermal stabilization run. Consequently, the simulant loading was increased to an equivalent $1269 \mathrm{~g}$ of $\mathrm{CeO}_{2}$-salt simulant per test cycle. Analyses of simulant from completed test cycles showed that essentially all of the chloride salts were converted or removed at both the 1015 and $1269 \mathrm{~g}$ loadings. The $25 \%$ increase in the chloride salt loading per charge had no perceptible effect on furnace element performance; however, it was necessary to increase the frequency of offgas line cleaning by more than a factor of two.

\subsection{Corrosion Coupons}

The majority of the coupons used for corrosion testing were made of Inconel 690, Haynes HR-160, Haynes 214, and Hastelloy X. In some tests, additional materials were used.

\subsubsection{Inconel 690, Haynes HR-160, Haynes 214, and Hastelloy X Coupons}

Two sets of corrosion coupons were evaluated. Coupon Set \#1 was used for 19 test cycles, and Set \#2 for 15 cycles. Each set contained two specimens of Inconel 690, Haynes HR-160, Haynes 214, and Hastelloy $\mathrm{X}$ (a new set of coupons is displayed in Figure 3.1). The corrosion rates for all coupon specimens were uniform throughout the testing and are summarized in Table 3.2. Coupon weight loss with respect to the number of test cycles completed is shown in Figures 3.2 and 3.3.

At the end of a test cycle, thin layers of oxidized metal would flake off of the coupons (Figure 3.4). The Haynes HR-160 coupons developed a "scale" that could not be removed with a cleaning brush (Figure 3.5). A coupon set was retired when corners began to break off (Figure 3.6). All coupons except for Hastelloy X formed a "wedge" shape on the lower half that was inserted directly into the simulant (Figure 3.7). Hastelloy X demonstrated the most uniform corrosion, retaining a rectangular profile. However, it also experienced the highest corrosion rate of the four materials (Table 3.2).

Location of the coupons within the boat affected the rates of corrosion. Room air pulled in through the front door of the furnace resulted in cooler temperatures at the front of the boat. The rate of corrosion for the Inconel 690-1 coupon (front of boat) was 21\% slower than the Inconel 690-2 coupon (back of boat). In addition, the Haynes 214-1 coupon (front of boat) was 17\% slower than the Haynes 214-2 coupon (middle of boat). Figure 3.8 shows the spacing of coupon Set \#1 within the sample boat. To reduce the effects of location with Coupon Set \#2, the coupons were placed closer together in the center of the boat.

The coupon tests closely represented the exposure conditions for the boats (i.e., high temperature and direct contact with the high-chloride solids), which are estimated to be the most severe corrosion 
conditions. Other metallic components of the furnace system are exposed to generally less severe conditions, most significantly lower temperatures. An exception was noted in the offgas line where temperature decreased to the point that the molten salt aerosols condensed on the inner surface of the pipe. Not surprisingly, at this region of contact of the pipe with molten salts, corrosion appeared to be more severe than on either side of that region, at either higher or lower temperatures.

Final weight loss results indicate that any of the four materials might be suitable as a fabrication material for the boats used to process HCP oxides, as well as for the baffle and parts of the offgas system. For Coupon Set \#1, the total weight loss for the Inconel 690, Haynes HR-160, and Haynes 214 coupons ranged from 42.61 to $48.12 \%$ (34.64 to $48.12 \%$, including coupons at the front of the boat). Hastelloy X was the only coupon that showed significantly more weight loss than the other materials, which ranged from 60.70 to $62.60 \%$. Coupon Set \#2 produced similar results. Weight loss for the Inconel 690, Haynes HR-160, and Haynes 214 coupons was 35.59 to $46.31 \%$ and for Hastelloy X was 51.85 to $52.15 \%$. The Haynes HR-160-3 coupon produced an unexpected lower weight loss of $29.32 \%$.

\subsubsection{Other Coupon Specimens}

Periodically, additional coupon materials were placed in the sample boat with the other coupon specimens. Zircaloy tubing (Figure 3.9) and tantalum foil did not survive a cycle. After the cycle was completed, all that remained were scattered corrosion products. Figure 3.10 shows the remains of a Zircaloy coupon.

One of the most important coupon tests was conducted placing a section of 3/4-in.-OD Inconel 600 tubing into the sample boat (tubing was partially submerged into the $\mathrm{CeO}_{2}$ salt simulant). Inconel 600 tubing is currently used for the internal offgas line within the PFP furnaces and was used during the initial test runs for this study. The section of tubing corroded severely and was nearly destroyed after three cycles (Figures 3.11 through 3.12). This was similar to the performance of the Inconel 600 internal offgas line (discussed in Section 3.4.1)

\subsection{Sample Boats and Baffle}

Two sample boats (Hastelloy X) and one baffle (Haynes HR-160) were used during the tests. Table 3.3 summarizes the corrosion performance by listing measured weight loss for these components. Figure 3.13 shows the rate of weight loss as a function of cycles completed.

\subsubsection{Sample Boats}

The behavior of the Hastelloy X boats was similar to the Hastelloy X coupons. Corroded metal would flake off the boat walls with a crackling sound when removed from the furnace after completing a test cycle. Weight loss from the boats from cycle to cycle was fairly constant (Figure 3.13), and attack on the boat was more severe on the inside surfaces, particularly below the level of the simulant (Figure 3.14). Attack by the chloride salts created a very rough surface, but the attack overall was uniform (not localized). This behavior would permit the use of a Hastelloy $\mathrm{X}$ boat for many cycles to the point of quite thin wall sections without "failure." No degradation was seen in the welds on the boats either, where some preferential attack might be expected, even in the absence of corrosion of the bulk metal. The test coupons did not include welds, so no similar information is available for the potential impacts to the welds or heat-affected zones for the other alloys (Haynes 214, Haynes HR-160, or Inconel 690). 
The main concern with the boats was the overall width. New boats displayed an initial width of 5.0 in. The widest point across the width of the boat would increase by $1 / 32$ in. to $3 / 32$ in. per test cycle. Initially with Boat \#2, this bowing was not monitored and could have been a factor that contributed to the failure of the first set of furnace elements (see Section 3.9). After the furnace element failure, if the boat bowed out to 3/32 in. or more, the walls were straightened with a vise. After 40 test cycles, Boat \#2 had lost $38.59 \%$ of its initial mass through corrosion that resulted in thin sidewalls. The boat was finally replaced due to the walls bowing out 3/32 in. to 1/8 in. after each cycle. Careful monitoring of Boat \#1 showed that a new boat would bow out $\sim 1 / 32$ in. per cycle. However, after only four test cycles, the widest point reached $53 / 32$ in. and required straightening.

\subsubsection{Baffle}

Only one baffle was required to complete all 50 test cycles. The initial rate of weigh loss was small, averaging $0.15 \mathrm{~g} /$ cycle. By the final test cycle, the average was $0.39 \mathrm{~g} /$ cycle. After approximately 30 test cycles, scale began to form on the top edge of the baffle (Figure 3.15), similar to the Haynes HR-160 coupons.

\subsection{Internal Offgas Line}

The results from the four different internal offgas line configurations evaluated are summarized in Table 3.4.

\subsubsection{Inconel 600 Offgas Line, 3/4-in.-OD Tubing (6-in. long)}

The first two internal offgas lines tested were Inconel 600 tubing, 6-in. overall length. This is the current configuration used by PFP for materials stabilization processing. The Inconel 600 tube demonstrated poor performance in the presence of HCP oxides. Only five test cycles were completed before the internal offgas line failed. Figure 3.16 shows the condition of this line after the fifth cycle, which corroded completely through and had to be removed from the furnace in several pieces. The performance of the second Inconel 600 line was similar to the first, nearly corroding through after three test cycles.

A hard ring of deposits formed inside of each tube, approximately where the offgas line exited the back wall of the furnace (Figure 3.17). The ring was removed from the first Inconel 600 line after completion of its third test cycle. This was also the area where the line completely corroded through (Figure 3.16). A short section of Inconel 600 tubing was placed in the simulant boat to serve as a corrosion coupon, as discussed in Section 3.2.2, to determine if the severe corrosion observed in the offgas line was caused by the steep temperature gradient that occurred from one end being inside the furnace at $1000^{\circ} \mathrm{C}$ and the other being outside the furnace at $600-700^{\circ} \mathrm{C}$. The coupon was nearly destroyed in three cycles, demonstrating that the corrosion was a direct result of the salts and not from the temperature gradient.

Samples of the deposit formed in the internal offgas line were collected and analyzed, using electron dispersive spectroscopy (EDS), to determine the elemental composition (see Appendix D). Even though $\mathrm{NaCl}$ and $\mathrm{KCl}$ were present in the $\mathrm{CeO}_{2}$-salt simulant at equal molar concentrations, the bulk of the deposit was found to be approximately $70 \mathrm{~mole} \% \mathrm{KCl}$ and $30 \mathrm{~mole} \% \mathrm{NaCl}$. The melting point of this fused salt composition is estimated to be approximately $720^{\circ} \mathrm{C}$. 


\subsubsection{Inconel 690 Offgas Line, 3/4-in.-OD Pipe (6-in. long)}

The Inconel 690 internal offgas line evaluation followed the testing with the Inconel 600 line. The Inconel 690 line was fabricated from 1/2-in.-OD Schedule 80 pipe, which served two purposes: 1) to maximize wall thickness, extending the service life of the offgas line, and 2) to create a rigid offgas line that could withstand several complete cleanings without promoting premature failure. Installation of the new line was similar to the Inconel 600 tube. The only difference was the thick walls of the turned pipe did not allow the swaging of a Swagelok ferrule when making connections to the bulkhead (Figure 3.18). However, $\sim 1 / 4$ of a turn from finger tight was sufficient for sealing the line under normal operating vacuum.

Corrosion performance was similar to the Inconel 690 coupons (Section 3.2.1). Over the course of eleven test cycles degradation to the line did not threaten its structural integrity and the line did not plug. Consecutive runs caused thin layers of oxidized metal to flake off of the inner walls of the tube (Figure 3.19). This corrosion was easily removed with a test tube brush. However, a hard ring of deposits formed inside the tube as with the Inconel 600 tube (Figure 3.20). The thick walls of the I-690 line allowed for more aggressive cleaning techniques (rodding, reaming, etc.).

\subsubsection{High Temperature Ceramic Offgas Line, 3/4-in.-OD Tubing (11-in. long)}

A 3/4-in.-OD tube of high-temperature ceramic (high-purity alumina) was tested for maximum corrosion resistance. Installation procedures were modified to facilitate an 11-in.-long tube, chosen over a 6-in. length to maximize the length of line exiting the furnace with high corrosion resistance. This was important since the gas temperature at the back of the furnace was still $600-700^{\circ} \mathrm{C}$.

The ceramic demonstrated excellent corrosion resistance to the corrosive offgas. A dark yellow ring of deposits formed in the tube near the outer back wall of the furnace. The ring was rodded-out ever two or three cycles to prevent plugging. The deposits were brittle and could be removed by repeatedly tapping the deposits with a steel rod. However, the end of the ceramic tube attached to the external offgas line chipped after 8 or 9 cycles (Figure 3.21).

\subsubsection{Inconel 690 Offgas Line, 3/4-in.-OD Pipe (11-in. long)}

The final internal offgas line tested was the same Inconel 690 as discussed in Section 3.4.2, but 11 in. in total length. This configuration demonstrated the same corrosion resistance as the 6 in. line. However, the line required cleaning after every three to five cycles. The increased cleaning frequency most likely resulted from the increased simulant loadings. A hard ring of deposits was also observed and was difficult to remove (Section 3.4.2).

Pipefitters from PFP are currently working on a tool that could simplify cleaning the internal offgas line without removing it from the furnace. Another possible solution would be to keep a steady supply of Inconel 690 lines in stock and replace the line when it is nearly plugged.

\subsection{External Offgas Line}

The external offgas line was insulated as recommended by PFP to match current glove box configurations. The fittings used to connect the 3/4-in.-OD Inconel 600 tubing to the internal offgas line and the filter were stainless steel, not Inconel. All nuts, ferrules, and elbows used to connect the 
individual pieces of Inconel 600 tubing between bends were also stainless steel. The mismatched materials coupled with temperatures close to $600^{\circ} \mathrm{C}$ at the start of the external offgas line caused one of the stainless steel nuts to "weld" to the threads on the elbow. The fittings exposed to cooler temperatures did not weld together and were easily disassembled with 12-in. pipe wrenches for cleaning. Pipefitters from PFP also experienced problems with the fittings welding together while running polycubes in the glove box. The standard procedure was to apply an anti-seize compound to all threads and ferrule surfaces on the offgas line to prevent welding. However, it should be noted that polycube stabilization requires an offgas flowrate three times larger than used for the furnace system evaluation. Consequently, the offgas line used in the glove box experienced much higher temperatures, which increased the chances for fittings to weld together.

The main concern for the external offgas line was plugging instead of corrosion. Typical gas temperatures ranged from $550-600^{\circ} \mathrm{C}$ at the hotter end (TC-101, Figure 2.2), and $250-350^{\circ} \mathrm{C}$ at the exit (TC-102, Figure 2.2). There were no significant signs of corrosion from the chlorides. During the entire series of processing cycles, the offgas line did not have a catastrophic failure. When processing $1015 \mathrm{~g}$ of simulant, seven to ten test cycles could be completed before cleaning was required. The cleaning frequency increased to every three to five cycles after increasing the simulant loading to $1269 \mathrm{~g}$ per cycle. The last two bends in the offgas line produced the highest plugging frequency. The last bend plugged twice during the corrosion study, completely sealing shut with salt deposits (Figure 3.22). The deposits were easily brushed out of the line with a test tube brush.

The offgas temperatures measured with TC-101 and 102 were sensitive to two variables. First, the amount of insulation on the line was very important. Any areas of the line exposed to the room air would quickly cool the offgas. Each time the offgas line was cleaned, the insulation was removed so that the line could be disassembled. Minor variations with re-insulating the line produced noticeable differences in the maximum offgas temperatures measured by the thermocouples (the difference was $50-100^{\circ} \mathrm{C}$ lower when the last $4 \mathrm{in}$. of the offgas line were not insulated. Offgas temperatures were also affected by the amount of deposits in the offgas line. It was observed during a particular test cycle that temperatures measured by TC- 102 would gradually drop from $350^{\circ} \mathrm{C}$ to $320^{\circ} \mathrm{C}$, even with a constant offgas flowrate and temperature measured by TC-101 (during the $2-\mathrm{hr} 1000^{\circ} \mathrm{C}$ dwell time in the furnace). Thin sheets of salt deposits had peeled off the inner walls of the offgas line and collected around the thermocouple sheath. This diverted the gases around the thermocouple and reduced the amount of gas making direct contact with the thermocouple. After removing TC-102 and cleaning the offgas line, temperatures returned to normal.

Cleaning the external offgas line was tedious because all the bends were composed of elbows and a tee. The process would have been simplified if each bend was a cross union as implemented at PFP.

\subsection{Filtration Systems}

Three different filtration systems were evaluated during the furnace test cycles. The salt particles collected by the various filtration systems were fine and exhibited a very low bulk density $\left(\sim 0.1 \mathrm{~g} / \mathrm{cm}^{3}\right)$. Approximately $30 \%$ of the chloride salt mass present in each $\mathrm{CeO}_{2}$-salt simulant charge would reach the filters, which did not make it appropriate to base filter performance on the percentage of salts collected in relation to the total chloride salts initially present in the simulant (all chloride salts were removed or converted by the end of the test cycle). Actual filter performance was based on visual inspections downstream of the filter housing for salt deposits and the number of test cycles that could be completed 
before blinding the filter elements. Table 3.5 summarizes the performance of each filtration system evaluated.

PFP is currently using a Pall filtration system that consists of a 304 stainless steel housing (P/N 7HD4886-2431, $63 \mathrm{lb}$ ) and a ceramic filter element rated at $2 \mu \mathrm{m}$ (Vitropore medium-silicon carbide, P/N C-23-12-DCSC-0). The initial test plan included an evaluation of this filtration system during the furnace system evaluation. However, the proper housing for the ceramic filter could not be obtained, but it was assumed the cartridge would blind quickly due to a low filtration surface area of $\sim 70$ in. $^{2}$ (similar to the results discussed in Section 3.6.1).

\subsubsection{Purlator Cartridge with Shelco Housing}

The porous metal filter from Purlator was not originally designed to fit in the filter housing from Shelco. A 10 in. section of pipe was used to support the Purlator cartridge in the Shelco housing. Hightemperature gaskets were cut out of a sheet of gasket material, and provided a sufficient seal for the testing. The filter completely blinded before the test cycle was completed. To complete the cycle, the filter housing was replaced with a knockout pot. While it was installed, salts were not able to penetrate through the filter cartridge that was rated for $10 \mu \mathrm{m}$. Close inspection of the filter showed a thin cake of salts deposited on the outer surface (dirty side) of the cartridge (Figure 3.23). This test provided a strong indication that more filtration surface area would be required to complete a test cycle than the $\sim 75$ in. $^{2}$ associated with the 10 in. Purlator cartridge.

\subsubsection{Nowata Filtration System (Glass-Wound Cartridges)}

The Nowata filtration system was the second type of cartridge filters tested. Four different size ratings were evaluated, as previously shown in Table 3.5. Each set of cartridges was able to finish all test cycles attempted. Figure 3.24 represents the initial measured pressure drop for each cartridge new, plus the final pressure drop at the end of each test cycle. The performance for the 10-, 20-, and 50- $\mu \mathrm{m}$ cartridges was the same. Each cartridge finished the first test cycle with 3.4-3.5 in. $-\mathrm{H}_{2} \mathrm{O} \Delta \mathrm{P}$. The 10- $\mu \mathrm{m}$ cartridge had the potential to complete a second cycle as achieved by the $20-\mu \mathrm{m}$ cartridge. With the $100-\mu \mathrm{m}$ cartridge three test cycles were completed, and a 6 in. $-\mathrm{H}_{2} \mathrm{O} \Delta \mathrm{P}$ was measured after the third cycle.

The glass-wound cartridges were simple to install and seal. The salts formed a cake on the outer surface of the cartridges (Figure 3.25), and did not penetrate through. The glass windings produce a tortuous path for the gases and, consequently, the actual size rating may not have been as important as with other filter constructions that rely heavily on pore size for filtration. Offgas temperatures did not damage the glass windings, but there was some darkening of the filter cartridge near the housing offgas inlet (Figure 3.26).

\subsubsection{Rosedale Filtration System (Pleated Metal Filters)}

The filtration system from Rosedale was the final filter configuration tested. The pleated metal filters screwed into a $1 \mathrm{in}$. NPT fitting, and the access flange sealed without any problems. The highest number of consecutive cycles completed per cartridge (five cycles for the 20 - $\mu \mathrm{m}$ filter element) was achieved with these filters (Table 3.5). The contributing factor to the success of these cartridges was the amount of available filtration surface area, which was four times the area of a set of glass-wound filters. Figure 3.27 represents the initial measured pressure drop for each new cartridge, plus the final pressure drop at the end of each test cycle. 
A thin film of salts deposited on the pleat protector (outer metal shell) (Figure 3.28). The bulk of the salts were on the pleated metal surface in the form of a thick cake (Figure 3.29). Both the 10- and 20- $\mu \mathrm{m}$ cartridges allowed traces of salts to penetrate through during the initial hour when salts began to volatilize out of the simulant. However, after completion of the test cycle, all that was visible was a very thin film of salts in the offgas line downstream of the filter and the flowmeter. The salts were only able to penetrate during the first cycle of a new cartridge. All cycles thereafter did not show salt penetration. Offgas temperatures did not affect the integrity of the filter cartridges.

\subsection{Knockout Pots}

Three different knockout pot configurations were tested. Overall performance for each configuration was poor when compared to the filter cartridges. Plugging occurred at points where a wire screen was used to secure packing or where packing had been pushed into inlet and outlet ports. Table 3.6 summarizes the performance of each knockout pot configuration. The basis for salt collection efficiency was normalized to the amount of material collected in the filters, which was assumed to be $100 \%$ of materials reaching the filter housings.

\subsubsection{2-in. Schedule 40 Stainless Steel Pipe}

The first knockout pot tested was the 2 -in. Schedule 40 pipe filled with 1/2-in. nominal ceramic Intalox saddles. The pot could be used for several cycles before plugging. However, most of the salts passed through, collecting in the gas scrubber and other sections of tubing downstream. The best collection efficiency achieved with this knockout pot was $23 \%$. Similar results were achieved when half of the pot was filled with wire mesh. Instead of increasing the salt collection efficiency, which did not exceed 17\%, the pressure drop increased at a faster rate due to the small openings on the mesh screen plugging up.

Cleaning the knockout pots was not difficult. Figure 3.30 shows ceramic and wire mesh packing that had been used for three cycles. The low density of the collected salts gave the appearance that large quantities of salts had been collected. However, actual weights never exceeded $1.3 \mathrm{~g}$ of salts per cycle. There were not any problems due to offgas temperatures or corrosion.

\subsubsection{Nowata Filter Housing Conversion}

The final knockout pot evaluated was the Nowata filter housing conversion. Loading the packing into the housing was not difficult. However, the orientation of the inlet and outlet ports did cause difficulty with plugging during the first run. The head assembly was intended to have filters mounted on a perforated pipe that was inserted into the center opening, which is the outlet port. When the housing was filled with packing, the small rectangular inlet filled with packing pieces and quickly plugged during the first run (Figure 3.31). To resolve the problem, the inlet and outlet ports were switched so the offgas would enter the packed section at the end of the internal gas tube. A screen was placed over the tube to prevent packing from entering the tube and causing a similar plugging problem as experienced with the original rectangular inlet. This reduced the frequency of plugging, but the wire screen at the end of the internal inlet tube still plugged after two test cycles. Striking the housing with a wrench dislodged some of the salts on the screen and allowed the knockout pot to complete the test cycle.

The Interpack metal packing performance was marginally better than the ceramic and wire mesh packing, which peaked at 33\% collection efficiency. Figure 3.32 shows packing after two cycles had been completed. Offgas temperatures did not damage the packing, and corrosion was minimal. 


\subsection{Cascade Cyclone Samplers}

The cascade cyclone samplers were used for one cycle. Overall performance was poor, which indicated that the particle size and density of the salts was too small for this method of solids collection. The salts did not collect in the particle reservoirs attached to the cyclone. Only a thin film of salts was deposited on the inner walls of the cyclone, as shown in Figures 3.33.

\subsection{Furnace Heating Elements}

Two complete sets of heating elements were used for the testing. In general, the elements performed well. Aside from one failure, there were no problems with operation. The voltage and current measurements recorded during testing did not indicate any problems with the heating elements. The furnace would pull an average $15.8 \mathrm{~A}$ at $213 \mathrm{VAC}$ during startup, and then hold $10.8 \mathrm{~A}$ at $143 \mathrm{VAC}$ during the final $2-\mathrm{hr}$ dwell at $1000^{\circ} \mathrm{C}$. Figure 3.34 shows a typical voltage/current plot from a test cycle. The power reading did not give warning to the failure with the first set of heating elements (discussed below). Corrosion products from the boat and coupons deposited on the surface of the elements, which left a black residue that did not appear to affect furnace performance.

Furnace element Set \#1 failed during the $16^{\text {th }}$ test cycle. The right side element arced to the sample boat and cut a hole through the boat wall (Figures 3.35 through 3.36). There may be three factors that contributed to the failure. First, the amount of bow in the simulant boat was not monitored until the first set of elements had failed (refer to 3.3.1 for bowing). The walls of the boat may have bowed enough to contact the side heating elements. Second, the element failure occurred while the furnace temperature was above $900^{\circ} \mathrm{C}$. The salts were boiling out of the simulant, which could have produced an environment more conductive to electricity. This, factored together with the boat walls close to the elements, would explain why the element arced. The wire inside the heating element was completely severed, which resulted in complete furnace shutdown. Also, during the previous cycle ( $15^{\text {th }}$ test cycle), the offgas line plugged, which may have resulted in a large inventory of chloride salts being deposited to the furnace chamber.

After the heating elements failed, a new complete set was installed. This set was used for the remainder of the testing, lasting 34 cycles without another failure. The longer life of the second set was accomplished by closely monitoring the amount of bow in the boat. If the widest point exceeded 5-3/32 in., the boat walls were straightened in a vise. Consequently, proper clearance between the heating elements and the boat walls was maintained, which reduced the potential for arcing. The boat required straightening after every 1 to 2 runs. An alternative solution to prevent arcing would have been to use a narrower boat that would have allowed more room for the boat to bow.

After the $43^{\text {rd }}$ test cycle, a crack down the entire length of the top heating element was observed (Set \#2), most likely caused by multiple thermal cycles and many hours at $1000^{\circ} \mathrm{C}$. The crack proceeded completely through the thickness of the element and allowed it to bow downward (Figure 3.37), but this did not result in a failure. 
Table 3.1. Total Number of Tests Cycles for Each Equipment Configuration Material Used

\begin{tabular}{|c|c|c|c|}
\hline $\begin{array}{c}\text { Item } \\
\text { Number }\end{array}$ & Equipment/Material Description & $\begin{array}{l}\text { Number of } \\
\text { Cycles Used }\end{array}$ & $\begin{array}{c}\text { Section } \\
\text { Discussed }\end{array}$ \\
\hline 1 & $\mathrm{CeO}_{2}$ Simulant, $1015 \mathrm{~g}$ Loading (16 g Chloride Salts) & 31 & 3.1 \\
\hline 2 & $\mathrm{CeO}_{2}$ Simulant, $1269 \mathrm{~g}$ Loading (20 g Salts) & 19 & 3.1 \\
\hline 3 & Corrosion Coupons, Set \#1 & 19 & 3.2 .1 \\
\hline 4 & Corrosion Coupons, Set \#2 & 15 & 3.2 .1 \\
\hline 5 & Simulant Boat \#1 & 10 & 3.3 .1 \\
\hline 6 & Simulant Boat \#2 & 40 & 3.3.1 \\
\hline 7 & Baffle \#1 & 50 & 3.3 .2 \\
\hline 8 & Inconel 600 Offgas Line \#1, 6-in. Long, Internal & 5 & 3.4 .1 \\
\hline 9 & Inconel 600 Offgas Line \#2, 6-in. Long, Internal & 3 & 3.4 .1 \\
\hline 10 & Inconel 690 Offgas Line \#1, 6-in. Long, Internal & 11 & 3.4 .2 \\
\hline 11 & High Temperature Ceramic, 11-in. Long, Internal & 11 & 3.4 .3 \\
\hline 12 & Inconel 690 Offgas Line \#1, 11-in. Long, Internal & 14 & 3.4 .4 \\
\hline 13 & Inconel 690 Offgas Line \#2, 11-in. Long, Internal & 6 & 3.4 .4 \\
\hline 14 & Inconel 600 Offgas Line, External (w/o Bends) & 4 & 3.5 \\
\hline 15 & Inconel 600 Offgas Line, External (w/ Bends) & 46 & 3.5 \\
\hline 16 & Purlator Sintered Metal Filter Cartridge, $10 \mu \mathrm{m}$ & 1 & 3.6 .1 \\
\hline 17 & Nowata Glass Wound Filter Cartridge, $10 \mu \mathrm{m}$ & 1 & 3.6 .2 \\
\hline 18 & Nowata Glass Wound Filter Cartridge, $20 \mu \mathrm{m}$ & 2 & 3.6 .2 \\
\hline 19 & Nowata Glass Wound Filter Cartridge, $50 \mu \mathrm{m}$ & 2 & 3.6 .2 \\
\hline 20 & Nowata Glass Wound Filter Cartridge, $100 \mu \mathrm{m}$ & 3 & 3.6 .2 \\
\hline 21 & Rosedale Pleated Metal Filters, $10 \mu \mathrm{m}$ & 3 & 3.6 .3 \\
\hline 22 & Rosedale Pleated Metal Filters, $20 \mu \mathrm{m}$ & 5 & 3.6 .3 \\
\hline 23 & 1/2-in. Nominal Intalox Ceramic Saddles & 14 & 3.7 .1 \\
\hline 24 & 1/2-in. Nominal Intalox Ceramic Saddles w/ Wire Mesh & 12 & 3.7 .1 \\
\hline 25 & 10-mm Nominal Interpack Stainless Packing & 7 & 3.7 .2 \\
\hline 26 & Cyclade In-Stack Cascade Cyclone Samplers & 1 & 3.8 \\
\hline 27 & Furnace Heating Elements, Set \#1 & 16 & 3.9 \\
\hline 28 & Furnace Heating Elements, Set \#2 & 34 & 3.9 \\
\hline
\end{tabular}


Table 3.2. Performance Summary for Inconel 690, Haynes HR-160, Haynes 214, and Hastelloy X Corrosion Coupons: initial and final weights, $\%$ weight loss, and rates of corrosion

\begin{tabular}{|c|c|c|c|c|c|c|c|c|}
\hline $\begin{array}{l}\text { Coupon } \\
\text { Set } \#^{(1)}\end{array}$ & Alloy & ID \# & $\begin{array}{c}\text { Initial Weight } \\
\text { [g] }\end{array}$ & $\begin{array}{c}\text { Final Weight } \\
\text { (Before Cleaning) } \\
{\left[\mathrm{g}^{(2)}\right.} \\
\end{array}$ & $\begin{array}{c}\text { \% Weight Loss } \\
\text { (Before Cleaning) }\end{array}$ & $\begin{array}{c}\text { Final Weight } \\
\text { (After Cleaning) } \\
{[\mathrm{g}]^{(3)}}\end{array}$ & $\begin{array}{c}\text { \% Weight Loss } \\
\text { (After Cleaning) }\end{array}$ & 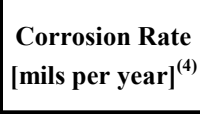 \\
\hline 1 & $\begin{array}{c}\text { Inconel } 690 \\
\text { Inconel } 690 \\
\text { Haynes HR-160 } \\
\text { Haynes HR-160 } \\
\text { Haynes } 214 \\
\text { Haynes } 214 \\
\text { Hastelloy X } \\
\text { Hastelloy X } \\
\end{array}$ & $\begin{array}{l}1 \\
2 \\
1 \\
2 \\
1 \\
2 \\
1 \\
2 \\
\end{array}$ & $\begin{array}{l}33.9546 \\
33.7457 \\
32.3037 \\
32.3436 \\
32.9590 \\
32.9212 \\
34.3922 \\
34.3434 \\
\end{array}$ & $\begin{array}{l}22.1923 \\
18.7790 \\
18.5375 \\
17.5279 \\
19.7816 \\
17.0795 \\
13.5162 \\
12.8451 \\
\end{array}$ & $\begin{array}{l}34.64 \% \\
44.35 \% \\
42.61 \% \\
45.81 \% \\
39.98 \% \\
48.12 \% \\
60.70 \% \\
62.60 \% \\
\end{array}$ & $\begin{array}{l}22.1398 \\
18.7100 \\
18.3925 \\
17.4391 \\
19.7048 \\
16.9029 \\
13.4286 \\
12.7265 \\
\end{array}$ & $\begin{array}{l}34.80 \% \\
44.56 \% \\
43.06 \% \\
46.08 \% \\
40.21 \% \\
48.66 \% \\
60.95 \% \\
62.94 \% \\
\end{array}$ & $\begin{array}{l}380.79 \\
484.71 \\
448.79 \\
480.84 \\
408.51 \\
494.39 \\
654.84 \\
677.60 \\
\end{array}$ \\
\hline 2 & \begin{tabular}{|c|} 
Inconel 690 \\
Inconel 690 \\
Haynes HR-160 \\
Haynes HR-160 \\
Haynes 214 \\
Haynes 214 \\
Hastelloy X \\
Hastelloy X \\
\end{tabular} & $\begin{array}{l}3 \\
4 \\
3 \\
4 \\
3 \\
4 \\
3 \\
4\end{array}$ & $\begin{array}{l}34.1691 \\
34.4224 \\
32.6275 \\
32.4397 \\
33.0253 \\
32.9331 \\
34.3398 \\
34.4467 \\
\end{array}$ & $\begin{array}{l}20.4203 \\
20.0320 \\
23.1576 \\
20.9288 \\
19.8943 \\
17.6867 \\
16.5073 \\
16.5382 \\
\end{array}$ & $\begin{array}{l}40.49 \% \\
42.64 \% \\
29.32 \% \\
35.59 \% \\
39.84 \% \\
46.31 \% \\
51.85 \% \\
52.15 \% \\
\end{array}$ & & & \\
\hline
\end{tabular}

1) Set \#1 was used for 19 test cycles, Set \# 2 for 15 test cycles.

2) This weight was taken before the coupons were chemically cleaned, (the coupons had been brushed of loose corrosion products prior to weighing).

3) Coupon Set \#2 was not chemically cleaned.

4) The corrosion rate for Coupon Set \#2 was not calculated.

Table 3.3. Performance Summary for Boats \#1 and \#2, and Baffle \#1: initial and final weights and final percent weight loss

\begin{tabular}{|c|c|c|c|c|}
\hline Alloy & ID \# $^{(\mathbf{1})}$ & $\begin{array}{c}\text { Initial Weight } \\
\text { [g] }\end{array}$ & $\begin{array}{c}\text { Final Weight } \\
\text { [g] }\end{array}$ & $\begin{array}{c}\text { Final \% Weight } \\
\text { Loss }\end{array}$ \\
\hline Hastelloy X & Boat \#1 & 2084 & 1888 & $9.40 \%$ \\
Hastelloy X & Boat \#2 & 2094 & 1286 & $38.59 \%$ \\
\hline Haynes HR-160 & Baffle \#1 & 351.08 & 336.18 & $4.24 \%$ \\
\hline
\end{tabular}

1) Boat \#1 was used for 10 test cycles, Boat \#2 for 40, and Baffle \#1 for 50.

2) Loose corrosion products were brushed off of each component before weighing. 
Table 3.4. Performance Summary for Internal Offgas Line Configurations

\begin{tabular}{|l|c|c|c|c|}
\hline \multicolumn{1}{|c|}{ Offgas Line Configuration } & $\begin{array}{c}\text { CeO, Simulant } \\
\text { Loading [g] }\end{array}$ & $\begin{array}{c}\text { Cleaning } \\
\text { Frequency }{ }^{(\mathbf{1})}\end{array}$ & $\begin{array}{c}\text { Did the Line } \\
\text { Plug? }\end{array}$ & $\begin{array}{c}\text { Did the Line } \\
\text { Fail? }\end{array}$ \\
\hline Inconel 600 Offgas Line \#1, 6-in. Long, Internal & 1015 & - & No & Yes \\
Inconel 600 Offgas Line \#2, 6-in. Long, Internal & 1015 & - & No & Near Failure \\
\hline Inconel 690 Offgas Line \#1, 6-in. Long, Internal & 1015 & Every 8-10 Cycles & No & No \\
\hline High Temperature Ceramic, 11-in. Long, Internal & 1015 & Every 2-3 Cycles & No & No \\
\hline Inconel 690 Offgas Line \#1, 11-in. Long, Internal & 1269 & Every 3-6 Cycles & No & No \\
Inconel 690 Offgas Line \#2, 11-in. Long, Internal & 1269 & Every 3-6 Cycles & No & No \\
\hline
\end{tabular}

1) The cleaning frequency was higher with the 11 in.-long Inconel 690 lines because of increased simulant loadings. It is uncertain why the ceramic tube plugged quickly at the lower simulant loading.

2) A failure was when the line corrodes completely through, leaving holes in the line walls.

Table 3.5. Performance Summary for Filter Systems Tested

\begin{tabular}{|c|c|c|c|c|c|c|}
\hline Filter Cartridge & $\begin{array}{l}\text { Simulant } \\
\text { Loading } \\
{[\mathrm{g}]}\end{array}$ & $\begin{array}{c}\text { Total } \\
\text { Number of } \\
\text { Cycles Used } \\
\end{array}$ & $\begin{array}{c}\text { Weight of Salts } \\
\text { on Cartridge } \\
{[\mathrm{g}]^{(1)}}\end{array}$ & $\begin{array}{c}\text { Total Salts } \\
\text { Collected } \\
{[\mathrm{g}]^{(2)}} \\
\end{array}$ & $\begin{array}{c}\text { Salts Collected } \\
\text { per Cycle } \\
{[g]^{(3)}} \\
\end{array}$ & $\begin{array}{c}\text { Percent } \\
\text { Collection } \\
\text { Efficiency }^{(4)}\end{array}$ \\
\hline Purlator Sintered Metal Filter Cartridge, $10 \mu \mathrm{m}^{(5)}$ & 1015 & 1 & - & - & - & $100 \%$ \\
\hline $\begin{array}{l}\text { Nowata Glass Wound Filter Cartridge, } 10 \mu \mathrm{m}^{(6)} \\
\text { Nowata Glass Wound Filter Cartridge, } 20 \mu \mathrm{m} \\
\text { Nowata Glass Wound Filter Cartridge, } 50 \mu \mathrm{m} \\
\text { Nowata Glass Wound Filter Cartridge, } 100 \mu \mathrm{m}\end{array}$ & $\begin{array}{l}1015 \\
1015 \\
1269 \\
1269\end{array}$ & $\begin{array}{l}1 \\
2 \\
2 \\
3\end{array}$ & $\begin{array}{c}5.90 \\
10.82 \\
15.37 \\
19.51\end{array}$ & $\begin{array}{l}5.90 \\
11.24 \\
16.68 \\
22.20\end{array}$ & $\begin{array}{l}5.90 \\
5.62 \\
8.34 \\
7.40\end{array}$ & $\begin{array}{l}100 \% \\
100 \% \\
100 \% \\
100 \%\end{array}$ \\
\hline $\begin{array}{l}\text { Rosedale Pleated Metal Filters, } 10 \mu \mathrm{m}^{(7)} \\
\text { Rosedale Pleated Metal Filters, } 20 \mu \mathrm{m}\end{array}$ & $\begin{array}{l}1269 \\
1269\end{array}$ & $\begin{array}{l}3 \\
5\end{array}$ & $\begin{array}{l}18 \\
30\end{array}$ & $\begin{array}{l}23 \\
33\end{array}$ & $\begin{array}{l}8 \\
7\end{array}$ & $\begin{array}{l}\sim 100 \% \\
\sim 100 \%\end{array}$ \\
\hline
\end{tabular}

1) The weight of salts reported for the Nowata glass wound filter is for two cartridges.

2) This includes salts removed from the filter housing.

3) Based on total salts collected.

4) $100 \%$ efficiency assumed if no salt deposits were observed downstream of filter.

5) The Purlator cartridge was not weighed before and after use. The cartridge blinded before completion of the test cycle.

6) The final $\Delta \mathrm{P}$ for this cartridge was $3.5 \mathrm{in}$ - $\mathrm{H} 2 \mathrm{O}$. It may have been possible to complete another test cycle with the $10-\mu \mathrm{m}$ cartridges.

7) The HCP oxides testing had finished before this filter cartridge was completely blinded. 
Table 3.6. Performance Summary for Knockout Pot Systems Tested

\begin{tabular}{|c|c|c|c|c|c|}
\hline Knockout Pot Configuration & $\begin{array}{c}\text { Simulant } \\
\text { Loading } \\
\text { [g] }\end{array}$ & $\begin{array}{c}\text { Total Number of } \\
\text { Cycles Before } \\
\text { Cleaning }\end{array}$ & $\begin{array}{c}\text { Total Salts } \\
\text { Collected [g] }{ }^{(1)}\end{array}$ & $\begin{array}{c}\text { Salts Collected } \\
\text { per Cycle } \\
\text { [g] }\end{array}$ & $\begin{array}{c}\text { Percent } \\
\text { Collection } \\
\text { Efficiency }\end{array}$ \\
\hline & 1015 & 1 & $<1$ & $<1$ & $<23 \%$ \\
2-in. Schedule 40 Stainless Steel Pipe with & 1015 & 3 & 4 & 1.3 & $23 \%$ \\
Intalox Saddles & 1015 & 3 & 4 & 1.3 & $23 \%$ \\
& 1015 & 4 & 5 & 1.3 & $22 \%$ \\
& 1015 & 3 & 4 & 1.3 & $23 \%{ }^{(3)}$ \\
\hline 2-in. Schedule 40 Stainless Steel Pipe with & 1015 & 6 & 5 & 0.8 & $14 \%{ }^{(4)}$ \\
Intalox Saddles and Wire Mesh & 1015 & 2 & 2 & 1.0 & $17 \%$ \\
& 1015 & 2 & 2 & 1.0 & $17 \%$ \\
\hline & 1015 & 2 & - & - & - \\
Nowata Filter Housing Conversion with 10-mm & 1015 & 1 & 1 & 1.0 & $17 \%$ \\
Nominal Interpack Packing & 1269 & 2 & 4 & 2.0 & $27 \%$ \\
& 1269 & 2 & 5 & 2.5 & $33 \%$ \\
& 2 & 4 & 2.0 & $27 \%$ \\
\hline
\end{tabular}

1) This was determined by weighing the entire knockout pot for the 2 in. Schedule 40 pipe configurations. The 10-mm nominal Interpack packing was removed from the housing and weighed separately.

2) This was normalized to the average performance of the filter cartridges for different simulant loadings. For a simulant loading of $1015 \mathrm{~g}$, the salts collected in the knockout pot were compared to $5.76 \mathrm{~g} /$ cycle. For the 1269 -g loading, the comparison was with $7.50 \mathrm{~g} / \mathrm{cycle}$.

3) The third test cycle was to replace the Purlator filter cartridge after blinding.

4) The first two cycles of this 6-cycle series were not completed. The first cycle resulted with a plugged external offgas line and the second cycle experienced a heating element failure.

5) The second test cycle was not completed due to a plugged external offgas line. 


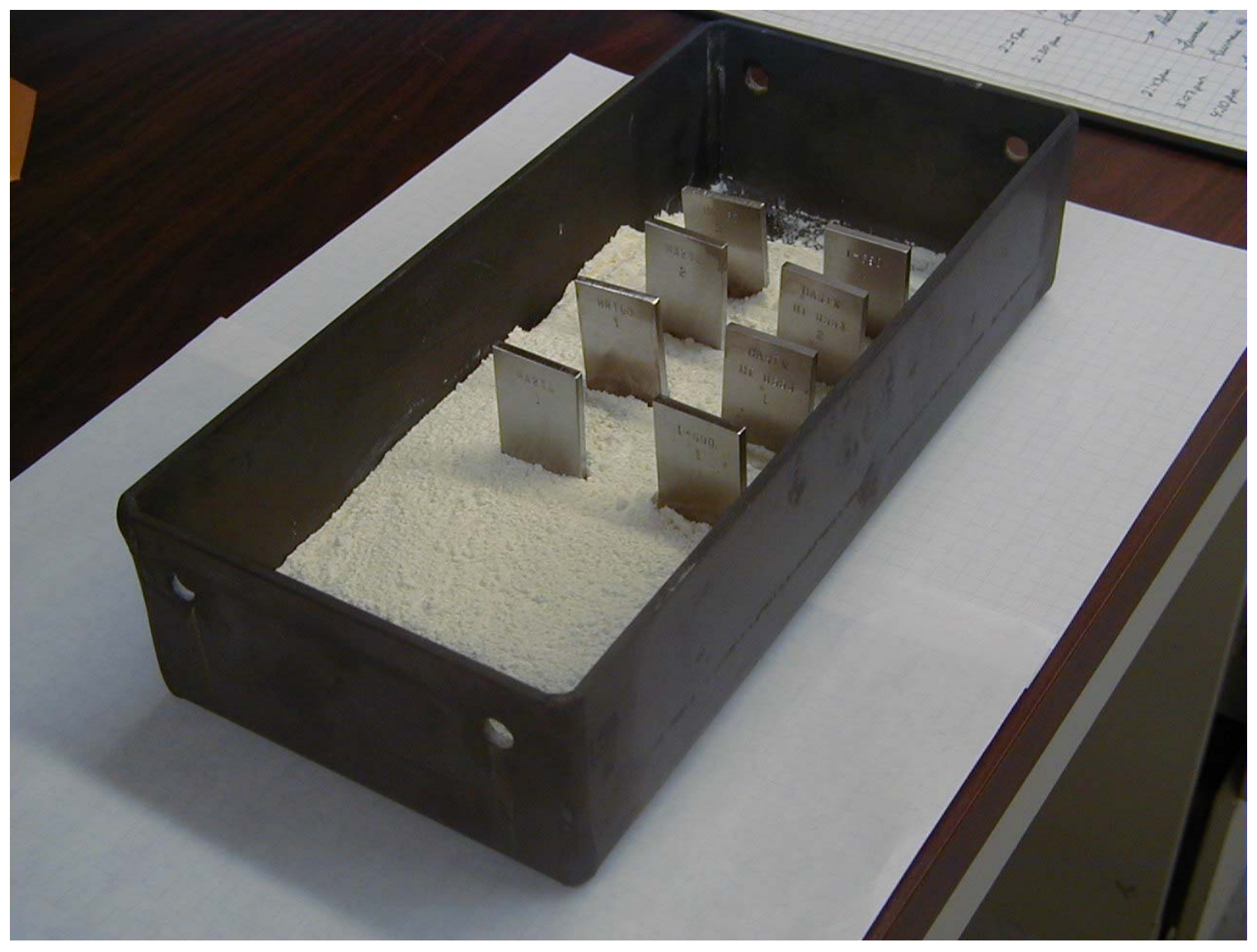

Figure 3.1. New Coupon Specimens Loaded in the Simulant Boat 


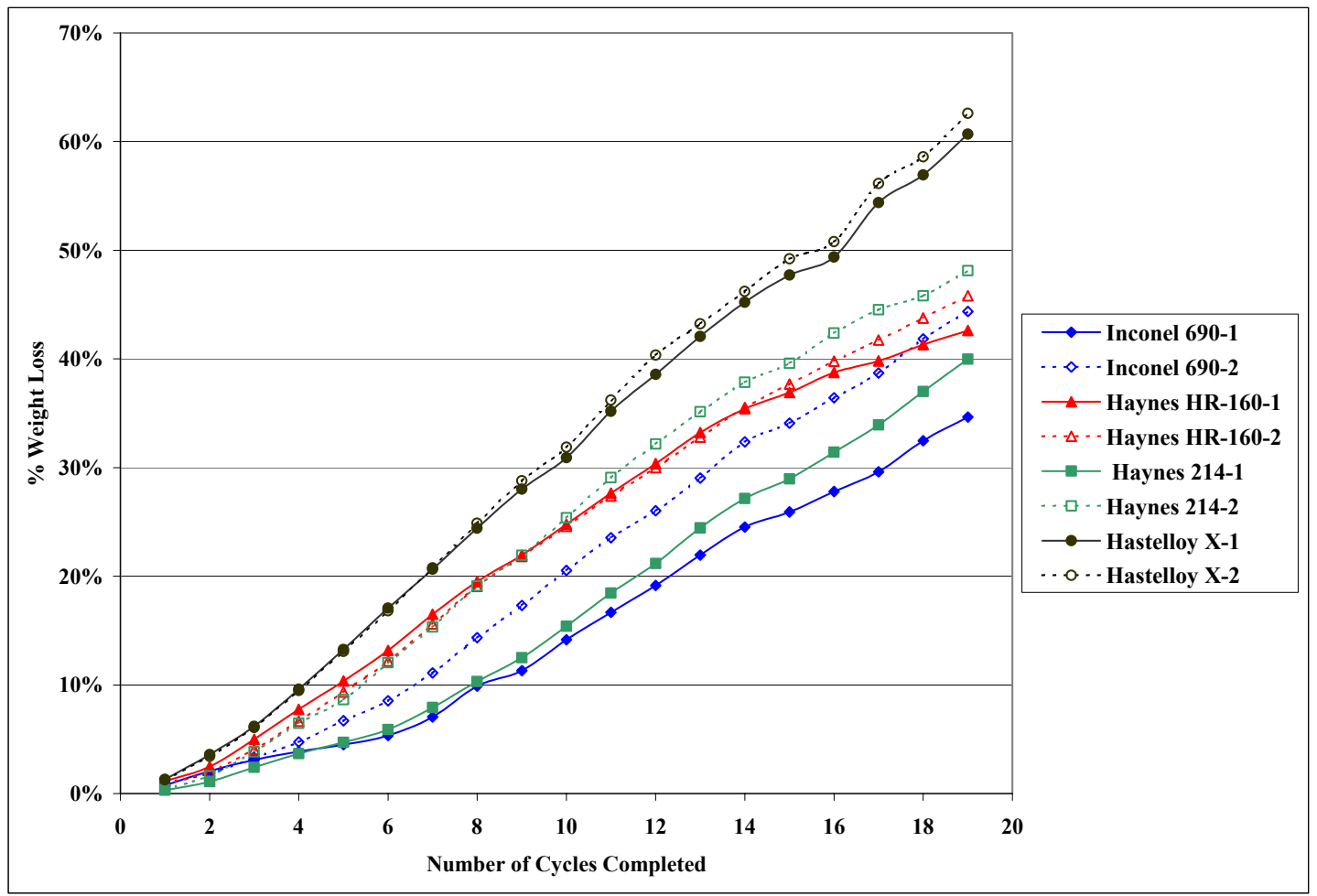

Figure 3.2. Percent Weight Loss Versus Number of Cycles Completed for Coupon Set \#1

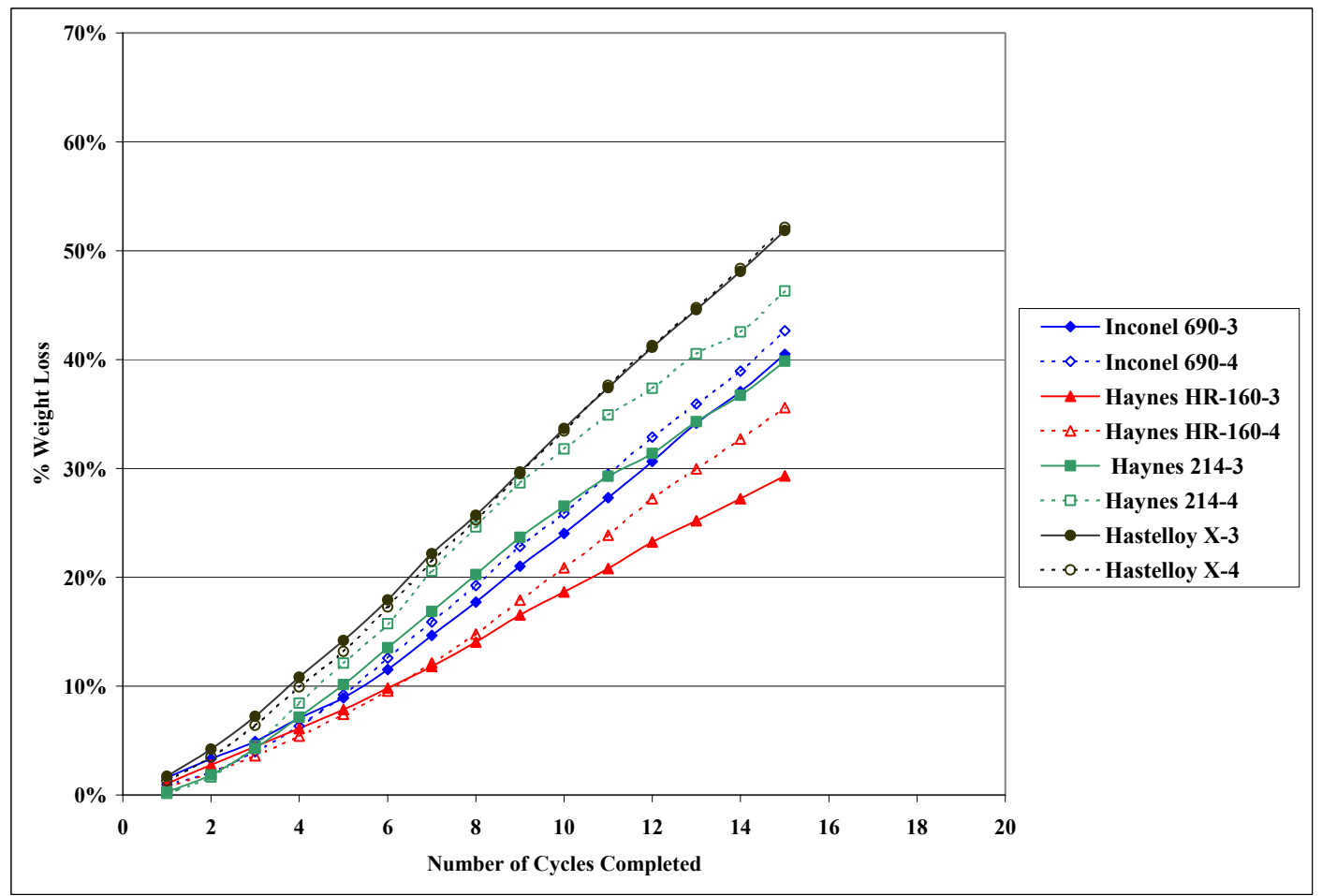

Figure 3.3. Percent Weight Loss Versus Number of Cycles Completed for Coupon Set \#2 


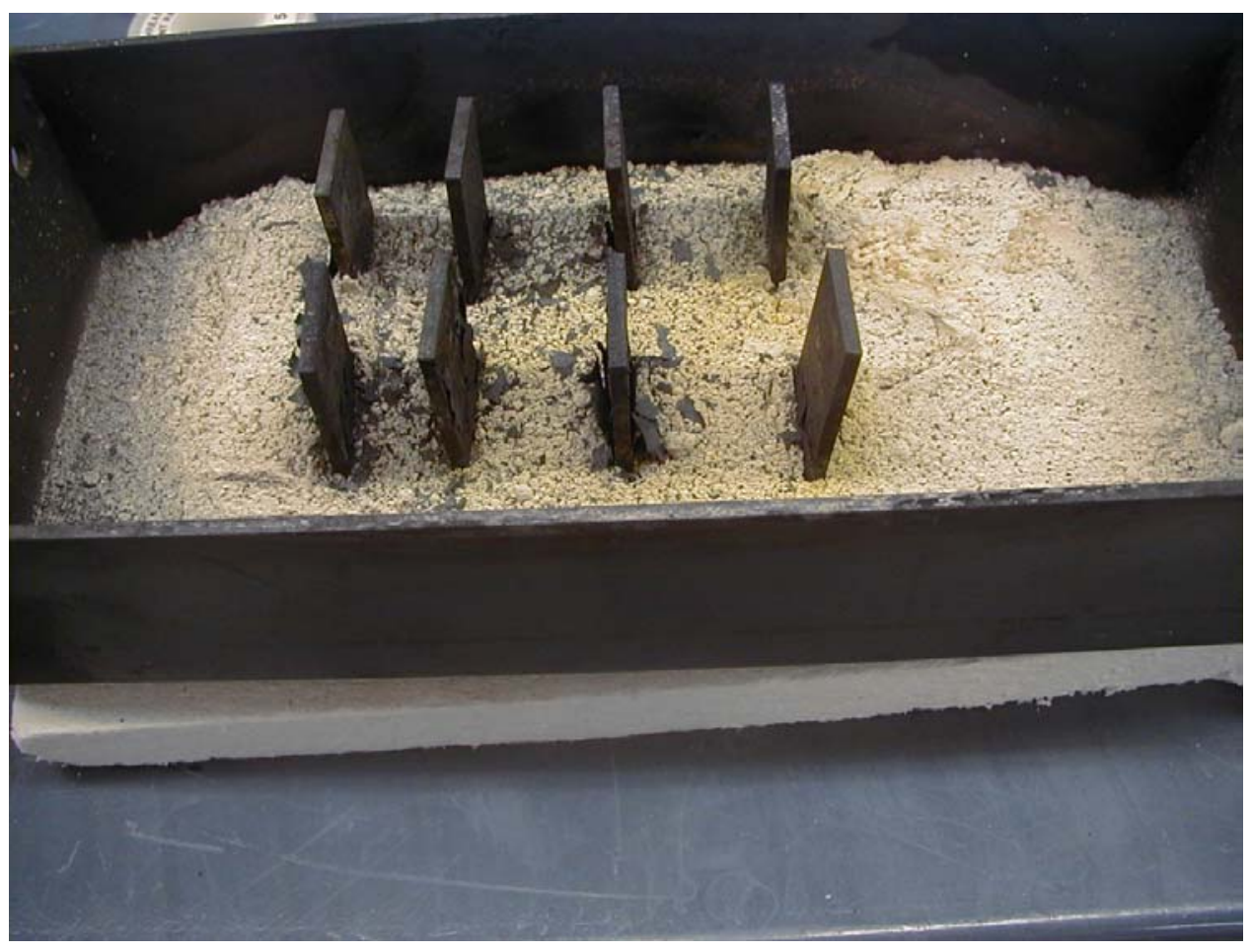

Figure 3.4. Coupon Specimens After a Test Cycle. Note the thin pieces of oxidized metal peeling off the coupons.

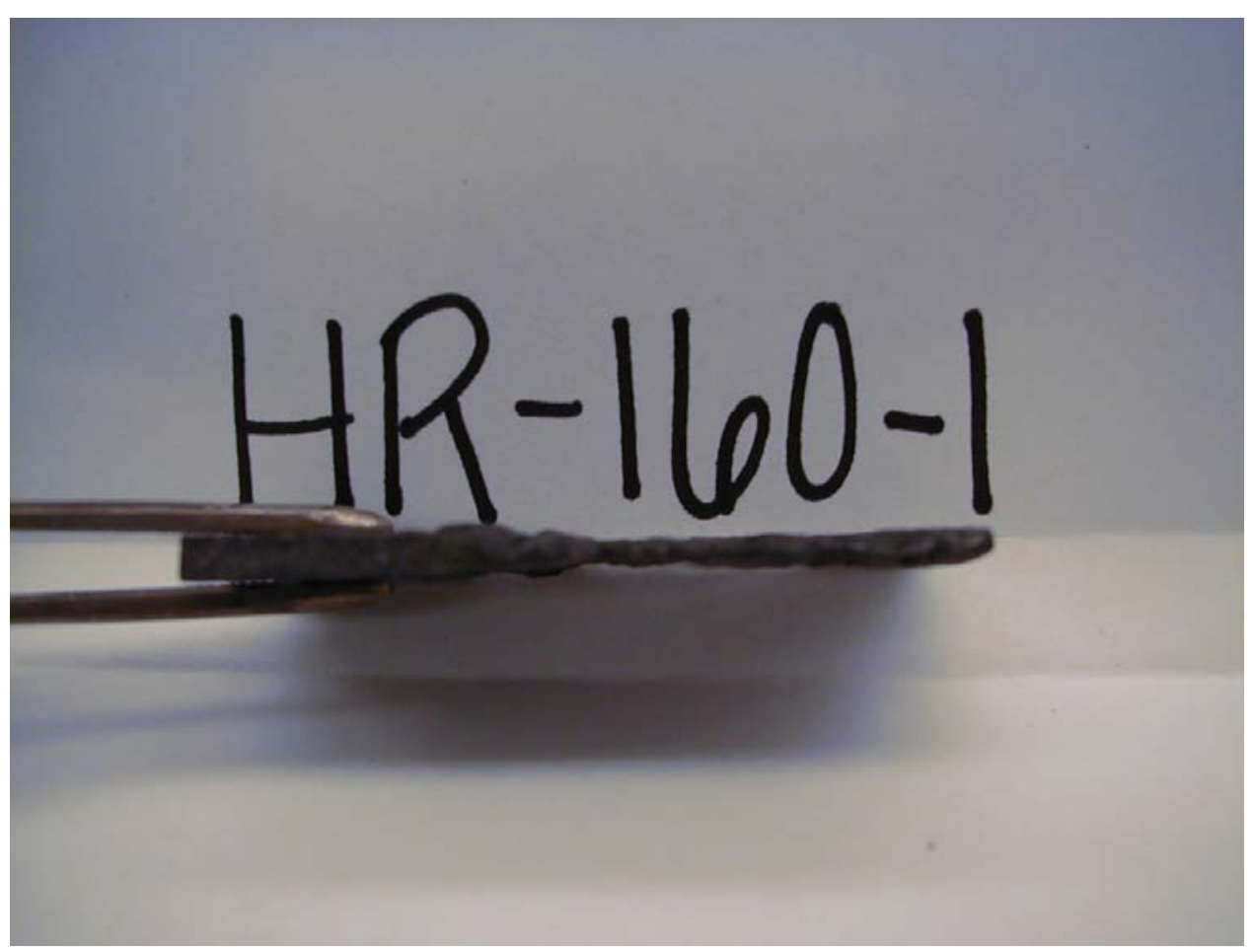

Figure 3.5. Haynes HR-160 Coupon with Scale Buildup 


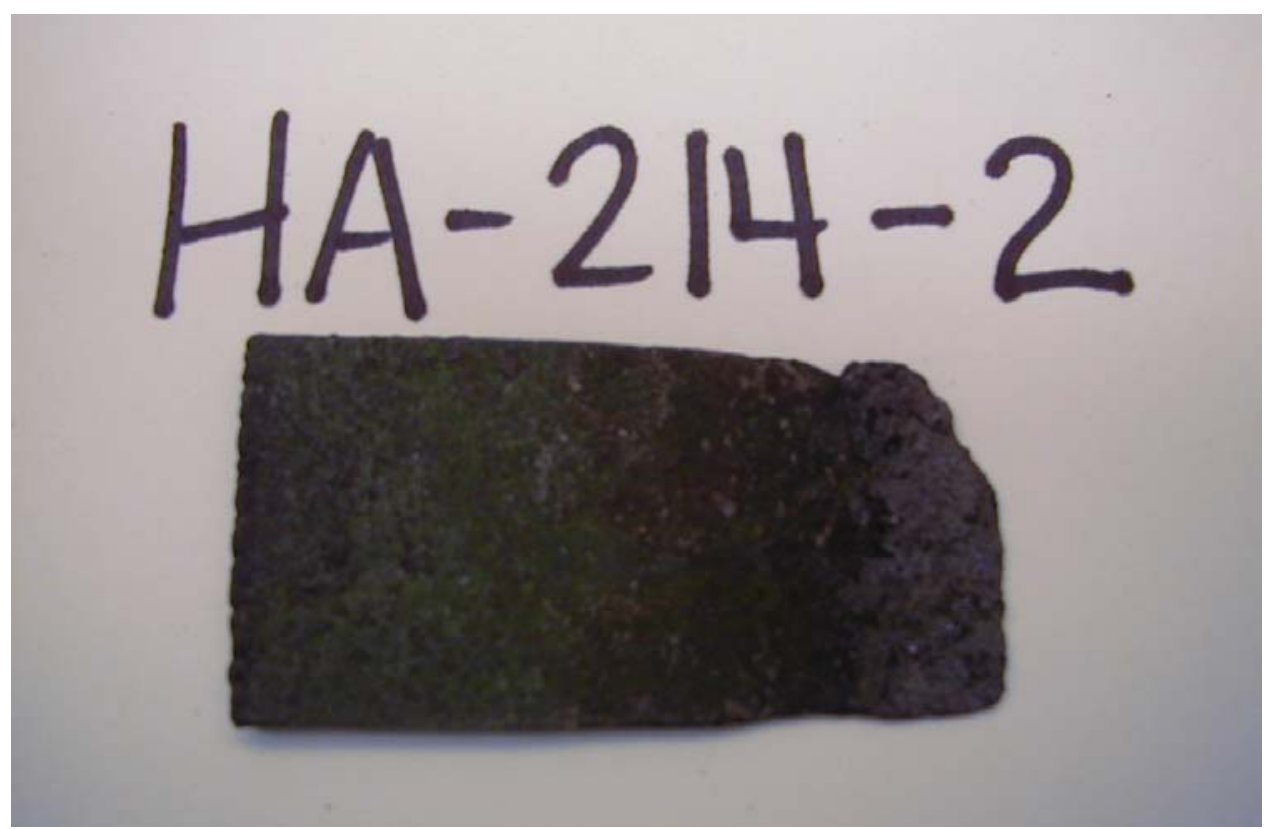

Figure 3.6. Haynes 214 Coupon with a Broken Corner

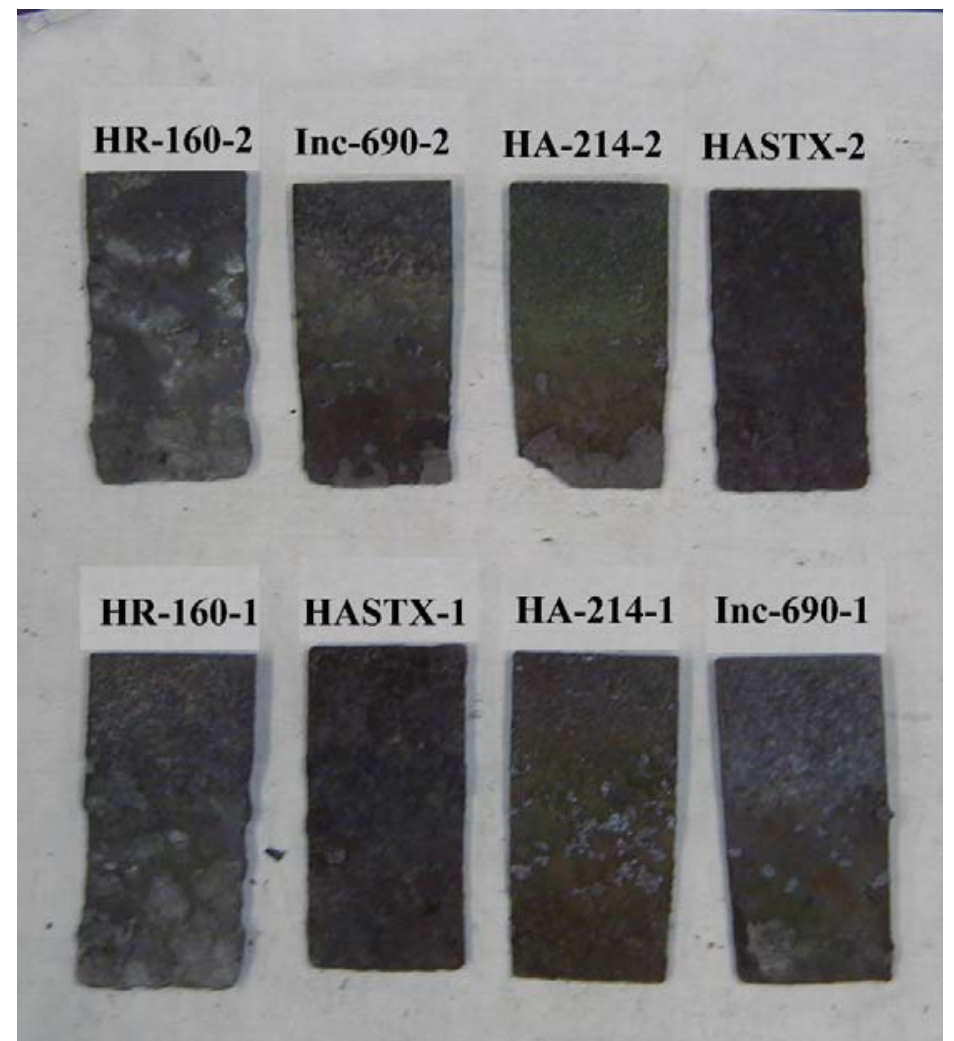

Figure 3.7. Wedge-Shaped Coupons from Set \#1 After 19 Consecutive Test Cycles. HR-160=Haynes HR-160, Inc-690=Inconel 690, HR-214=Haynes 214, HASTX= Hastelloy X. 


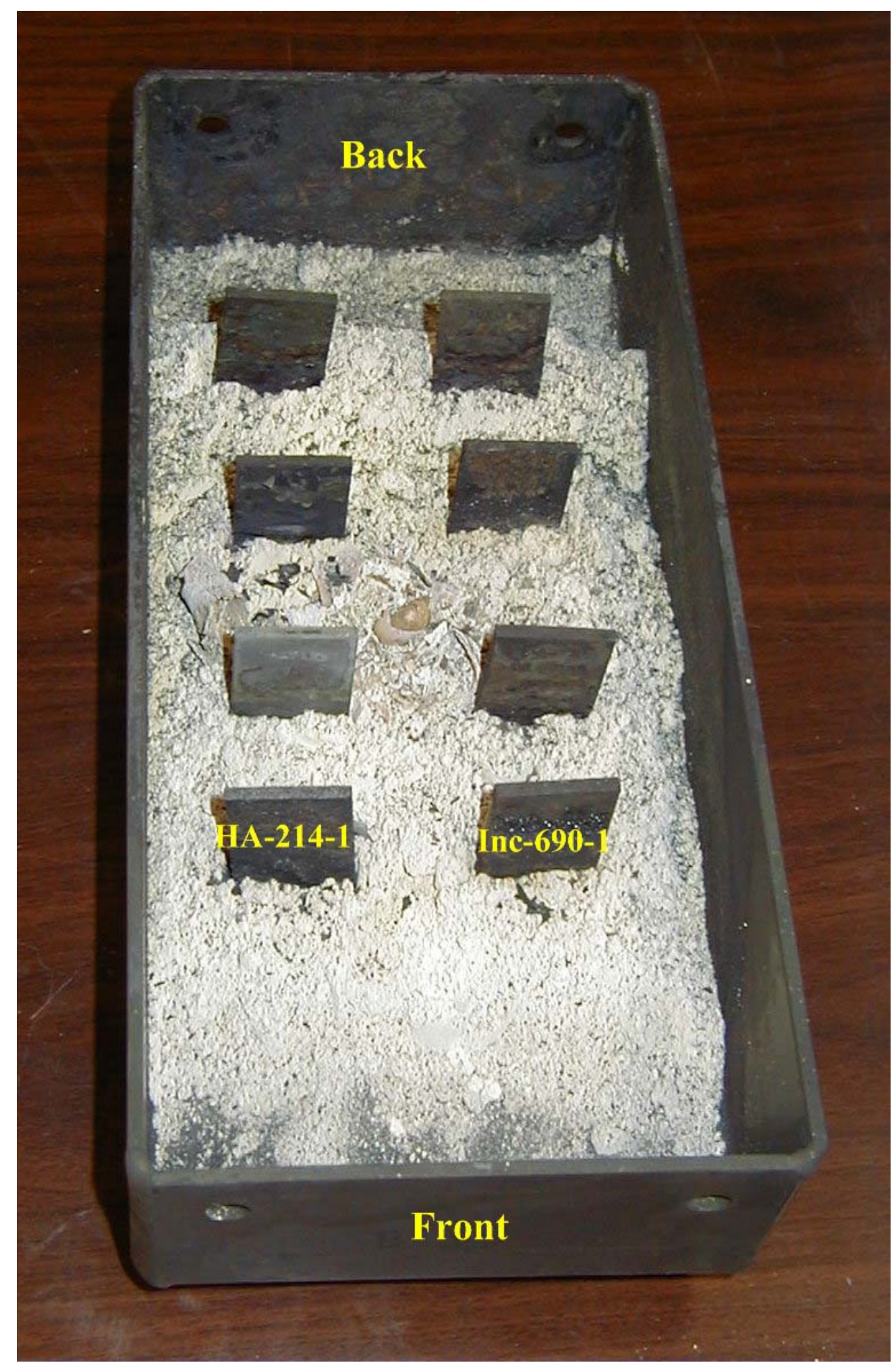

Figure 3.8. Inconel 690-1 (Inc-690-1) and Haynes 214-1(HA-214-1) Coupons at the Front of the Simulant Boat 


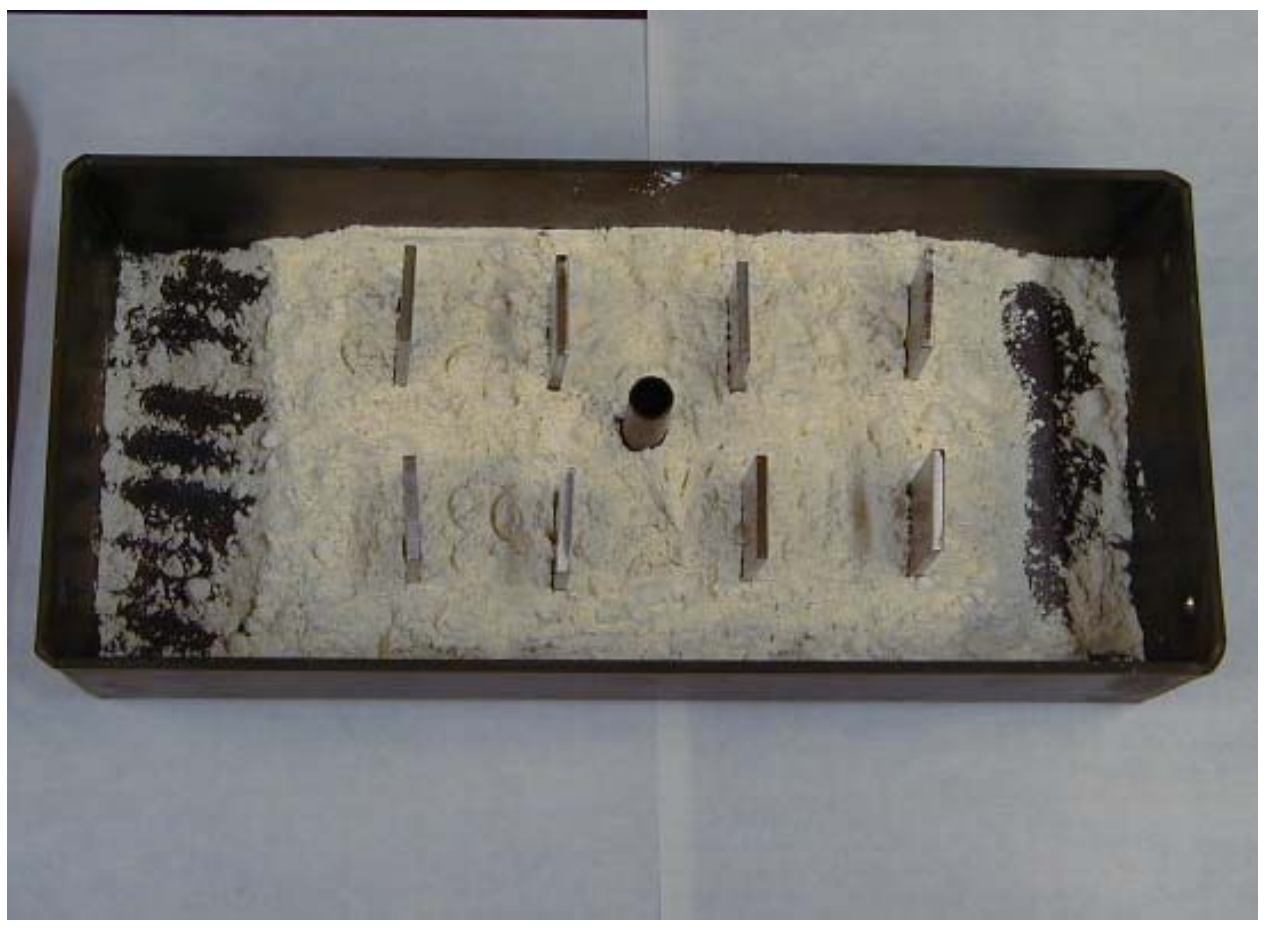

Figure 3.9. Zircaloy Tubing (center) Used as a Corrosion Coupon

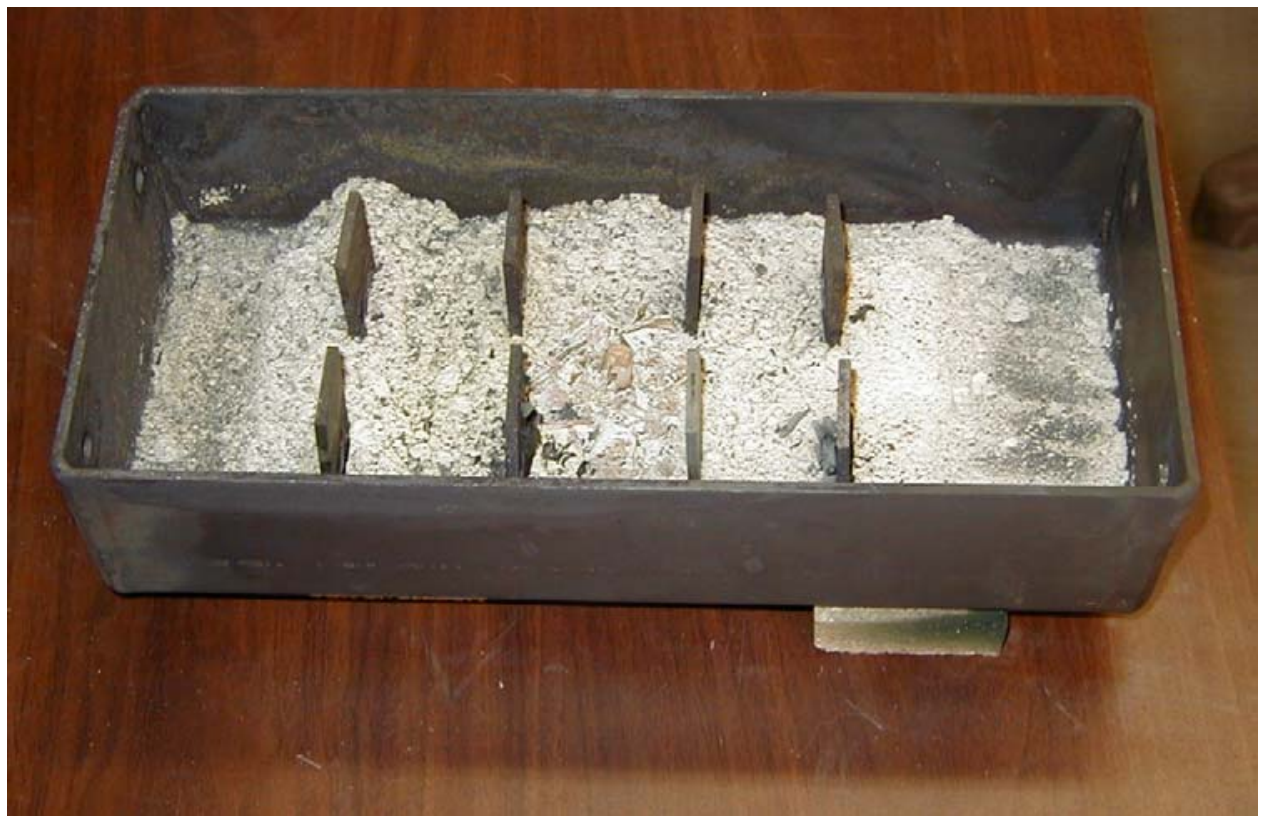

Figure 3.10. Zircaloy Tubing Residue (center) After One Test Cycle 


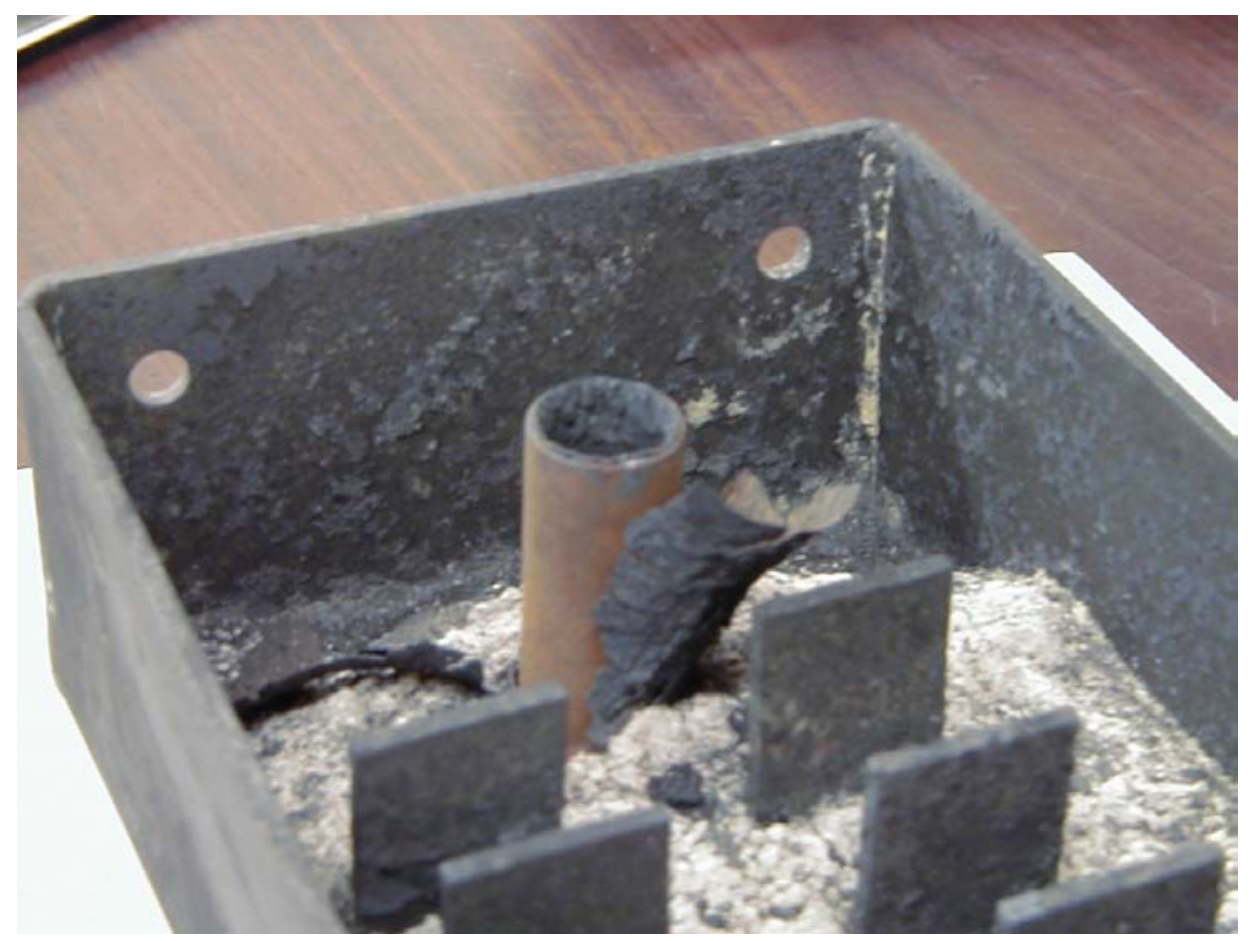

Figure 3.11. Inconel 600 Tubing (left center) Used as a Corrosion Coupon. Condition after one test cycle.

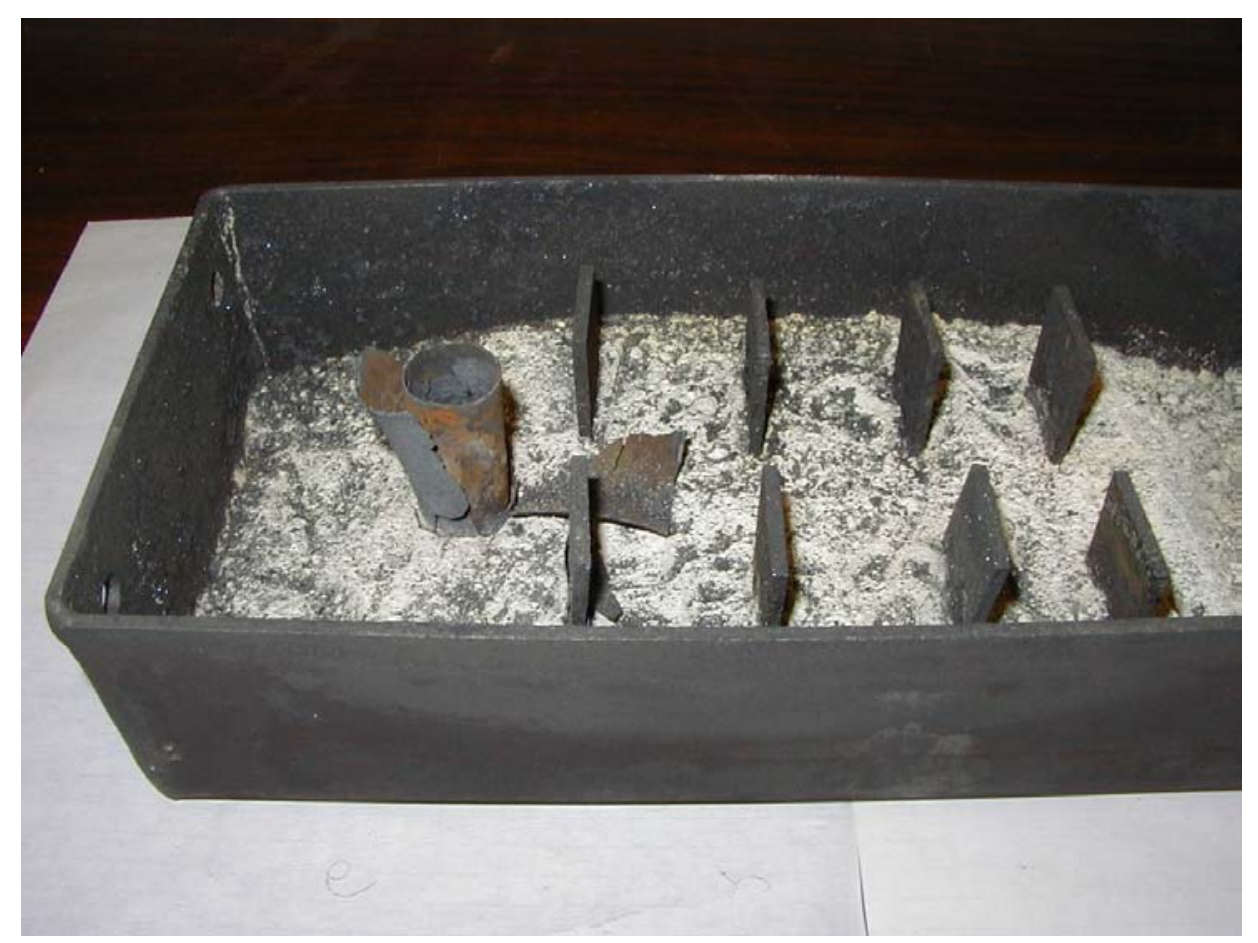

Figure 3.12. Inconel 600 Tubing Used as a Corrosion Coupon. Condition after three test cycles. 


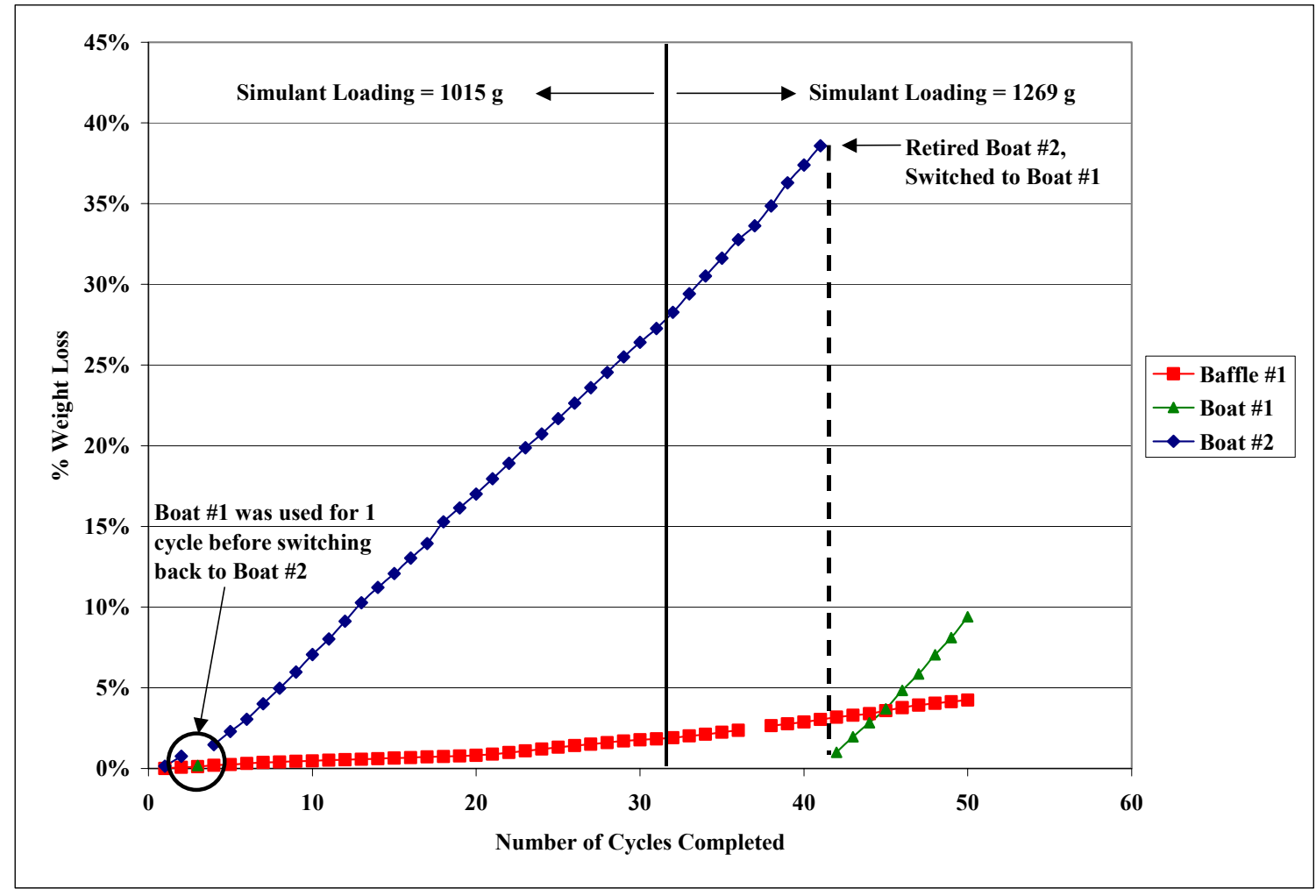

Figure 3.13. Percent Weight Loss Versus Number of Cycles Completed for Simulant Boats \#1 and \#2, and Baffle \#1

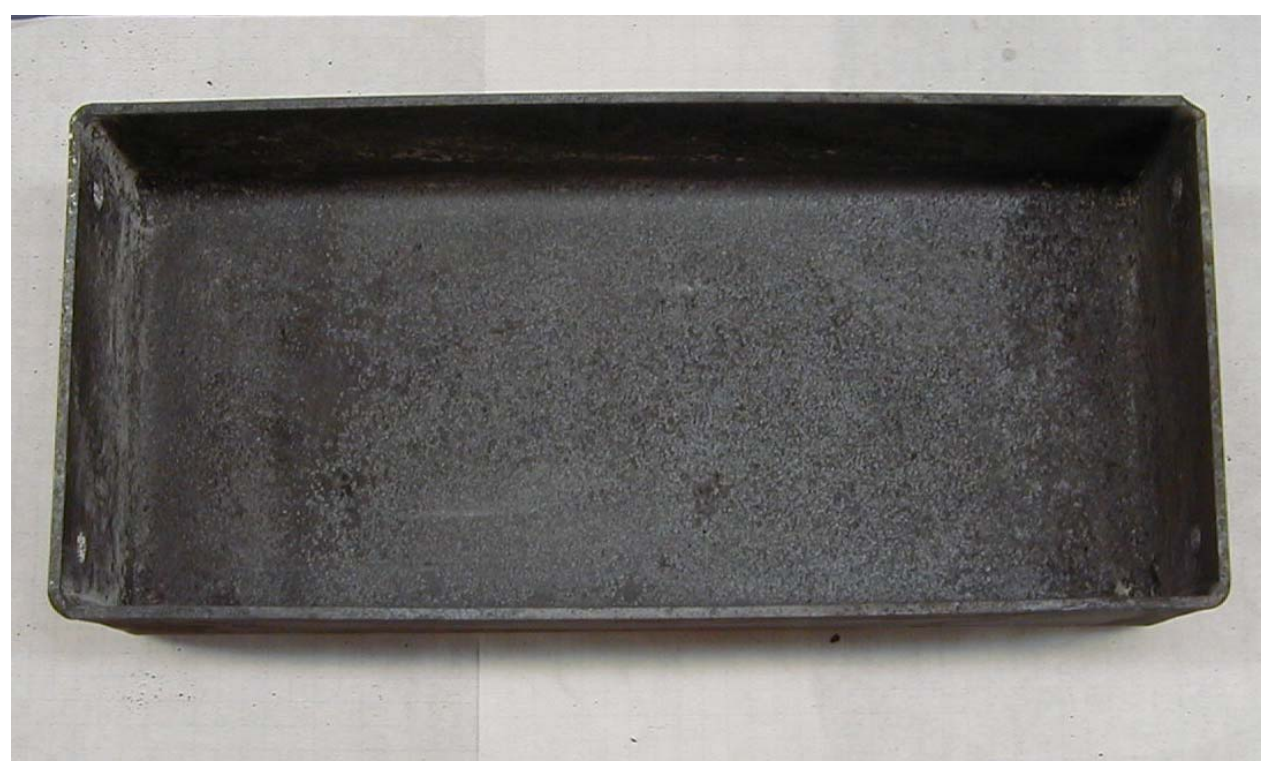

Figure 3.14. Corrosion at the Bottom of Simulant Boat \#2 After Five Test Cycles 


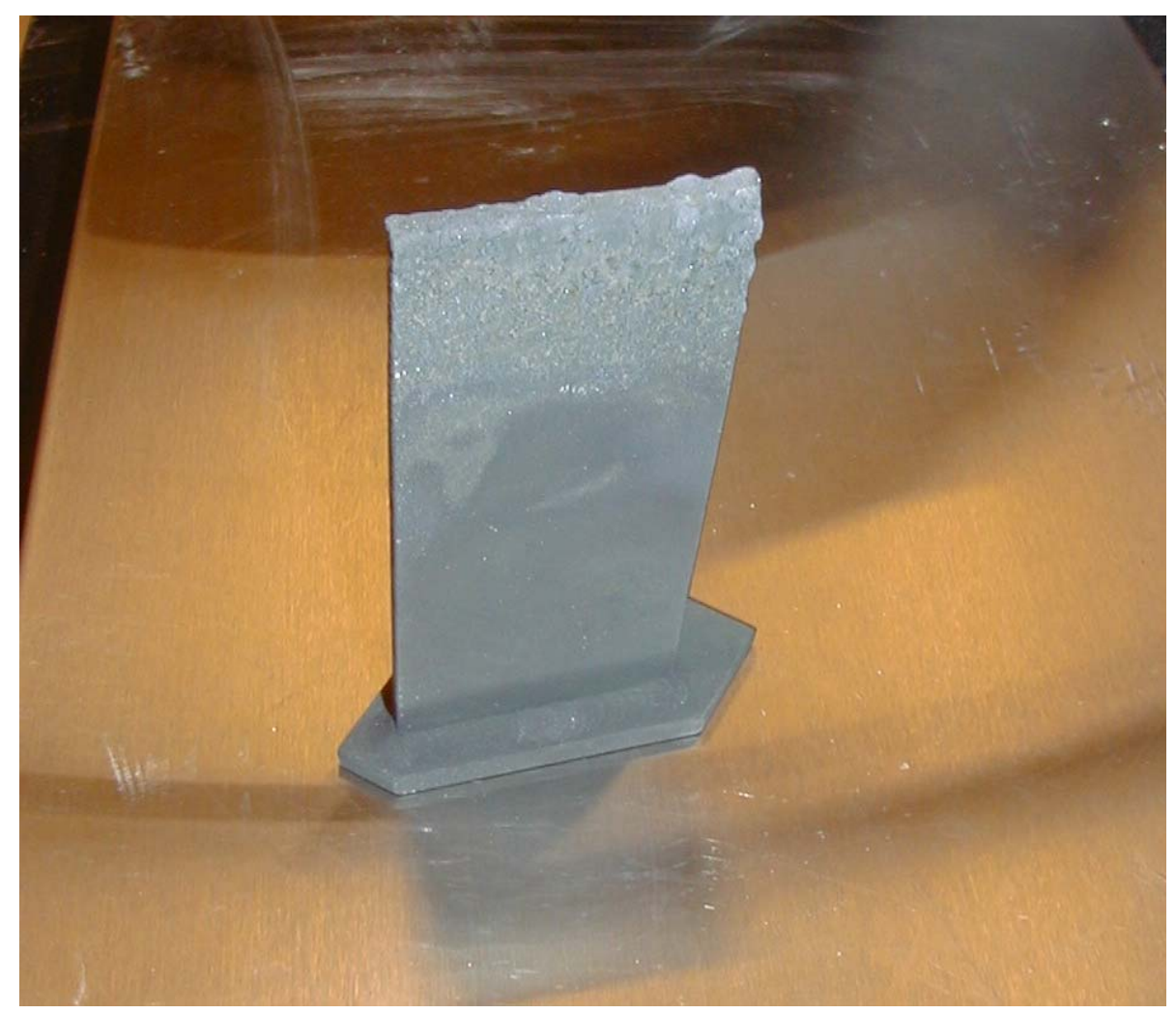

Figure 3.15. Scale Buildup on Baffle After 50 Test Cycles

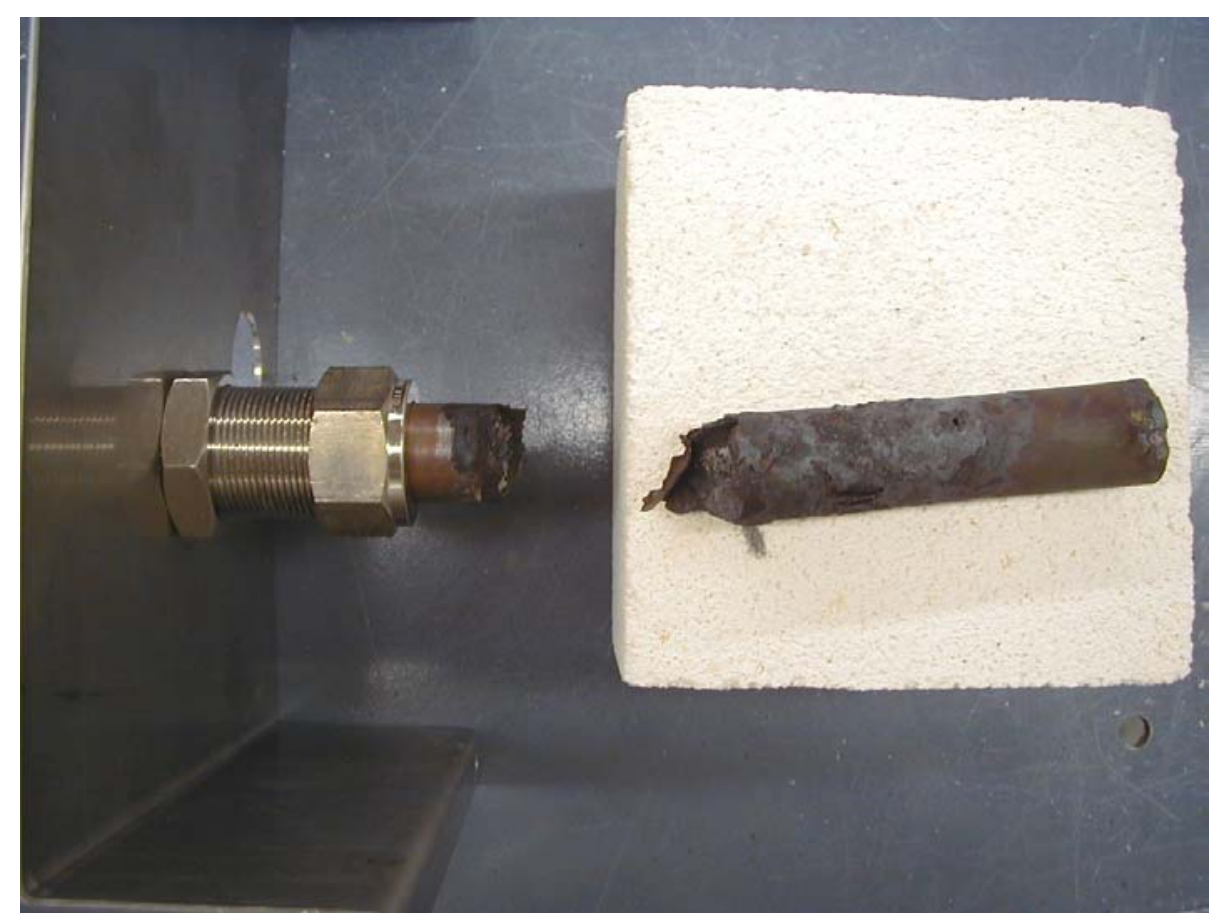

Figure 3.16. Inconel 600 Internal Offgas Line After Five Test Cycles 


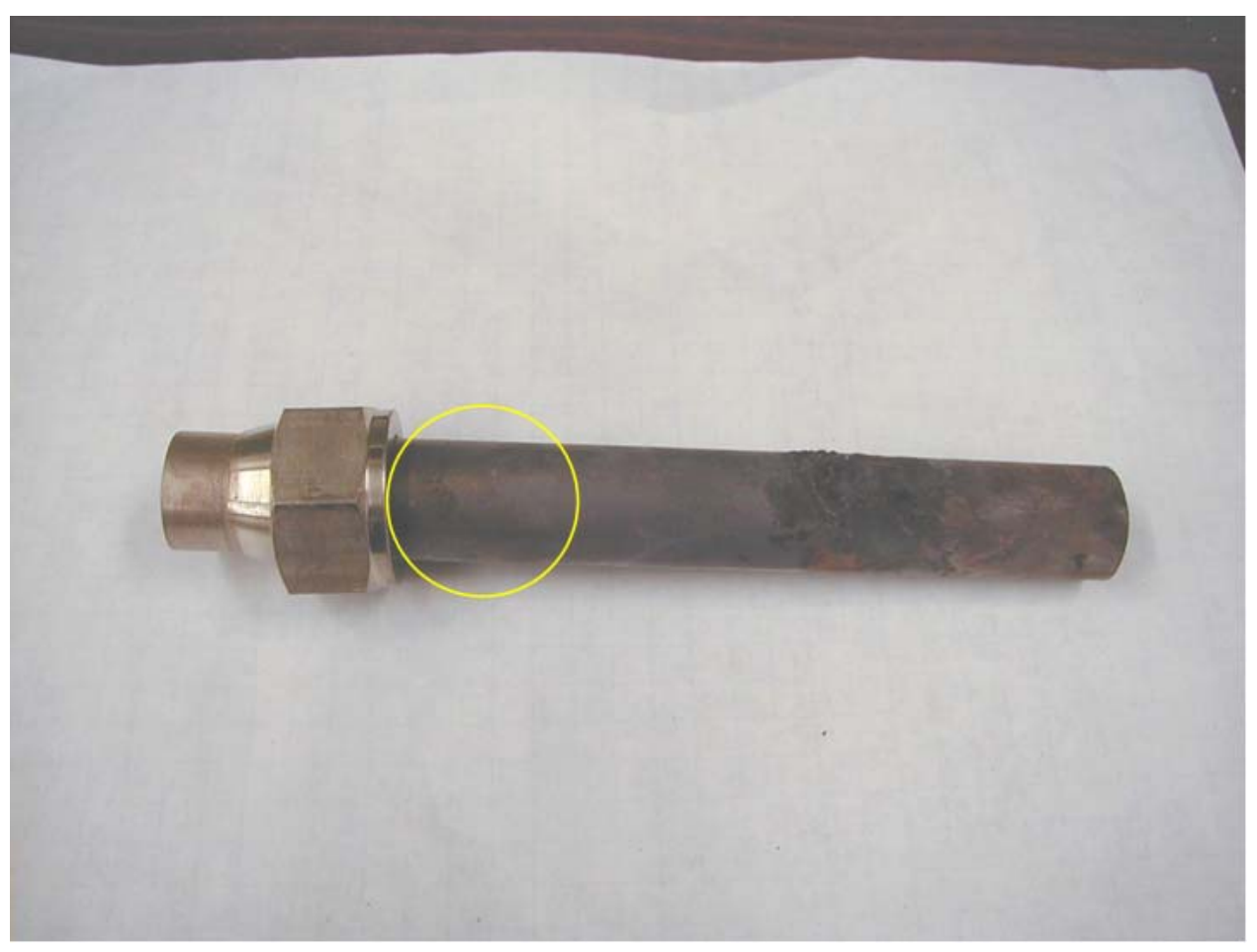

Figure 3.17. Approximate Location of Hard Deposits that Formed in the Inconel 600 Internal Offgas Line

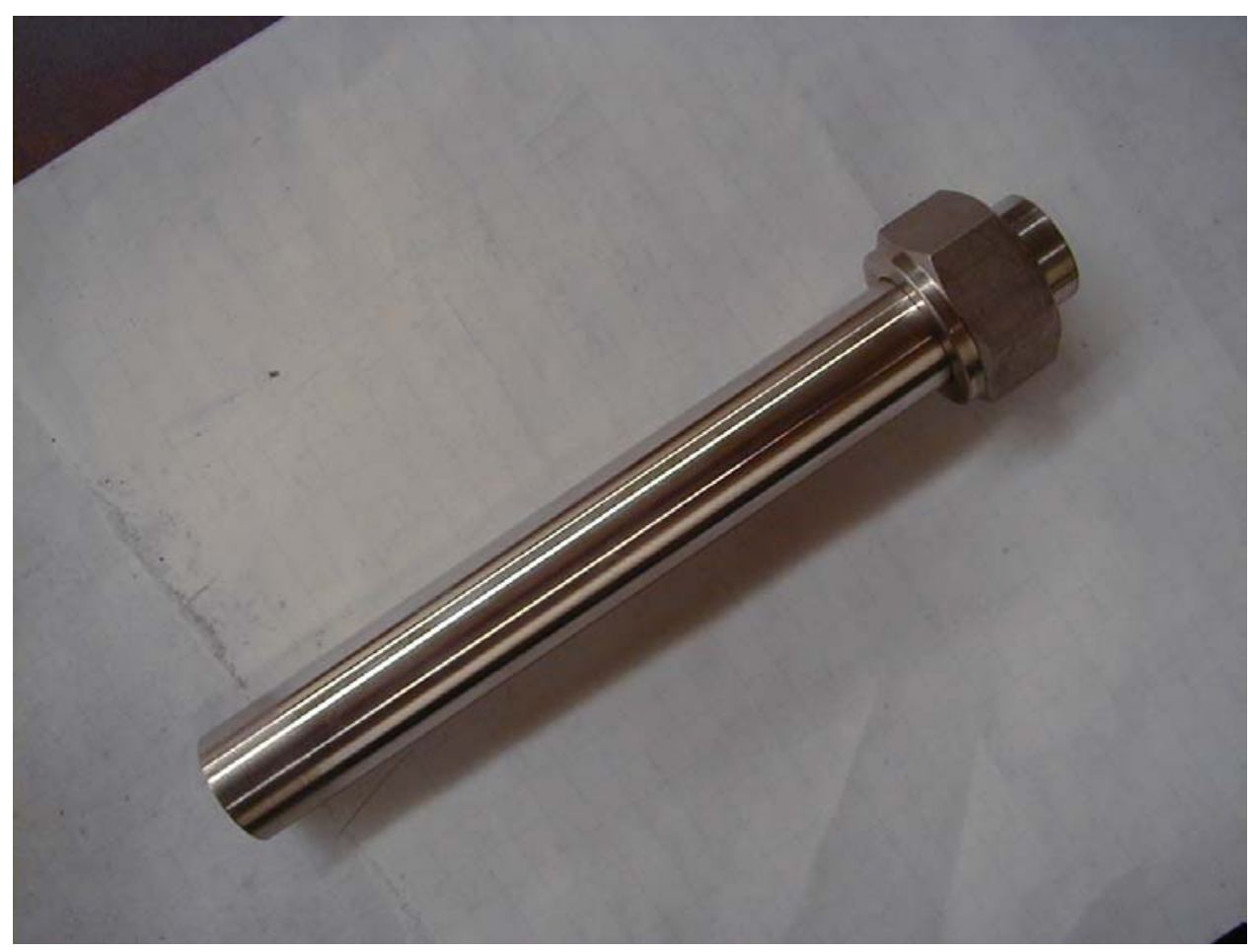

Figure 3.18. Inconel 690 Internal Offgas Line Ready for Installation 


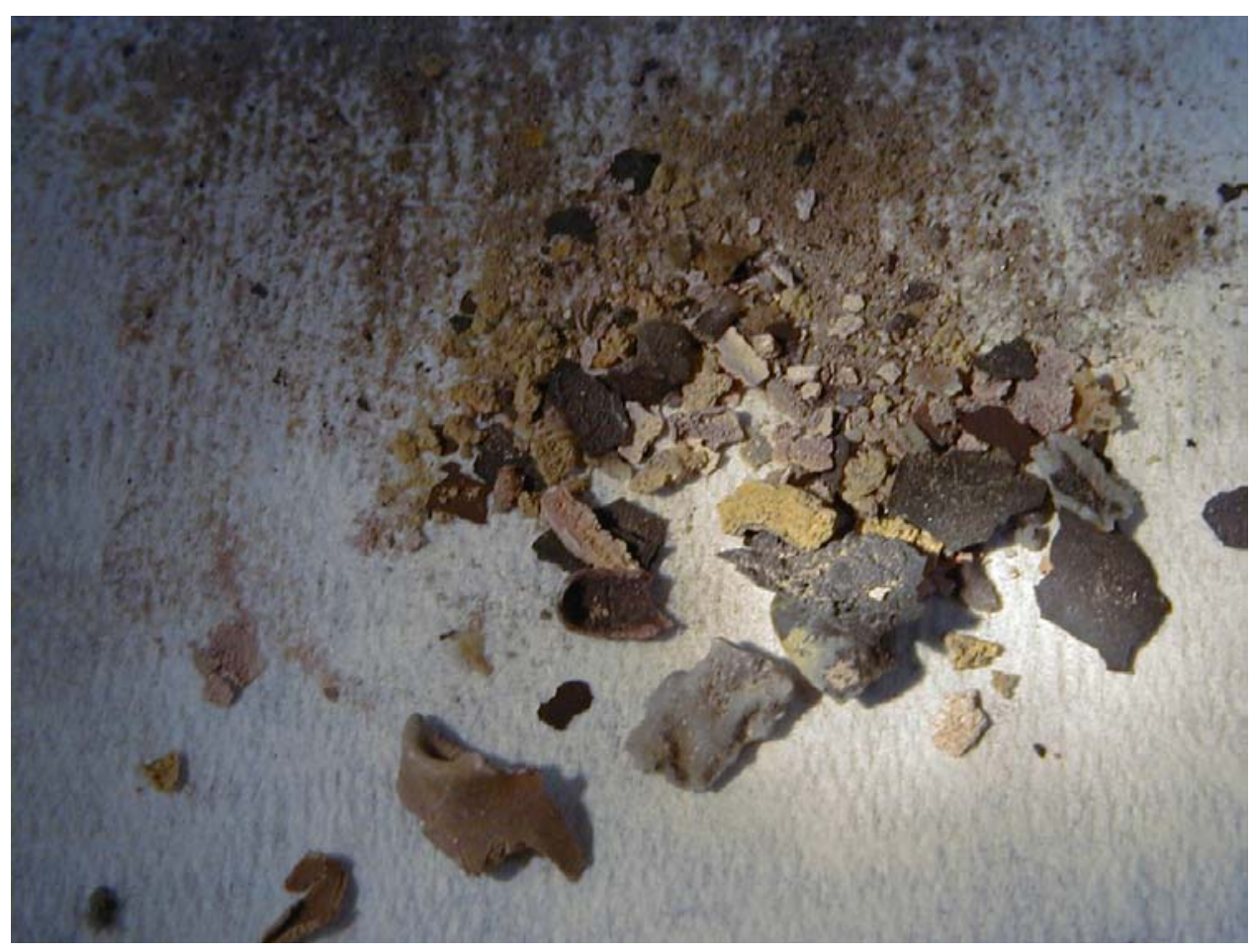

Figure 3.19. Salt Deposits and Corrosion Products Removed from Inconel 690 Internal Offgas Line

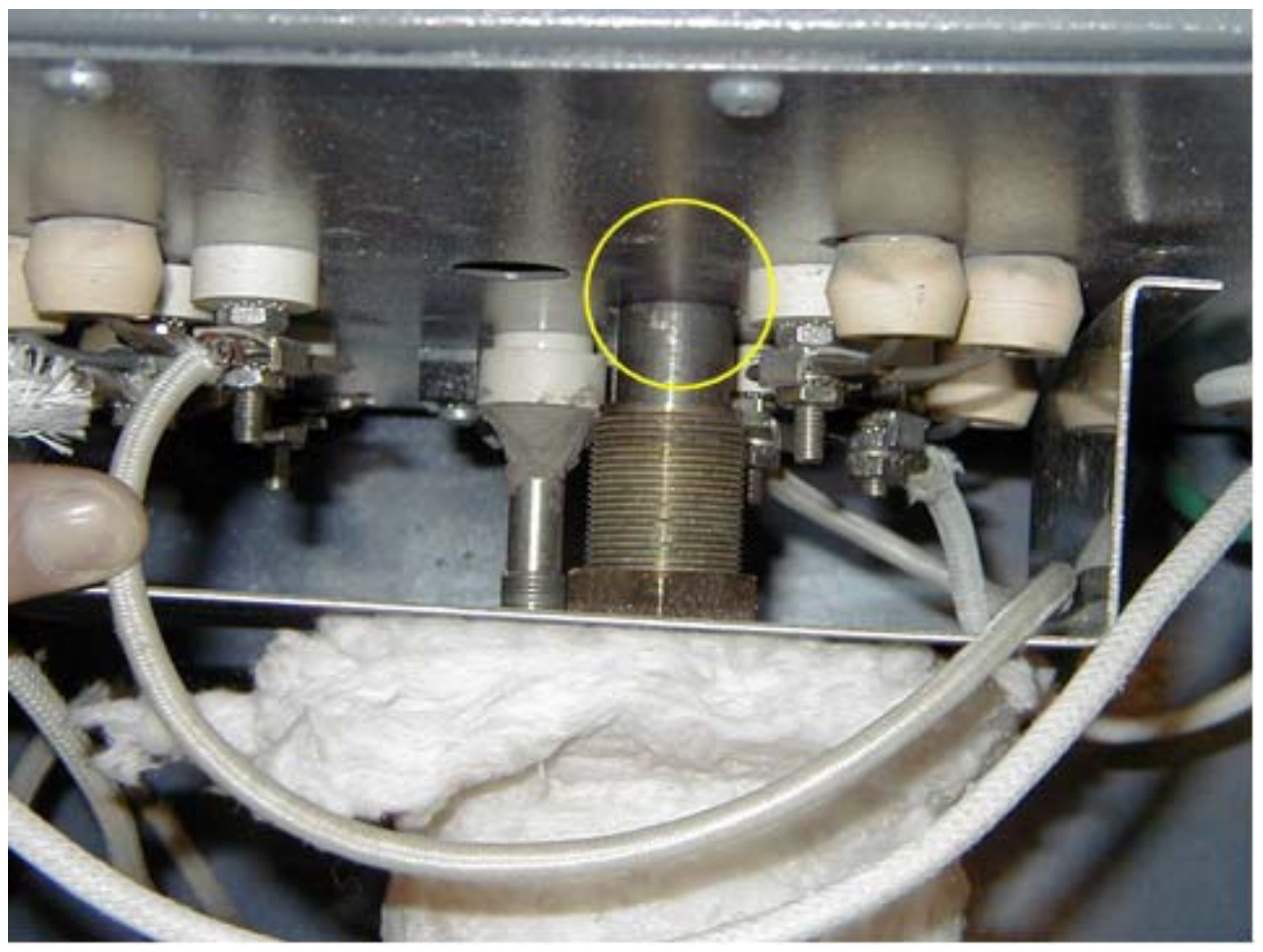

Figure 3.20. Approximate Location of Hard Deposits Removed from Inconel 690 Internal Offgas Line 


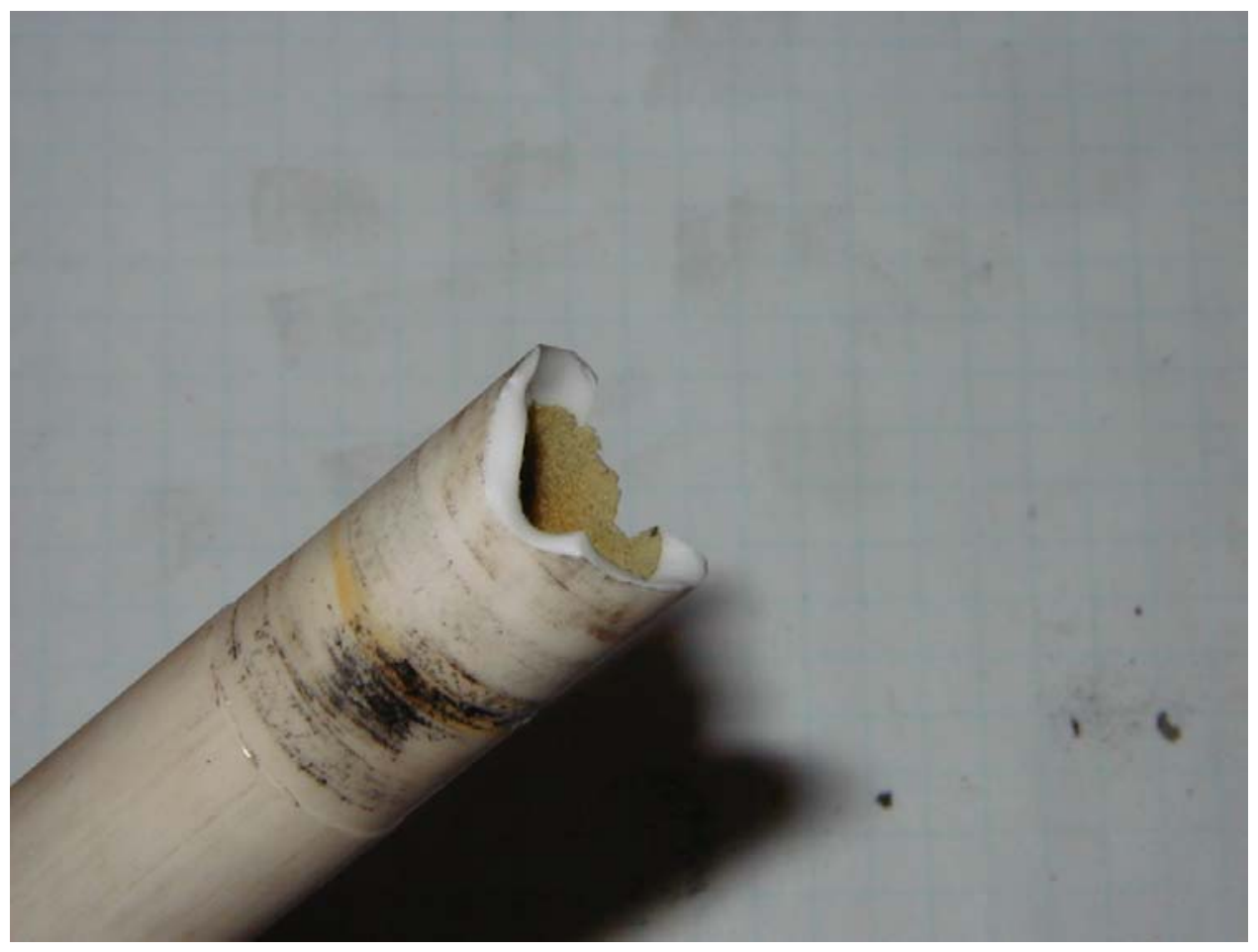

Figure 3.21. Chipped End of Ceramic Internal Offgas Line

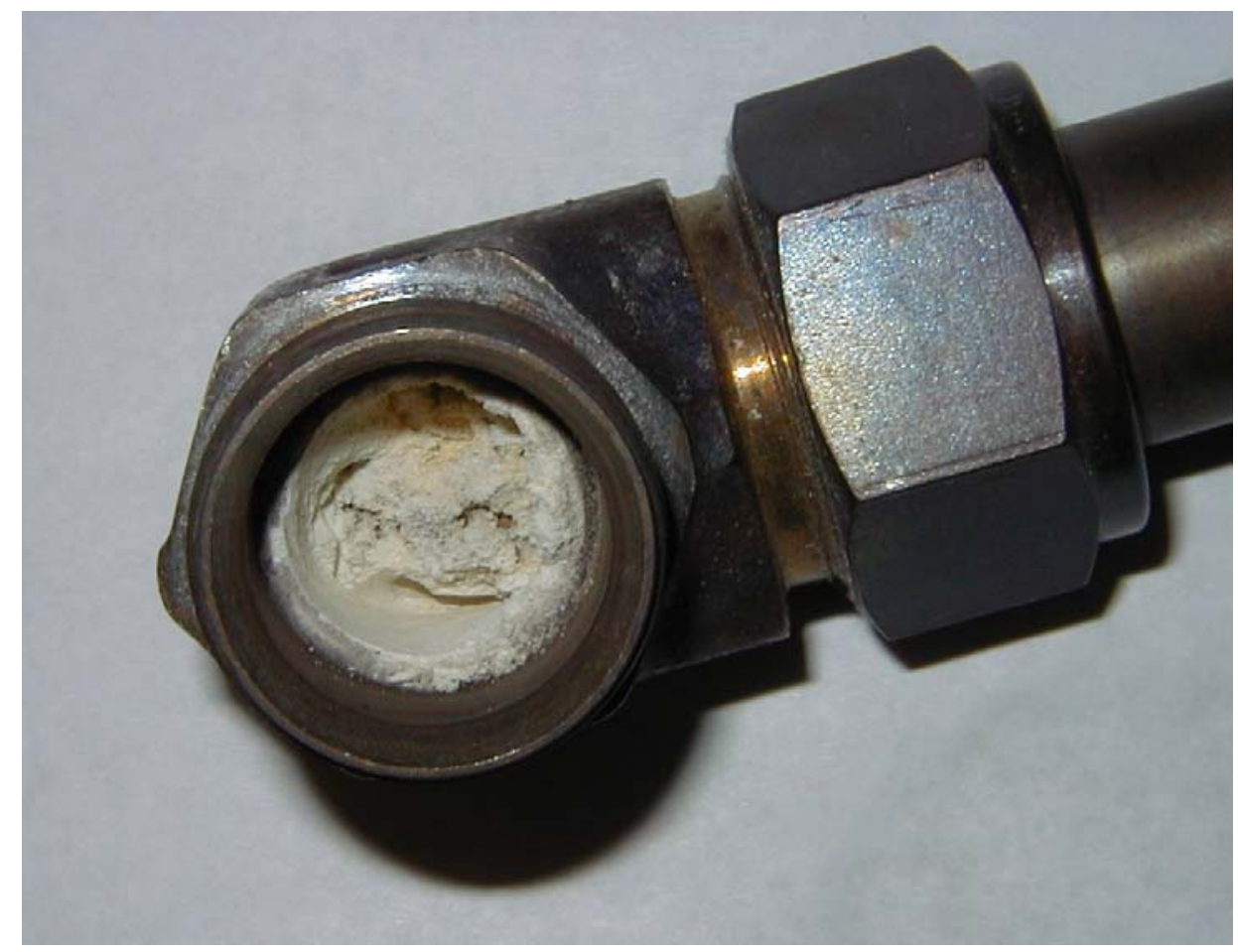

Figure 3.22. Final Bend on Inconel 600 External Offgas Line Plugged with Salt Deposits 


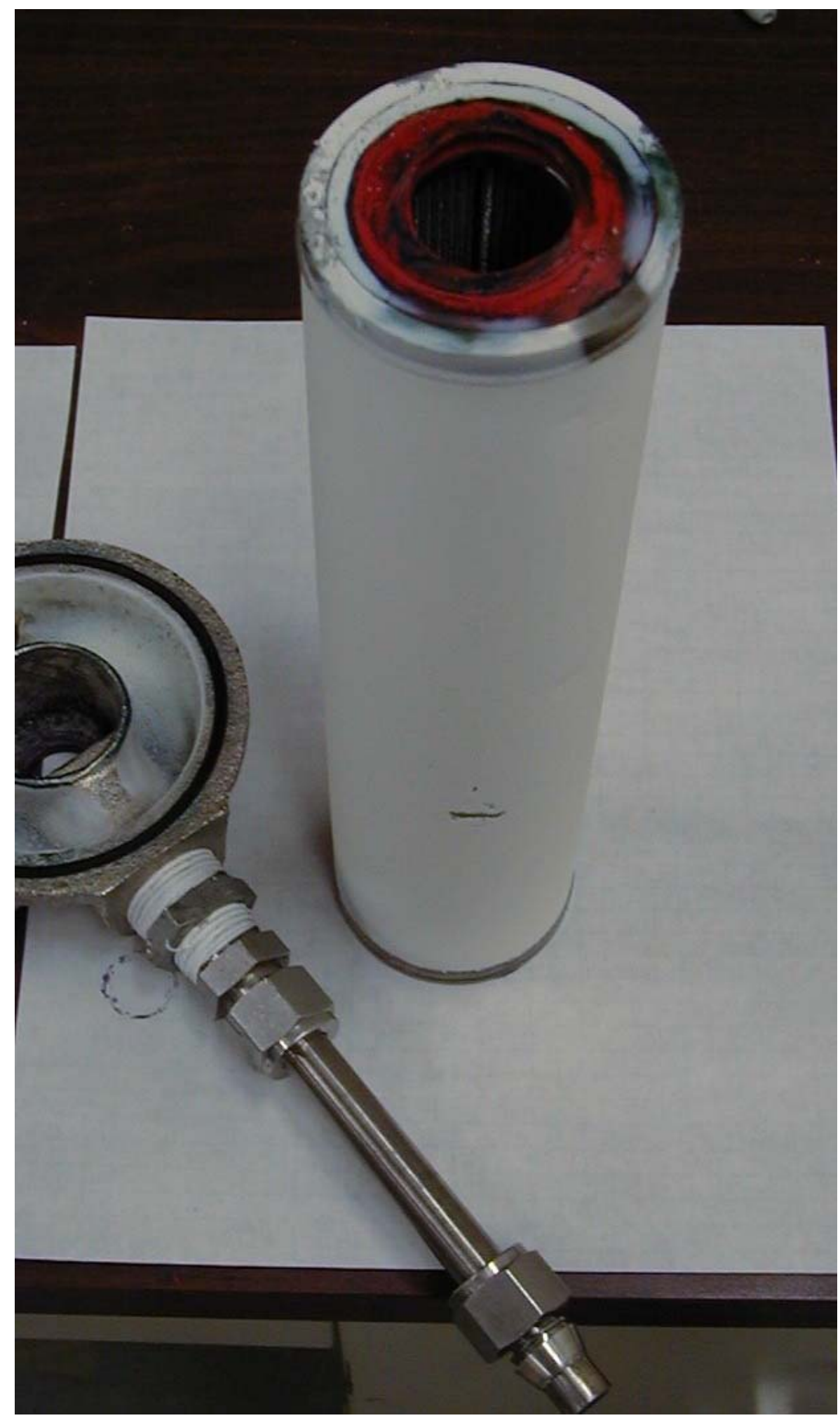

Figure 3.23. Purlator Sintered Metal Cartridge Blinded by Salt Deposits 


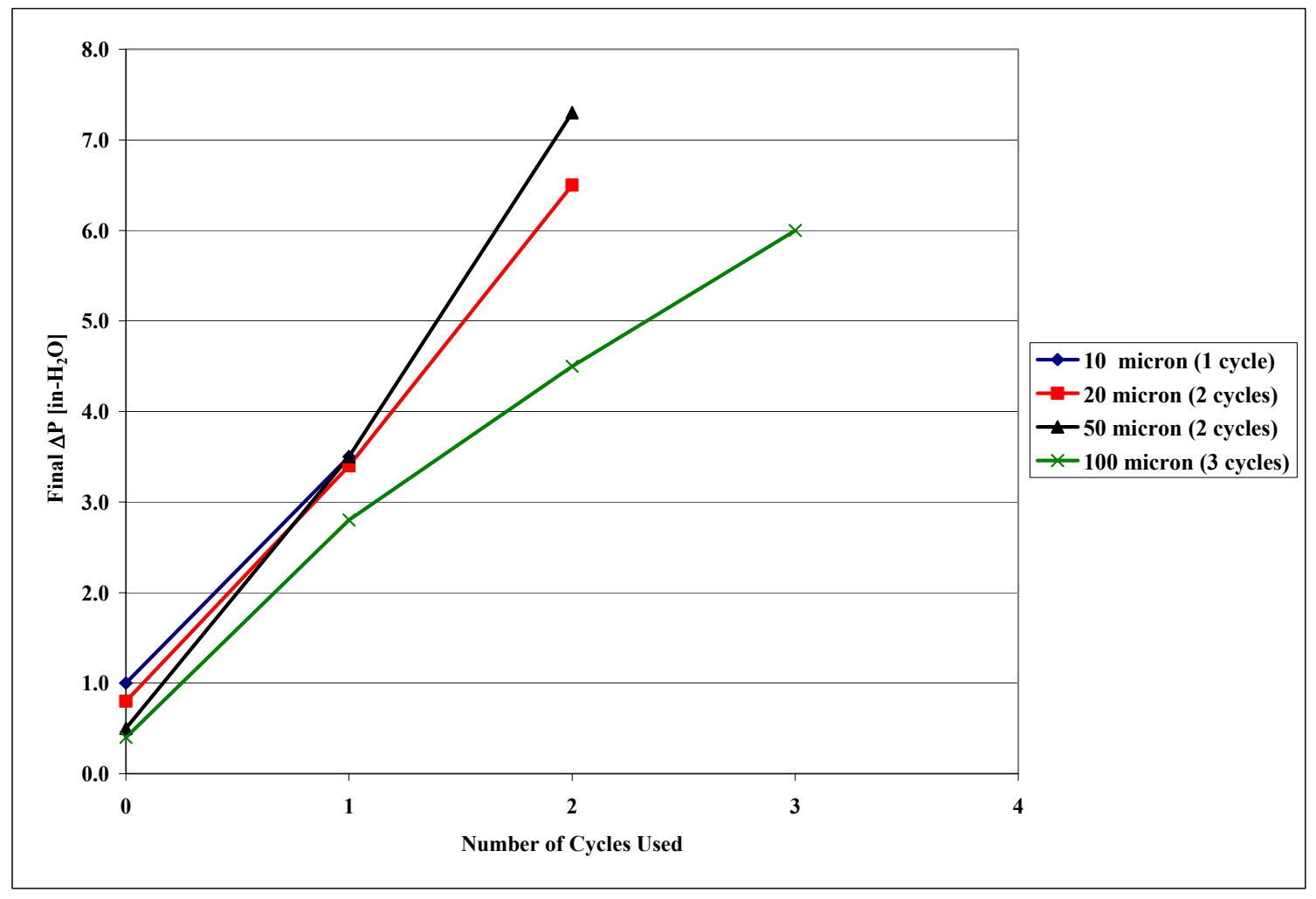

Figure 3.24. New Cartridge Initial Pressure Drop and Final Pressure Drop at the End of Each Completed Cycle for Nowata Woven Glass Filter Cartridges. Legend indicates total number of cycles completed with each filter cartridge. 


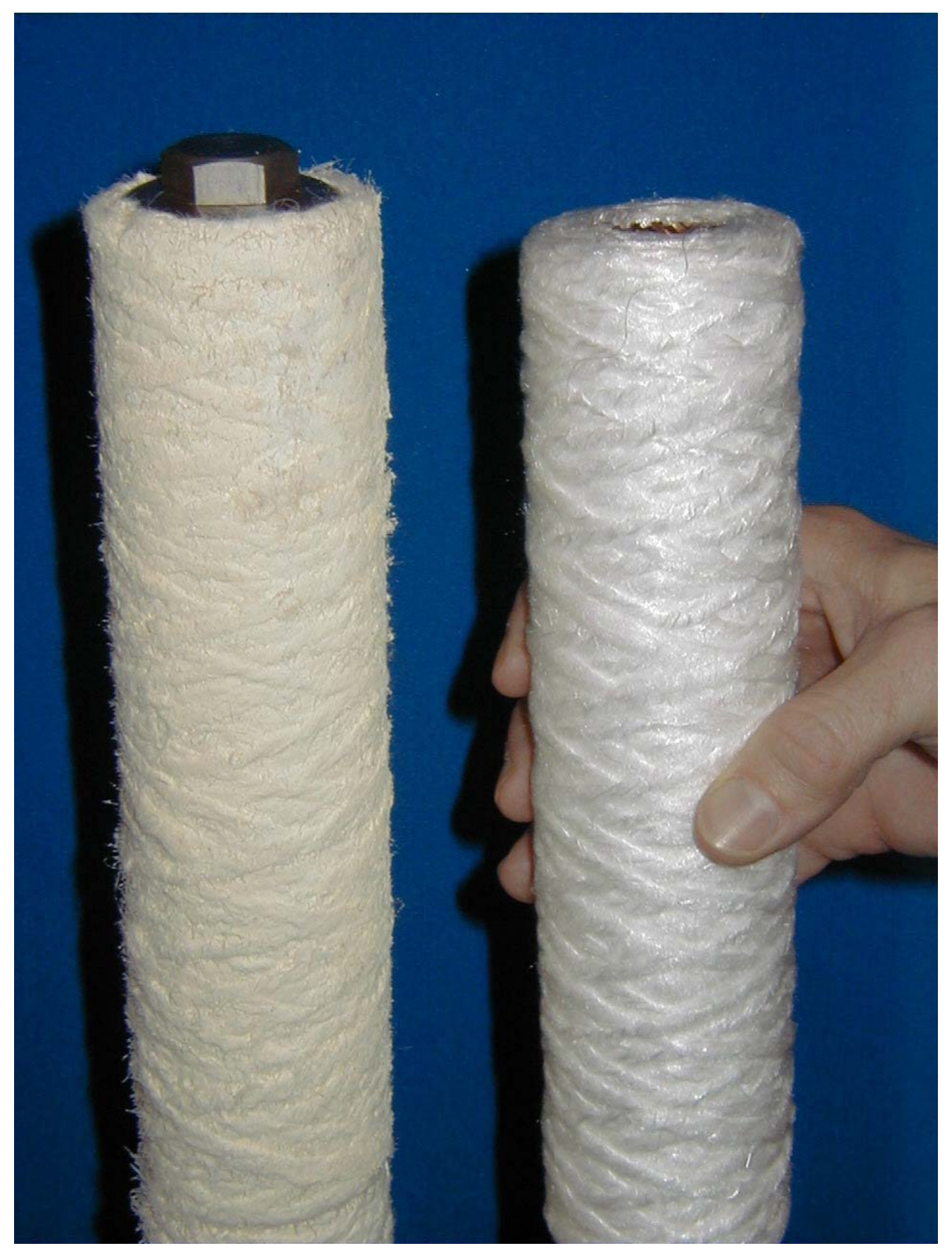

Figure 3.25. Woven Glass Fiber Cartridge (left) Blinded by Salts Compared to New Cartridge (right) 


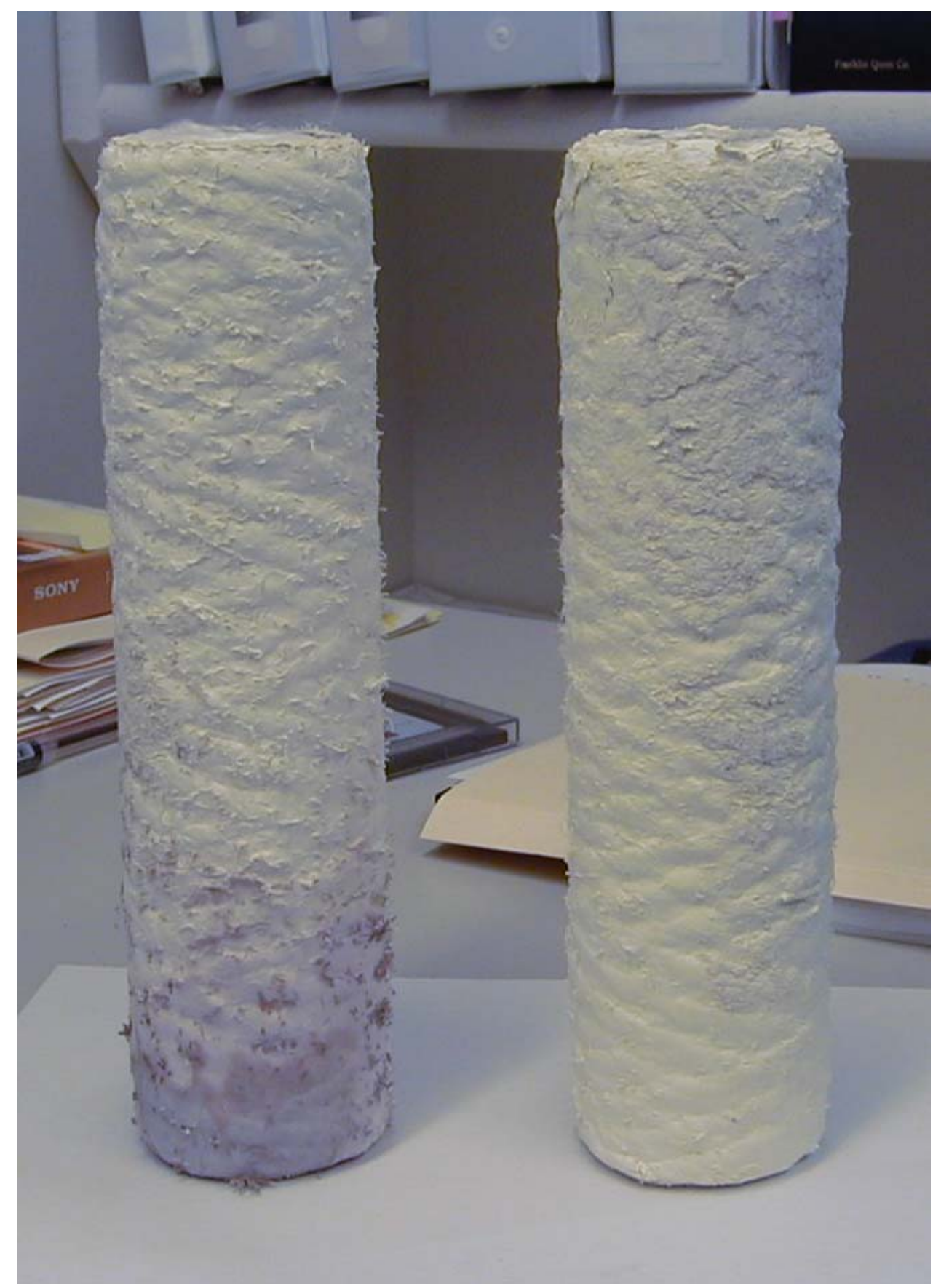

Figure 3.26. Darkened Area (lower left) of $100-\mu \mathrm{m}$ Woven Glass Filter Cartridge After Three Test Cycles 


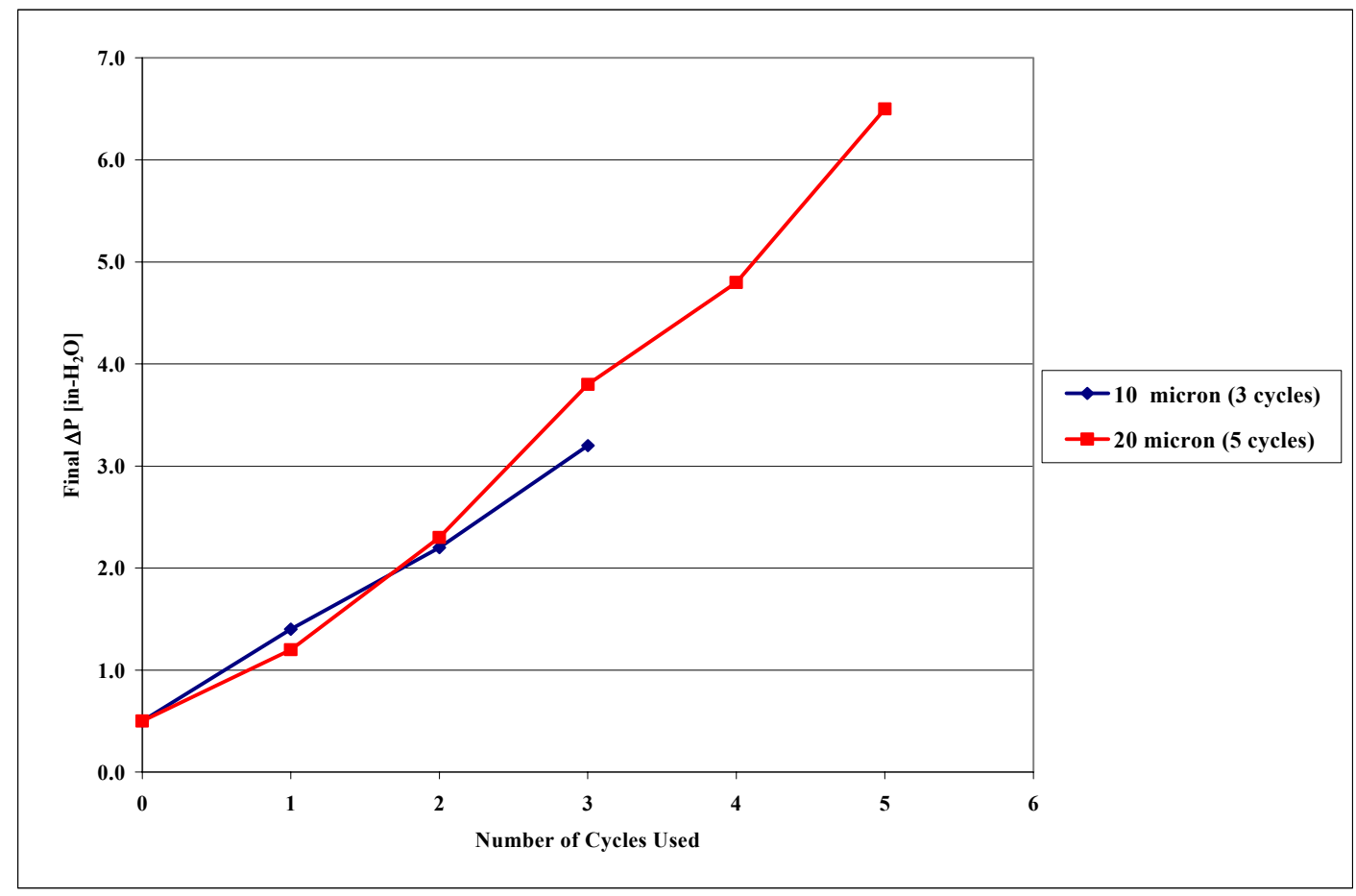

Figure 3.27. New Cartridge Pressure Drop and Final Pressure Drop at the End of Each Completed Cycle for Rosedale Pleated Metal Filters. Legend indicates total number of cycles completed with each filter cartridge.

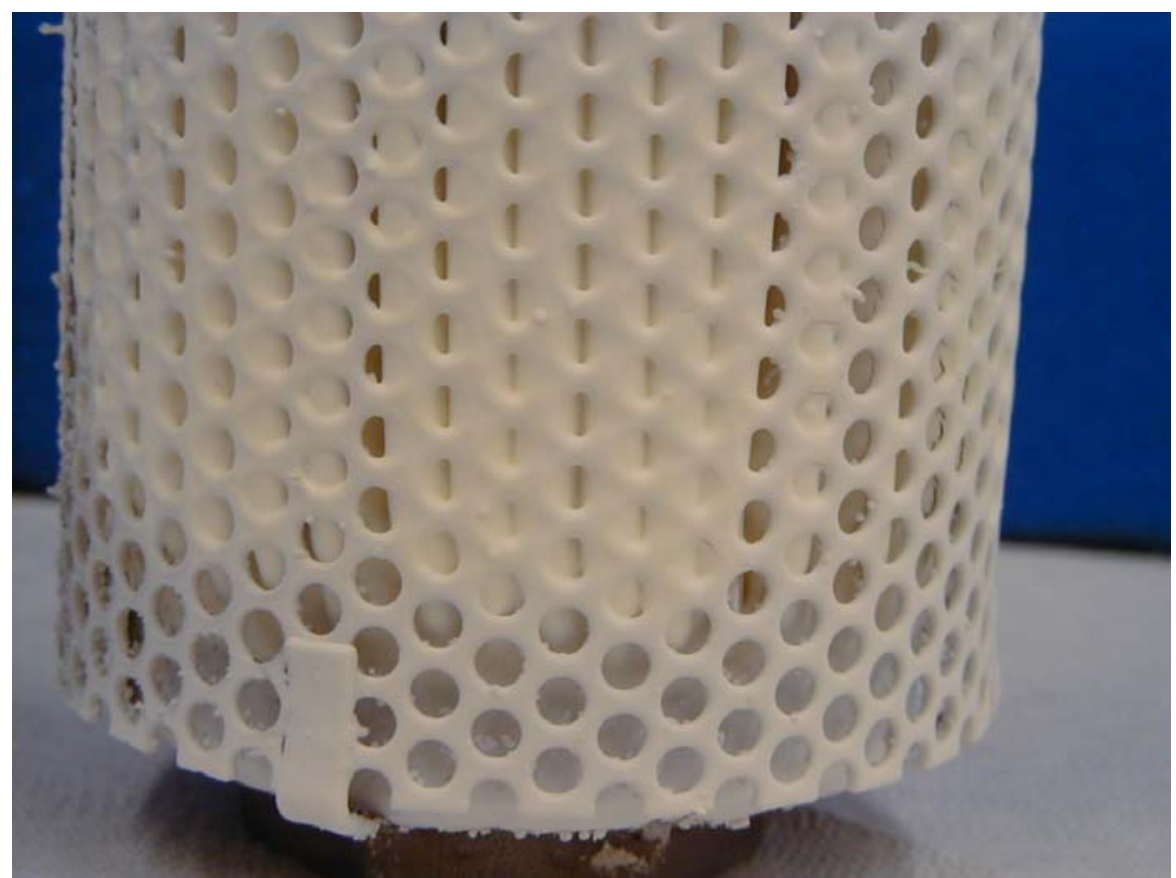

Figure 3.28. Salt Deposits on Outer Shell (pleated protector) of 20-micron Rosedale Pleated Metal Filter Cartridge After Five Test Cycles 


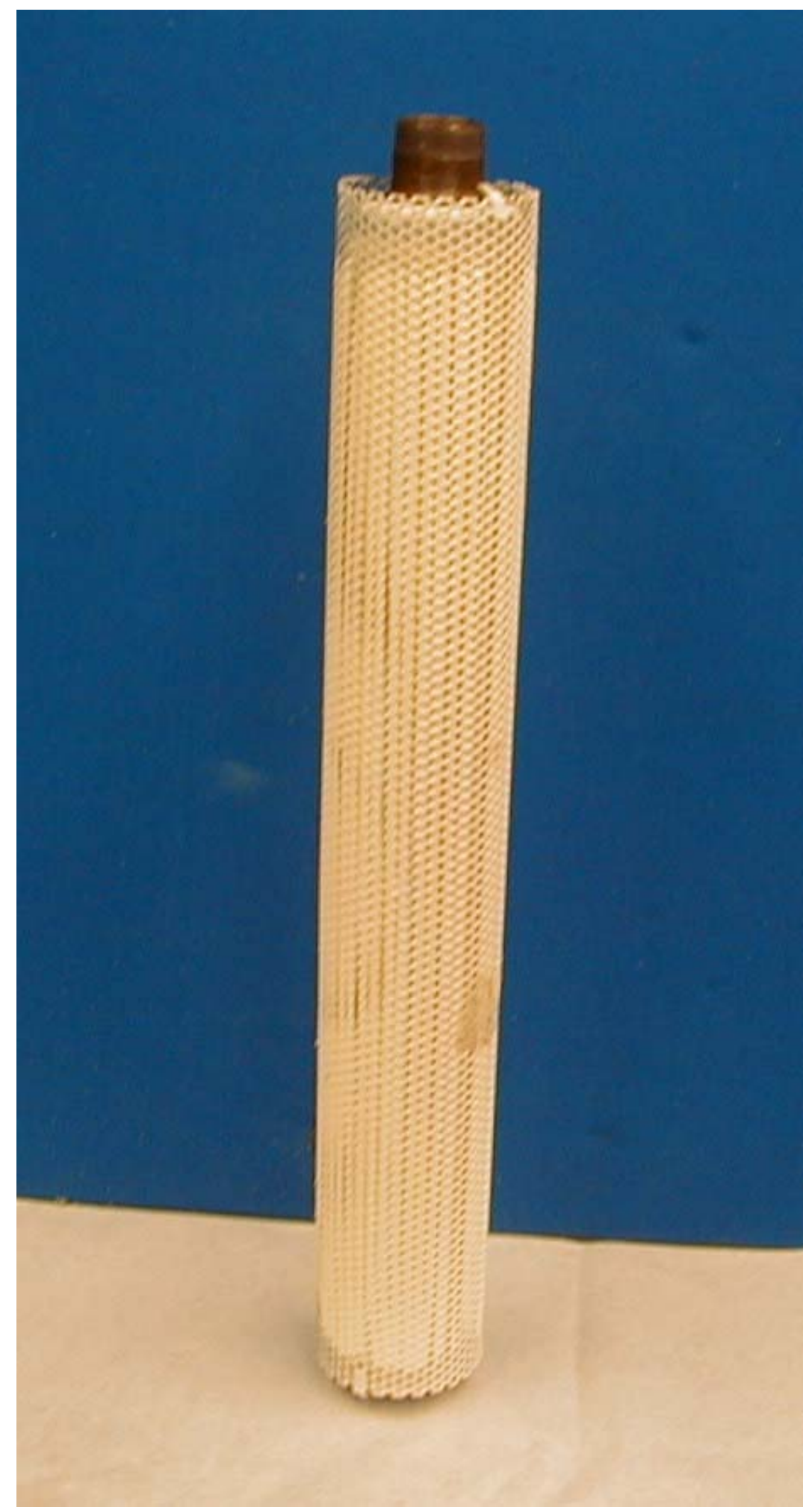

Figure 3.29. 20-micron Rosedale Pleated Metal Filter Cartridge Blinded by Salt Deposits After Five Test Cycles 


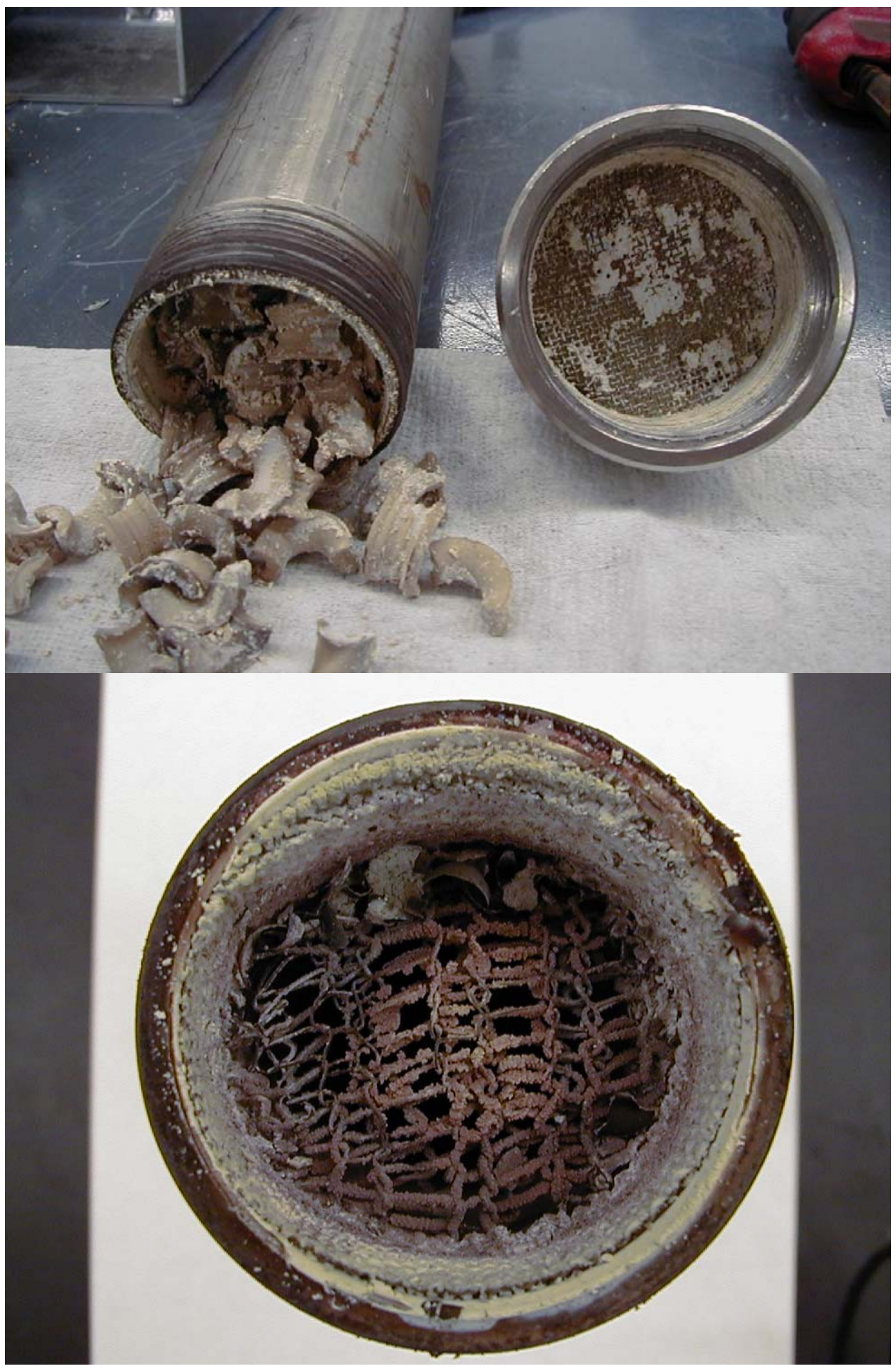

Figure 3.30. Intalox Ceramic Packing (top) and Wire Mesh (bottom) in 2 in. Schedule 40 Stainless Steel Knockout Pot. Condition after three test cycles. 


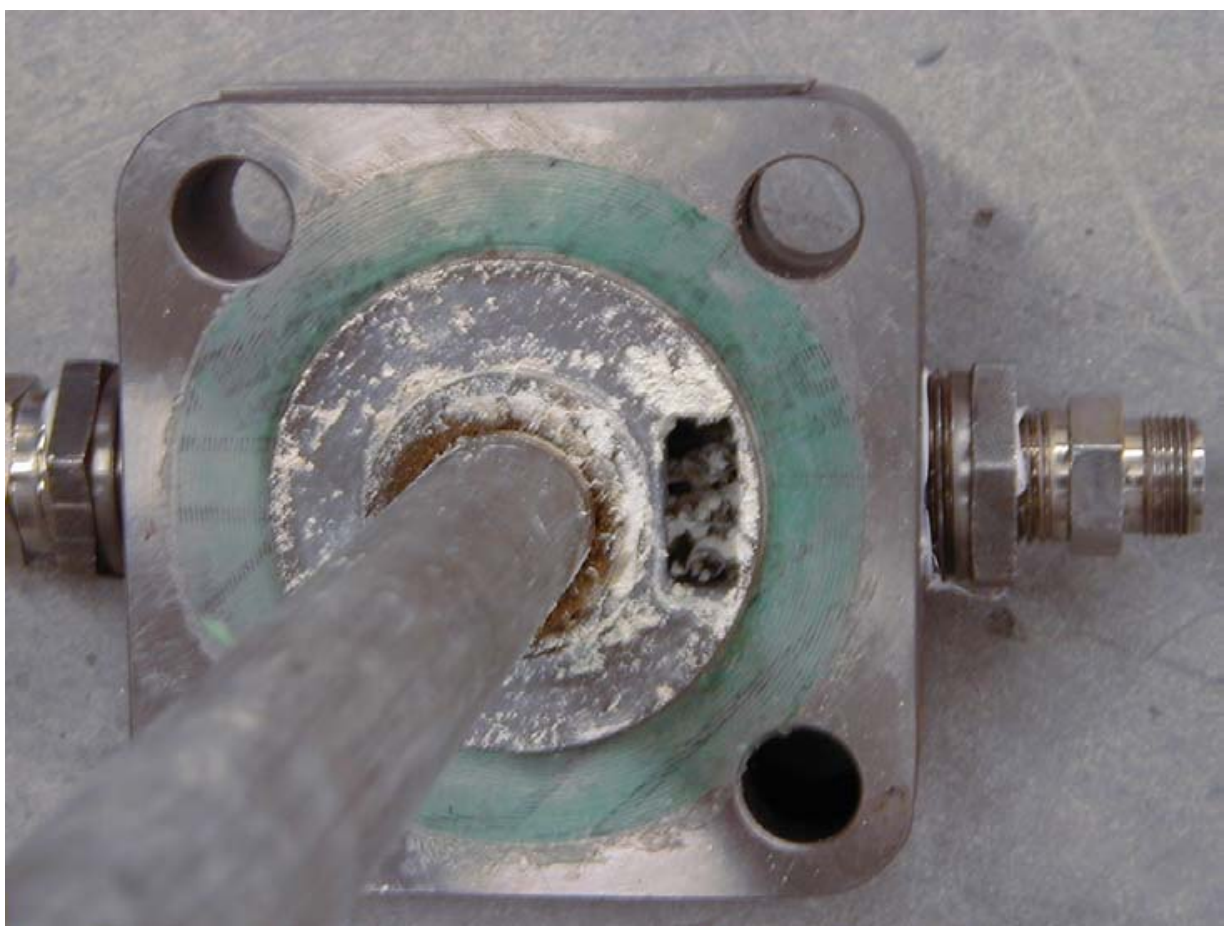

Figure 3.31. Inlet Port of the Nowata Housing that Filled with Packing and Plugged During the First Cycle

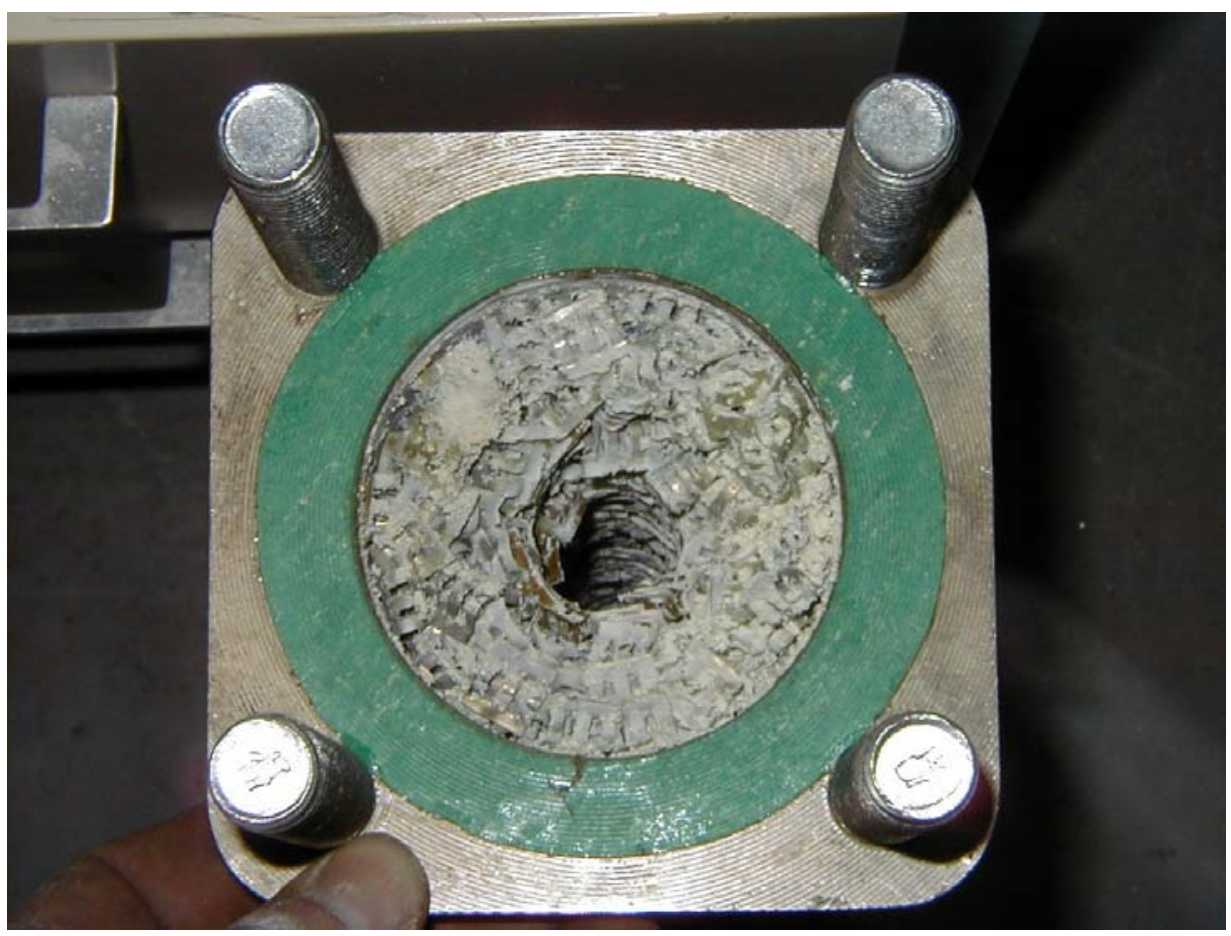

Figure 3.32. Interpack 10-mm Nominal Packing After Two Test Cycles 


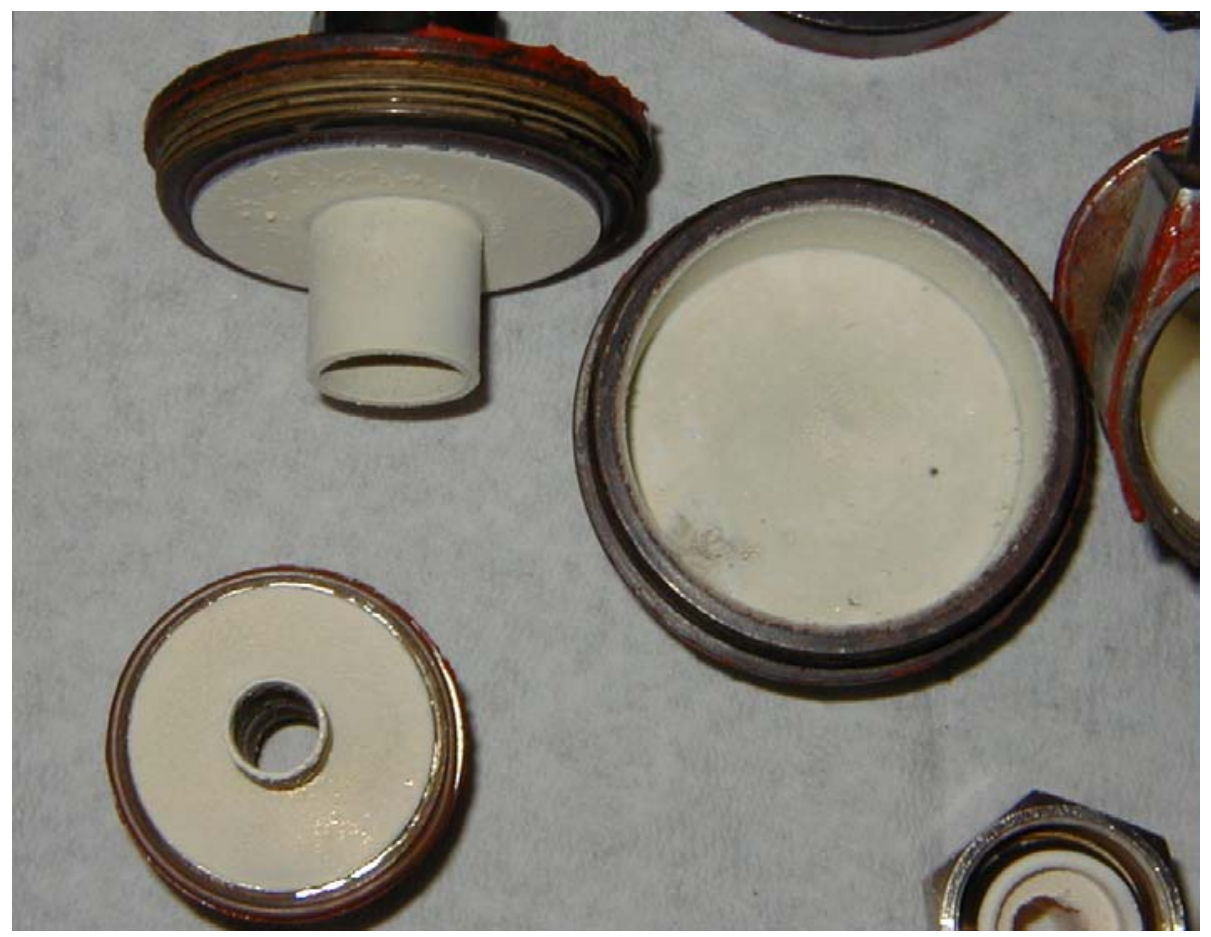

Figure 3.33. Salt Deposits on Internal Walls of In-Stack Cascade Cyclone Samplers

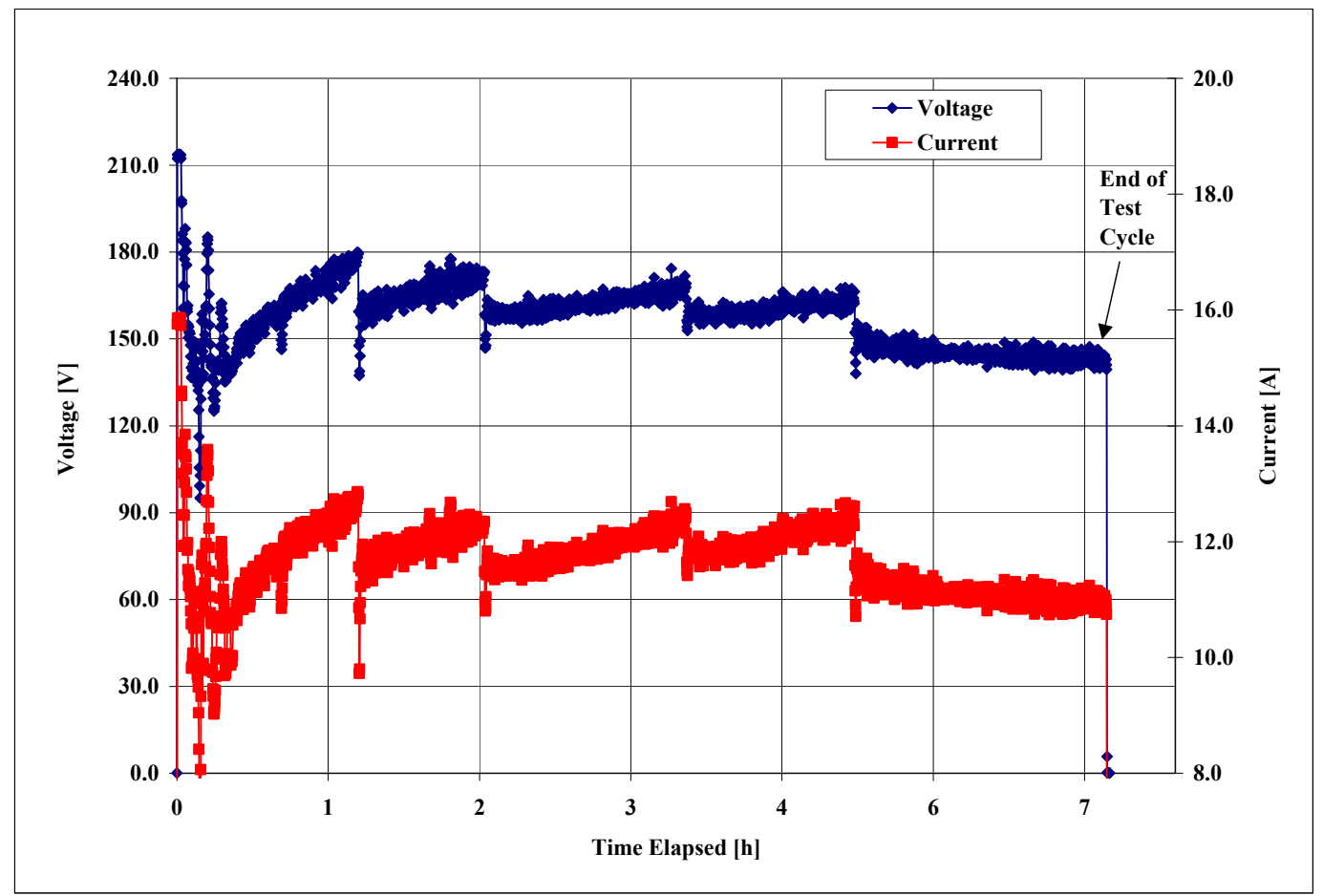

Figure 3.34. Typical Furnace Voltage/Current Profile During a Test Cycle 


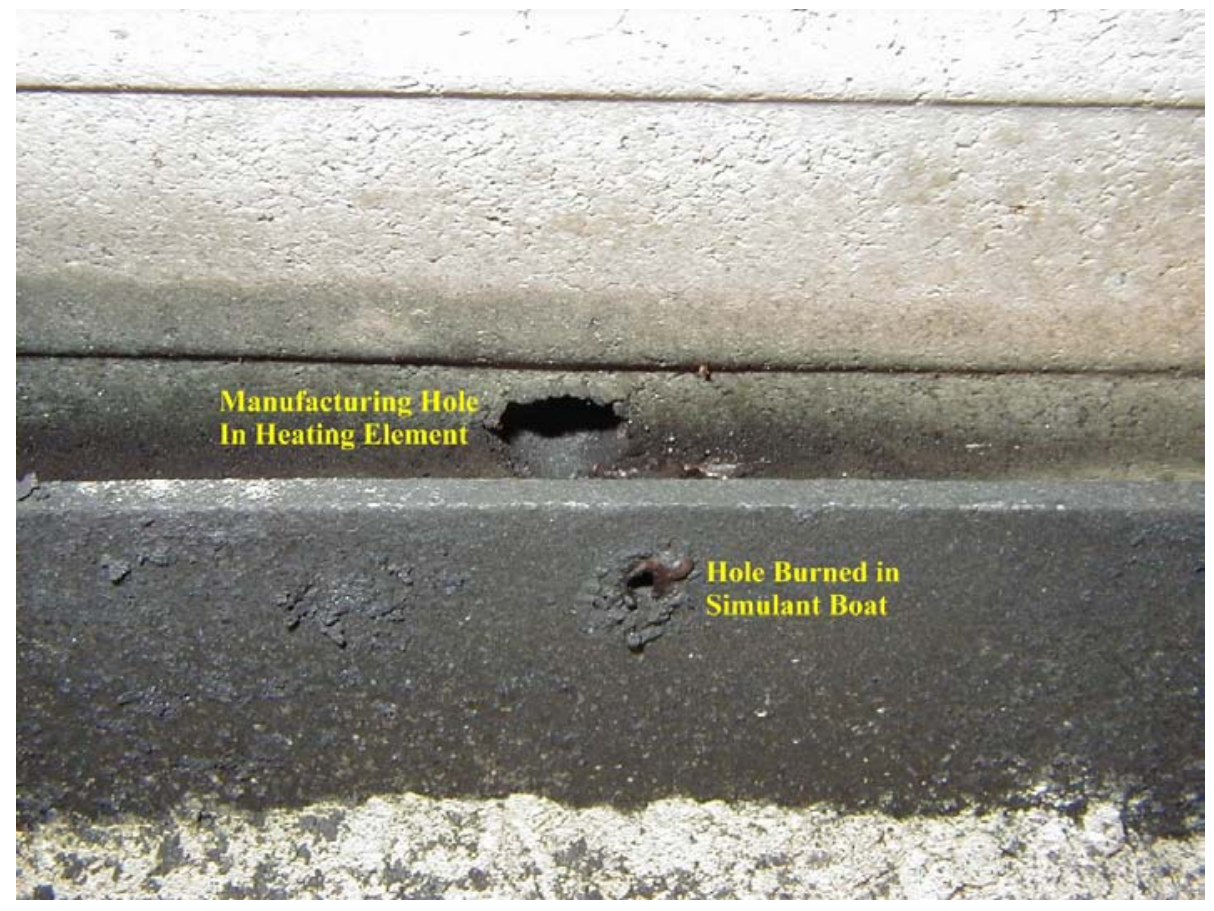

Figure 3.35. Hole Caused by the Side-Heating Element Arcing to the Boat

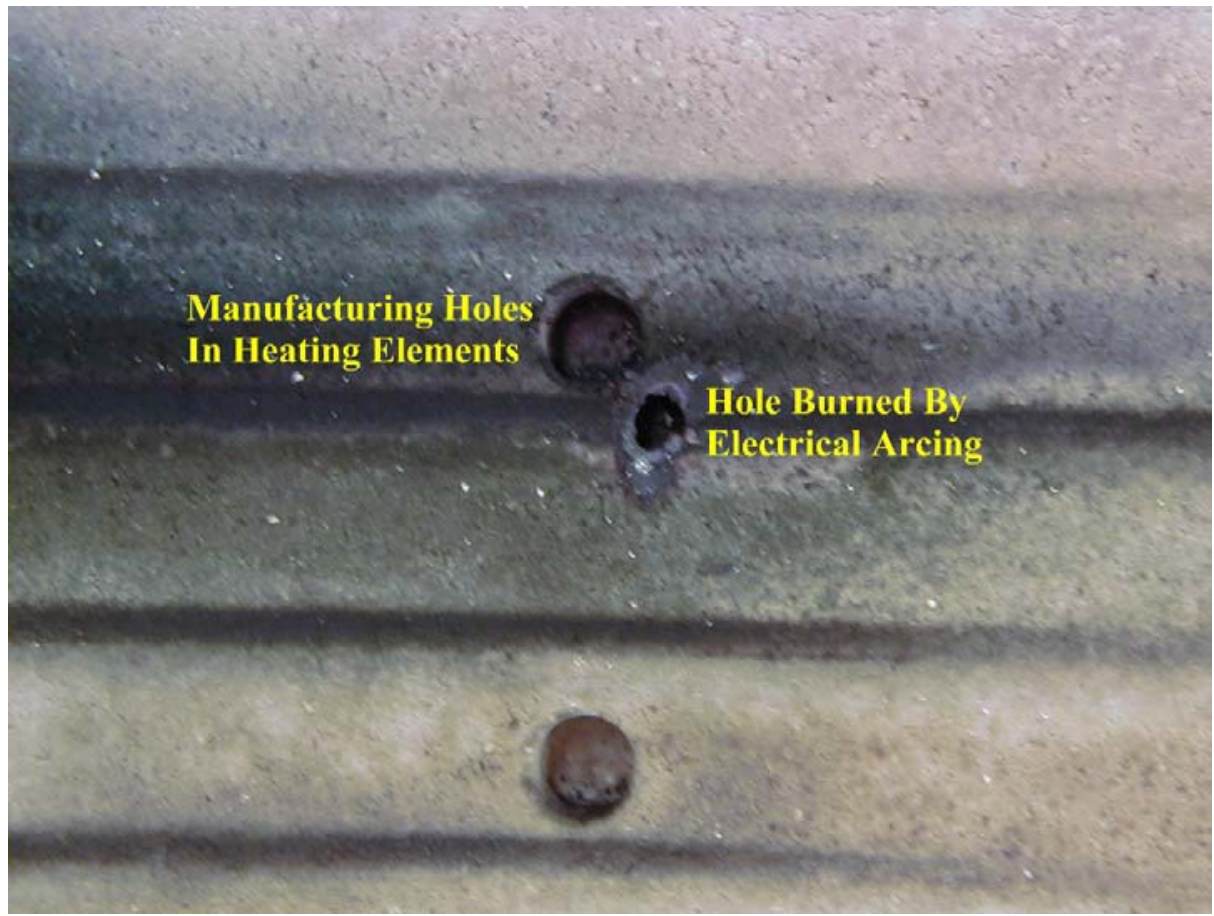

Figure 3.36. Area Where Side-Heating Element Failed and Arced Across to the Simulant Boat 


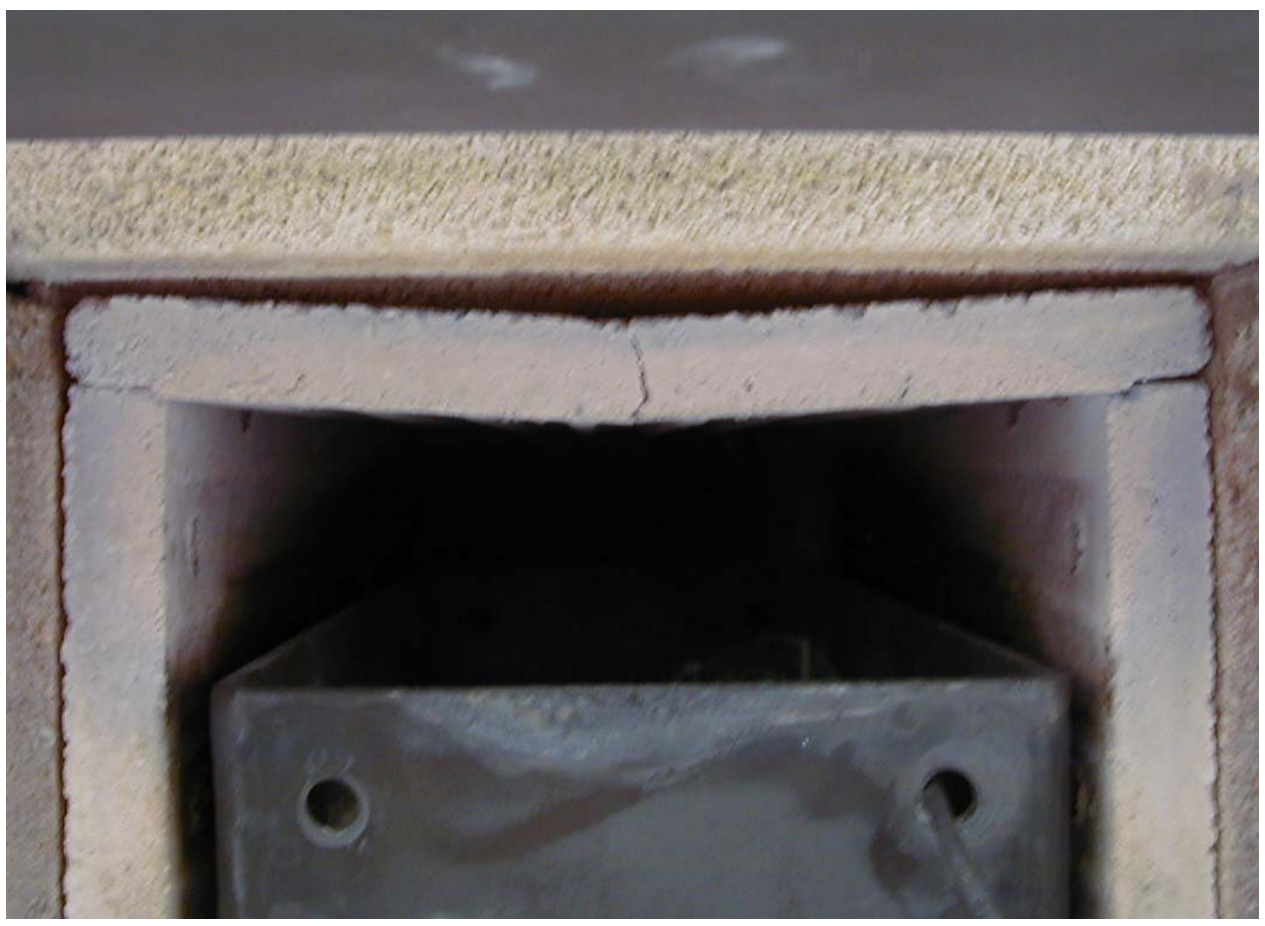

Figure 3.37. Top Heating Element After 31 Test Cycles (Set \#2).

Element has cracked and bowed downward. 


\subsection{Conclusions and Recommendations}

Testing with a prototypical high-temperature furnace and the associated offgas system successfully identified system vulnerabilities and demonstrated mitigative approaches to address potential issues associated with thermal stabilization of washed HCP items. Table 4.1 summarizes the system vulnerabilities and the recommend mitigation options.

Table 4.1. Furnace System Vulnerabilities and Recommended Mitigation Approaches

\begin{tabular}{|c|c|c|}
\hline $\begin{array}{c}\text { Identified } \\
\text { Vulnerability }\end{array}$ & Failure Mode & Recommended Mitigation Approach \\
\hline $\begin{array}{l}\text { Furnace element } \\
\text { failure }\end{array}$ & Arcing through boat & $\begin{array}{l}\text { Do not allow boat to contact furnace } \\
\text { element } \\
\text { - Monitor and maintain appropriate boat } \\
\text { width } \\
\text { - Consider using a boat alignment tool for } \\
\text { proper placement of boat in furnace }\end{array}$ \\
\hline $\begin{array}{l}\text { Internal offgas line } \\
\text { failure }\end{array}$ & Corrosion & $\begin{array}{l}\text { Change Inconel } 600 \text { tube to heavy-wall } \\
\text { Inconel } 690 \text { tube/pipe. } \\
\text { Bore-out bulkhead to eliminate fittings } \\
\text { and simplify cleaning/line replacement }\end{array}$ \\
\hline $\begin{array}{l}\text { Internal and External } \\
\text { offgas line plugging }\end{array}$ & $\begin{array}{l}\text { Chloride salt } \\
\text { condensation }\end{array}$ & $\begin{array}{l}\text { - Maximize salt removal during HCP item } \\
\text { washing } \\
\text { Bore-out bulkhead to eliminate fittings } \\
\text { and simplify cleaning/line replacement } \\
\text { - Plan for routine/frequent line clean out } \\
\text { and/or plan for routine/frequent line } \\
\text { replacement } \\
\text { - Consider larger pipe diameter } \\
\text { - Monitor pressure drop to assess salt build } \\
\text { up in lines }\end{array}$ \\
\hline Filter failure & $\begin{array}{l}\text { Blinding from } \\
\text { chloride salt } \\
\text { accumulation }\end{array}$ & $\begin{array}{l}\text { - Maximize salt removal during HCP item } \\
\text { washing } \\
\text { - Use pleated stainless steel filters to } \\
\text { increase filter surface area. }\end{array}$ \\
\hline $\begin{array}{l}\text { Boat distortion } \\
\text { (bowing) }\end{array}$ & $\begin{array}{c}\text { Thermal cycling and } \\
\text { corrosion }\end{array}$ & $\begin{array}{l}\text { - Consider fabricating Hastelloy X boats } \\
\text { with width reduced by } \sim 1 / 4 \text { in. }\end{array}$ \\
\hline
\end{tabular}

The Thermolyne Model FA-1630-1 furnace was found to be reliable for stabilizing charges of $\mathrm{CeO}_{2}$ simulant impregnated with either $16 \mathrm{~g}$ or $20 \mathrm{~g}$ chloride salts $(45 \mathrm{~mole} \% \mathrm{NaCl}, 45 \mathrm{~mole} \% \mathrm{KCl}$, and 10 mole $\% \mathrm{MgCl}_{2}$ ), representing $1600 \mathrm{~g}$ or $2000 \mathrm{~g}$ of washed $\mathrm{PuO}_{2}$ containing a residual of $1 \mathrm{wt} \%$ chloride salts. An offgas flowrate of 1.0 SCFM was sufficient for removing the volatilized salts from the furnace chamber, resulting in a heating element life of $30+$ test cycles. During the 50 furnace test cycles, only one furnace element failed. This failure occurred on the $16^{\text {th }}$ cycle, and is believed to be the result of 
arcing caused by contact between a side furnace element and the Hastelloy X sample boat. During this cycle, the width of the sample boat had increased to about 5.25 in. as a result of the thermal cycling. By monitoring the boat width, and adjusting it back to $5.0 \mathrm{in}$. with a vise, additional furnace element failures were prevented. Therefore, it is recommended that, during actual operations, PFP operators examine the sample boats for evidence of bowing after every cycle and ensure that the boat is accurately centered between the side heating elements as it is loaded into the furnace. Developing a tool to provide proper boat alignment should be considered.

Materials of construction for the internal offgas line should be either heavy-wall Inconel 690 or a hightemperature ceramic. Both of these materials demonstrated the best corrosion resistance when in contact with the offgas and condensed molten chloride salts. However, the Inconel 690 offgas line was more durable than the ceramic line and could better withstand aggressive cleaning methods necessary to remove hardened salt deposits. Inconel 600 tubing should not be used as an internal offgas line due to severe corrosion that resulted in catastrophic failure after only five test cycles. While the internal offgas line underwent significant corrosive attack (with both Inconel 600 and Inconel 690), the cooler external offgas line (Inconel 600 tubing) was structurally sound even after 46 cycles. Therefore, the existing Inconel 600 tubing associated with the current PFP furnace system is suitable for the external offgas line.

Plugging in the internal and external (between furnace and filter) offgas line was the most frequent means of operational failure. The failures were found to be preventable by routine line cleaning. To minimize potential hang-up points and simplify cleaning and line replacement, it is recommended that the bulkhead fitting at the exit of the furnace be bored out and that the internal offgas line be extended through it. Also, evidence of significant offgas line plugging was detected in some cases when the pressure drop through the offgas line was observed.

Based on the chloride salt loadings in the simulant tested, the following cleaning frequencies are recommended as initial guidelines for the thermal stabilization operations at PFP. Required cleaning frequencies are difficult to predict and heavily dependent on the composition and quantity of materials processed for each furnace charge. For example, an increased salt loading of $25 \%$ resulted in a need to more than double the cleaning frequency. Modifications to the cleaning frequency guidelines must be determined by trial-and-error and close monitoring of measured pressure drop.

\section{Internal Offgas Line:}

- $\quad$-690 pipe, 6-in. long

- $\quad$ For items containing $16 \mathrm{~g}$ chloride salts per charge: Clean after every 8 to 10 cycles.

- $\quad$ Ceramic tube, 11-in. long

- For items containing $16 \mathrm{~g}$ chloride salts per charge: Clean after every 2 to 3 cycles.

- $\quad$ I-690 pipe, 11 -in. long

- For items containing $20 \mathrm{~g}$ chloride salts per charge: Examine after every cycle. Clean after every 3 to 6 cycles. (For most of the processing, this line was cleaned after every 3 cycles, i.e., the same frequency used to perform cleaning of the downstream I-600 tubing; however, in one series, it was possible to process 6 cycles without cleaning.) 


\section{External Offgas Line:}

I-600 tubing

- For items containing $16 \mathrm{~g}$ chloride salts per charge: Clean after every 6 to 7 cycles. (Note: plugging occurred when attempting 11 cycles)

- For items containing $20 \mathrm{~g}$ chloride salts per charge: Clean every $\sim \mathbf{3}$ cycles. (Note: External offgas line has plugged when attempting 4 cycles; however, in several series, very little build up in the lines was found after 3 cycles. With careful monitoring of the pressure drop across this portion of the offgas system it may be possible to operate for more than 3 cycles between cleanings.)

Salt collection downstream of the furnace was best accomplished when using filter cartridges with high filter surface area. Both the Nowata wound-glass and the Rosedale pleated stainless steel cartridges achieved 100\% collection efficiencies, and could be used for multiple test cycles. The pleated stainless steel cartridges, which exhibit three to five times more surface area per unit volume than the other filters tested, provided the longest service life. Under the conditions tested, a 20-in.-long, 2.6-in.-diameter pleated stainless steel cartridge, which roughly fits within the current PFP filter footprint, was operated for five cycles before blinding. The knockout pots tested achieved about a third of the collection efficiency observed with the filter cartridges and are not recommended as a method for salt collection.

During the furnace testing, information was collected on corrosion rates by monitoring the appearance and weight loss of system components (baffle plate, boat, offgas tube) and corrosion coupons (Inconel 690, Haynes HR-160, Haynes 214, and Hastelloy X) placed in the sample boat. This testing showed that in the high-temperature, chloride salt environment, the materials tested exhibited high corrosion rates (400 to 700 mils per year), but the mechanism was predominantly uniform corrosion as compared to localized corrosion (pitting). Inconel 690 and Haynes HR-160 displayed the lowest relative corrosion rates. Hastelloy X corroded more rapidly when compared to the other three alloys, but its overall performance was still sufficient for withstanding the HCP oxides environment.

The simulant boats constructed of Hastelloy X survived up to 40 test cycles before being retired without any failures, including welds. Welds and heat-affected zones can be susceptible to preferential attack in certain environments. Welded corrosion specimens were not included in these tests, so weld and heataffected zone attack cannot be assessed for the test alloys, except for the Hastelloy X from which the boats were made. Based on the long service life achieved in the testing, and the absence of weld and heat-affected zone attack, Hastelloy X should be retained as the material of construction for the boats. However, to minimize risk of heater element failure from contact with the boat, consideration should be given to decreasing the boat width by about $1 / 4$ in.

With the recommended mitigation approaches discussed here, reasonable process operability should be achieved during thermal stabilization of the washed HCP items at PFP. The $1 \mathrm{wt} \%$ chloride salt content in the simulant represents the expected residual salt level in a moderately efficient washing process. More efficient washing will reduce the mass of chloride salts charged to the furnaces and improve the overall thermal stabilization operability. 


\subsection{Reference}

Perry, R.H., Green, D.W., Perry's Chemical Engineers' Handbook, $6^{\text {th }}$ ed., The McGraw-Hill Companies, Inc., New York, 18-23 (1984). 


\section{Appendix A}

\section{Basis for Simulant Composition}

This appendix summarizes the technical basis for selecting the simulant used to represent the washed HCP solids that will undergo thermal stabilization at PFP. This simulant composition was based on the assumption that the HCP items will undergo three stages of countercurrent washing. Most of the information provided here is described in much greater detail in Letter Report 41921-RPT02, "Evaluation of Solids Rinsing to Treat PFP High Chloride Plutonium Solids".

In summary, it was determined that a $1 \%$ salt mixture, consisting of $10 \% \mathrm{MgCl}_{2}$ and the balance an equimolar mixture of $\mathrm{NaCl}$ and $\mathrm{KCl}$ in $\mathrm{CeO}_{2}$, provided a reasonable corrosion potential challenge to the furnace system. All three salts are volatile chlorides relative to $\mathrm{CaCl}_{2}$ and $\mathrm{CaF}_{2}$, the only other halide salts expected in the PFP solids. A 1\% salt level is equal to the expected maximum residual level of salts for three stages of countercurrent rinsing, based on computer modeling and a combination of conservative assumptions for rinsing. These assumptions include the worst case for high salt concentration (about $35 \%$ salt); poor solids settling characteristics (based on laboratory test results with a variety of simulants); and a final filtration step that does not further dewater decanted solids.

Inefficiencies introduced during full-scale operations beyond those experienced in laboratory testing or identified in computer modeling could increase the actual maximum residual salt level. It appears that a $1 \%$ level of any of these salts (assuming that the $\mathrm{MgCl}_{2}$ is converted to $\mathrm{MgO}$ ) does not create a simulant that would exceed the $0.5 \%$ moisture uptake limit. In fact, the only salt found to exceed the moisture limit was the relatively nonvolatile $\mathrm{CaCl}_{2}$ salt (moisture limit exceeded when $\mathrm{CaCl}_{2}$ present at $1.2 \%$ ). Setting the $\mathrm{MgCl}_{2}$ content at $10 \%$ of the total salt mixture provides the desired challenge as a simulant, when the $\mathrm{MgCl}_{2}$ decomposes to $\mathrm{MgO}$ during furnace heatup (to $950^{\circ} \mathrm{C}$ ) and produces $\mathrm{HCl}$ as a byproduct. At the same time, it does not dilute the other two salts that are expected to volatilize primarily at the maximum calcining temperature $\left(950^{\circ} \mathrm{C}\right)$, where the corrosion rate is expected to be greatest.

Five considerations were taken into account in establishing a salt composition and concentration for corrosion tests:

1. initial (unwashed) composition of the HCP items

2. estimated residual salt concentrations based on washing/rinsing tests conducted with simulants and deionized water used for each stage of rinsing

3. expected effects of countercurrent rinsing on residual salt concentrations, developed through computer modeling

4. salt limits based on moisture uptake tests

5. volatility of salts used in the tests.

To provide a basis for the initial, unwashed HCP items, the processes used at Rocky Flats Environmental Technology Site (RFETS) that generated the HCP items were reviewed, along with all available analytical data on the HCP items at PFP. This review is provided in Appendix A of Letter Report 41921RPT02. The RFETS processes and the relative salt compositions used in each process are listed below. 


\section{Potential Salt Composition for Simulants Based on RFETS Process Chemistry}

\begin{tabular}{|c|c|c|c|c|c|c|c|}
\hline \multirow{2}{*}{ Process } & \multicolumn{7}{|c|}{ Mole \% } \\
\hline & $\mathrm{NaCl}$ & KCl & $\mathrm{MgCl}_{2}$ & MgO & $\mathrm{CaCl}_{2}$ & $\mathrm{CaO}$ & $\mathbf{C a F}$ \\
\hline $\begin{array}{l}\text { Plutonium Fluoride Bomb } \\
\text { Reduction - Fresh }\end{array}$ & & & & & & 100 & \\
\hline $\begin{array}{l}\text { Plutonium Fluoride Bomb } \\
\text { Reduction - Spent }\end{array}$ & & & & & & 20 & 80 \\
\hline Direct Oxide Reduction & & & & & 69 & 31 & \\
\hline $\begin{array}{l}\text { Molten Salt Extraction - Low } \\
\mathrm{MgCl}_{2} \text { Concentration }\end{array}$ & 46 & 46 & 6 & & & & \\
\hline $\begin{array}{l}\text { Molten Salt Extraction - Optimum } \\
\mathrm{MgCl}_{2} \text { Concentration }\end{array}$ & 35 & 35 & 30 & & & & \\
\hline $\begin{array}{l}\text { Molten Salt Extraction - Optimum } \\
\mathrm{CaCl}_{2} \text { Concentration }\end{array}$ & 48 & & 26 & & 26 & & \\
\hline Electrorefining & 49.5 & 49.5 & & 1 & & & \\
\hline
\end{tabular}

For purposes of evaluating the residual levels of salt in rinsed simulants, a nominal chloride salt content of $34.5 \%$ in $\mathrm{CeO}_{2}$ (equivalent to $25 \%$ salts on a $\mathrm{PuO}_{2}$ basis) was established for initial unwashed $\mathrm{HCP}$ items, based on the fact that approximately three-quarters of the solids inventory consists of $\mathrm{PuO}_{2}$ solids with $25 \%$ or less impurities.

Starting with simulants containing various pure and mixed component chloride salts (at $34.5 \%$ weight percent) in $\mathrm{CeO}_{2}$, a series washing tests were conducted and the residual salt concentrations were measured or calculated (from mass balances). Next, the effects of countercurrent rinsing were estimated by developing a simple model to predict residual salt levels using an equation for multistage countercurrent extraction of wet salt-laden solids using settling and decanting (Brian 1972) and adapting the last rinsing stage to include an additional step of filtration. An iterative computer model that duplicated the simple countercurrent extraction equation was also developed to optimize the management of rinsewater of the countercurrent process. The data from the laboratory washing tests were used as input into the model. Using a set of conservative and/or worst-case assumptions, the countercurrent model predicted a $1 \%$ residual salt level in the washed solids. The performance of the countercurrent rinsing system is sensitive to the fraction of water retained with the solids after each stage of settling and decanting, as well as the ability of the filter to further dewater the decanted solids. It is also adversely affected by the salt concentration in the solids up to about $35 \%$ salt. After factoring in conservative potential inefficiencies for settling and decanting and filtering at the worst case salt concentration in the full-scale process at PFP, it was projected that a residual salt level of $1 \%$ or less should be achievable using the optimum configuration for rinsewater management.

At concentrations of $2 \%, \mathrm{NaCl}, \mathrm{KCl}$ and $\mathrm{CaF}_{2}$ did not appear to adversely affect the moisture uptake behavior of $\mathrm{CeO}_{2}$ solids. Adding $\mathrm{MgCl}_{2}$ to a simulant had only a very modest effect, because it was mostly converted to $\mathrm{MgO}$ during calcining and $\mathrm{MgO}$ does not pick up nearly as much moisture as $\mathrm{MgCl}_{2}$. Only $\mathrm{CaCl}_{2}$ caused significant moisture uptake compared to the other chlorides.

In establishing the composition of the salt mixture used for the prototype furnace system testing, the volatilities of the chloride salts were considered. Salt mixtures containing large quantities of $\mathrm{CaCl}_{2}$ and $\mathrm{CaF}_{2}$ salts were excluded because these salts have very low volatilities compared to $\mathrm{NaCl}, \mathrm{KCl}$, and $\mathrm{MgCl}_{2}$. Mixtures containing the latter three salts come from the electrorefining and some of the molten salt extraction processes, and generally contain equimolar concentrations of $\mathrm{NaCl}$ and $\mathrm{KCl}$. $\mathrm{The}_{\mathrm{MgCl}}$ 
content in the molten salts for these processes range from $<1 \%$ for the molten salt extraction process to between $6 \%$ and $30 \%$ of the total salt inventory for the electrorefining process. However, $\mathrm{MgCl}_{2}$ is expected to convert to $\mathrm{MgO}$ and $\mathrm{HCl}$ in humid air at temperatures between $250^{\circ} \mathrm{C}$ and $500^{\circ} \mathrm{C}$ (Smith et al. 2000), much lower temperatures than the final calcination temperature of $950^{\circ} \mathrm{C}$. In four of the seven analyzed PFP HCP oxide items that contained all three salts, the $\mathrm{MgCl}_{2}$ concentration was approximately $10 \%$ of the total salt inventory.

\section{References}

Brian, PT. 1972. Staged Cascades in Chemical Processing. Prentice-Hall, Inc., Englewood Cliffs, NJ.

Smith, DM, MP Neu, E Garcia, and LA Morales. 2000. "Hydration of Plutonium Oxide and Process Salts, $\mathrm{NaCl}, \mathrm{KCl}, \mathrm{CaCl}_{2}, \mathrm{MgCl}_{2}$ : Effect of Calcination of Residual Water and Rehydration." Waste Management 20:479-490. 


\section{Appendix B}

\section{Furnace Operation using Heating Cycle Planned for High-Chloride Pu Oxide Processing}

The following procedure was used to perform the furnace test runs:

1. Clean furnace and/or replace heating elements and any other corroded or otherwise damaged components, including the offgas system.

2. Document condition of the test apparatus by photographing the inside of the furnace and (as possible) the insides of the offgas system components. Weigh the boats, baffle, the internal offgas line section passing through the furnace wall, and the filter cartridges or knockout pot (packing only on heavier knockout pot housings).

3. Load a boat with $\mathrm{CeO}_{2} / \mathrm{Cl}$ simulant.

4. Put one set of corrosion coupons into the boat half immersed in powder. Position a Type K thermocouple into the $\mathrm{CeO}_{2}$ powder in the boat, and plug thermocouple into reader/datalogger.

5. Place the loaded boat into furnace, close the door and turn on controller.

6. Start offgas blower and set offgas flow rate at 1 SCFM.

7. Heat from room temp to $500 \mathrm{C} @ 300 \mathrm{C} / \mathrm{hr}$

8. Heat from 500C to 700C@200C/hr

9. Heat from 700C to 900C @ 125C/hr

10. Heat from 900C to $1000 \mathrm{C} @ 75 \mathrm{C} / \mathrm{hr}$

11. Hold temperature@1000C for 2 hr.

12. Allow controller to cool below $300^{\circ} \mathrm{C}$ before removing boat.

13. Remove boat and set aside to cool.

14. Before emptying the boat removed from the furnace, photograph the boat with simulant and the corrosion coupon set.

15. Sample the $\mathrm{CeO}_{2}$ in the boat by removing a sample from an area not contaminated with corrosion products and placing in a sample vial. Label the vial with cycle number, and store the vial in archive sample storage for later analysis.

16. Empty the boat when cool enough; clean out by dry brushing with nonmetallic brush to remove residue but without significantly affecting corrosion products if any.

17. Carefully dry brush the corrosion coupons with same or similar brush.

18. Photograph the empty boat, thermocouple, and coupons.

19. Weigh the boat and coupons and record on data sheets.

20. Refill the emptied boat with fresh simulant, install the thermocouple, and place the brushed coupons in the simulant as before to prepare for the next cycle.

21. Photograph the air baffle.

B. 1 
22. Brush off the air baffle, reweigh, and record data.

23. Photograph the inside of the furnace when cool enough, and clean out any residue inside the furnace cavity.

24. Remove the offgas exit tube from the back of the furnace when cool.

25. Inspect the inside and photograph if possible.

26. Brush out the tube with a nonmetallic brush, weigh, and record data and observations.

27. Repeat this inspection and cleaning for other offgas system components as determined to be necessary (e.g., knockout pot).

28. Reassemble the furnace/offgas system to prepare for the next cycle.

29. Repeat steps $3-28$.

Note: Monitoring frequencies for any test parameter increased or decreased as determined necessary from initial testing, and at the direction of the principal investigator.

Table B.1. Matrix of Parameters Measured During Testing

\begin{tabular}{|l|l|l|}
\hline \multicolumn{1}{|c|}{ Parameter } & \multicolumn{1}{|c|}{ Frequency } \\
\hline Furnace Temperature & Continuously & Furnace controller \\
\hline Boat/Simulant Temperature & Once per 10 sec & $\begin{array}{l}\text { Thermocouple } \\
\text { readout/datalogger }\end{array}$ \\
\hline $\begin{array}{l}\text { Offgas Line Temperature near Furnace } \\
\text { Exit }\end{array}$ & Once per 10 sec & $\begin{array}{l}\text { Thermocouple } \\
\text { readout/datalogger }\end{array}$ \\
\hline Offgas Flow Rate & Once per 15 min & Visual/Manual - data sheet \\
\hline Condition of Boat w/Coupons & Once per cycle & $\begin{array}{l}\text { Photograph/written observations } \\
\text { (b) }\end{array}$ \\
\hline Condition of Cleaned Boat & Once per cycle & Photograph/written observations \\
\hline Condition of Cleaned Coupons & Once per cycle & Photograph/written observations \\
\hline Weight of Boat & Once per cycle & Data sheet \\
\hline Weight of Coupons & Once per cycle & Data sheet \\
\hline $\begin{array}{l}\text { Condition of Furnace Interior (inc. } \\
\text { heating elements) }\end{array}$ & Once per cycle & Photograph/written observations \\
\hline Heater Element Performance & Once per 10 sec & Voltage/Current - Datalogger \\
\hline $\begin{array}{l}\text { Condition of Offgas Line (Section } \\
\text { exiting furnace) }\end{array}$ & Once per cycle & Photograph/written observations \\
\hline Weight of Offgas Line Section & Once per cycle & Photograph/written observations \\
\hline $\begin{array}{l}\text { Condition of Filter Element and Filter } \\
\text { Holder }\end{array}$ & Once per cycle & Photograph/written observations \\
\hline $\begin{array}{l}\text { Weights of Filter Element and Filter } \\
\text { Holder }\end{array}$ & Once per cycle & Data sheet \\
\hline
\end{tabular}

(a) As testing progressed the monitoring frequency of the parameters was adjusted up or down as determined necessary by the principal investigator.

(b) Photographs, observations and other recorded data shall clearly identify the cycle number and other pertinent information.

(c) The filter element needed to be monitored more frequently (e.g., a $\Delta \mathrm{P}$ cell to measure pressure drop from plugging). 


\section{Appendix C}

\section{Cycle-by-Cycle Summary for HCP Oxides Furnace Corrosion Tests}

Blue Text indicates equipment modification or new batch of simulant

Red Text indicates plugging or failure

Green Text indicates that a piece of equipment was cleaned

Cycle \#1

- Controlled furnace with Thermolyne controller (no ramping).

- Simulant Batch \#1, Boat \#2, Baffle \#1, Coupon Set \#1, Inconel 600 offgas line \#1.

- Knockout pot was completely filled with packing: Final DP $=1.3$ in $-\mathrm{H}_{2} \mathrm{O}$.

- Problems with datalogger when boat TC was higher than $\sim 500^{\circ} \mathrm{C}$ (disconnected TC-100).

Cycle \#2

- Simulant Batch \#2, Boat \#2, Baffle \#1, Coupon Set \#1, Inconel 600 offgas line \#1.

- Cleaned knockout pot before cycle: Final DP $=0.30$ in $-\mathrm{H}_{2} \mathrm{O}$.

- Problems with datalogger when boat TC was higher than $\sim 500^{\circ} \mathrm{C}$ (disconnected TC-100).

$\underline{\text { Cycle \#3 }}$

- Simulant Batch \#2, Boat \#1, Baffle \#1, Coupon Set \#2, Inconel 600 offgas line \#1.

- Did not clean knockout pot before cycle: Final DP $=0.66$ in $-\mathrm{H}_{2} \mathrm{O}$.

Cycle \#4

- Problems with datalogger when boat TC was higher than $\sim 500^{\circ} \mathrm{C}$ (disconnected TC-100).

- Switched to new controller (programmed ramp rates to match PFP temperature program).

- Simulant Batch \#2, Boat \#2, Baffle \#1, Coupon Set \#1, Inconel 600 offgas line \#1.

- Did not clean knockout pot before cycle: Final DP $=1.0$ in $-\mathrm{H}_{2} \mathrm{O}$.

- Cleaned Inconel 600 offgas line inside furnace before cycle: removed hard ring of material inside the tube near the ferrules.

- Recorded TC-100 manually to avoid problems with datalogger.

\section{Cycle \#5}

- Simulant Batch \#2, Boat \#2, Baffle \#1, Coupon Set \#1, Inconel 600 offgas line \#1.

- Cleaned knockout pot before cycle: Final DP $=0.13$ in $-\mathrm{H}_{2} \mathrm{O}$.

- Reconfigured $3 / 4$ " offgas line between back of furnace and knockout pot. Installed 4-elbows and insulated the entire section of line.

- Problems with datalogger. Disconnected TC-100 and the voltage/current leads in order to stabilize temperature readings from TC-101 through 103.

\section{$\underline{\text { Cycle \#6 }}$}

- Simulant Batch \#2, Boat \#2, Baffle \#1, Coupon Set \#1, Inconel 600 offgas line \#2.

- The first offgas line had completely corroded through and was replaced.

- Did not clean knockout pot before cycle: Final DP $=0.34$ in $-\mathrm{H}_{2} \mathrm{O}$.

- Problems with datalogger. Disconnected TC-100 and the voltage/current leads in order to stabilize temperature readings from TC-101 through 103. 


\section{Cycle \#7}

- Simulant Batch \#2, Boat \#2, Baffle \#1, Coupon Set \#1, Inconel 600 offgas line \#2.

- Did not clean knockout pot before cycle: Final DP $=0.88$ in $-\mathrm{H}_{2} \mathrm{O}$.

- Problems with datalogger fixed. Grounded outside sheath of all TC's located inside the furnace

Cycle \#8 (including the controller TC).

- Simulant Batch \#2 and \#3, Boat \#2, Baffle \#1, Coupon Set \#1, Inconel 600 offgas line \#2.

- Cleaned knockout pot before cycle: Final DP $=0.60$ in $-\mathrm{H}_{2} \mathrm{O}$.

\section{$\underline{\text { Cycle \#9 }}$}

- Simulant Batch \#3, Boat \#2, Baffle \#1, Coupon Set \#1, Inconel 690 offgas line \#1(6").

- Did not clean knockout pot before cycle: Final DP $=0.56$ in $-\mathrm{H}_{2} \mathrm{O}$.

- The second offgas line had nearly corroded through and was replaced with a piece of $3 / 4$ " Inconel

Cycle \#10 690 pipe turned down to $3 / 4$ " O.D.

- Simulant Batch \#3, Boat \#2, Baffle \#1, Coupon Set \#1, Inconel 690 offgas line \#1(6").

- Did not clean knockout pot before cycle: Final DP $=0.74$ in $-\mathrm{H}_{2} \mathrm{O}$.

- Cleaned Inconel 690 offgas line \#1.

\section{Cycle \#11}

- Simulant Batch \#3, Boat \#2, Baffle \#1, Coupon Set \#1, Inconel 690 offgas line \#1(6”).

- Did not clean knockout pot before cycle: Final DP $=0.94$ in $-\mathrm{H}_{2} \mathrm{O}$.

\section{Cycle \#12}

- Simulant Batch \#3, Boat \#2, Baffle \#1, Coupon Set \#1, Inconel 690 offgas line \#1(6”).

- Cleaned knockout pot before cycle: Final DP $=0.44$ in $-\mathrm{H}_{2} \mathrm{O}$.

Cycle \#13

- Simulant Batch \#3, Boat \#2, Baffle \#1, Coupon Set \#1, Inconel 690 offgas line \#1(6”).

- Changed water in scrubber before starting cycle.

- Did not clean knockout pot before cycle: Final DP $=0.60$ in $-\mathrm{H}_{2} \mathrm{O}$.

Cycle \#14

- Simulant Batch \#3 and \#4, Boat \#2, Baffle \#1, Coupon Set \#1, Inconel 690 offgas line \#1(6").

- Started cycle with a Purolator 10-micron, 10" long cartridge filter in place of the knockout pot (did not clean the knockout pot). The filter blinded when the furnace reached $\sim 950^{\circ} \mathrm{C}\left(7 \mathrm{in}-\mathrm{H}_{2} \mathrm{O}\right.$, no traces of salts downstream of filter). Re-installed knockout pot after filter blinded.

Cycle \#15

- Simulant Batch \#4, Boat \#2, Baffle \#1, Coupon Set \#1, Inconel 690 offgas line \#1(6”).

- Cleaned and modified knockout pot. Half of pot is packed with same packing as before. Other half of pot is packed with wire mesh.

- Section of the $3 / 4^{\prime \prime}$ Inconel 600 offgas line plugged when the furnace was at $967^{\circ} \mathrm{C}$. Cycle was completed with little gas flow through the furnace. Most of the plugging was located in two

Cycle \#16 elbows closest to the knockout pot.

- Simulant Batch \#4, Boat \#2, Baffle \#1, Coupon Set \#1, Inconel 690 offgas line \#1(6”).

- Did not clean knockout pot before starting cycle.

- Cleaned Inconel 600 offgas line (U-bend).

- Right heating element failed when the furnace was at $957^{\circ} \mathrm{C}$. Hole formed on the surface of the element, which arced and cut a hole in the wall of the boat. Metal and refractory were deposited of the far side element. 


\section{Cycle \#17}

- Simulant Batch \#4, Boat \#2, Baffle \#1, Coupon Set \#1, Inconel 690 offgas line \#1(6”).

- First cycle with new heating elements.

- Began monitoring the amount of bow on the sample boat (the bow is the widest point between the left and right sides of the boat). The boat was placed in a vice and adjusted to 5.0" wide.

- Added a condenser to the offgas line upstream of TC-103. Condenser is followed by a heated section of line. This is to provide a dry gas stream to F-100.

- Did not clean knockout pot before cycle: Final DP $=0.18$ in $-\mathrm{H}_{2} \mathrm{O}$.

\section{Cycle \#18}

- Simulant Batch \#4, Boat \#2, Baffle \#1, Coupon Set \#1, Inconel 690 offgas line \#1(6").

- Did not clean knockout pot before cycle: Final DP $=0.34$ in $-\mathrm{H}_{2} \mathrm{O}$.

- Boat measured 5-1/16" bow.

\section{Cycle \#19}

- Simulant Batch \#4, Boat \#2, Baffle \#1, Coupon Set \#1, Inconel 690 offgas line \#1(6").

- Replaced knockout pot with 2-micro cyclones in series. Cyclones did not collect any salts (only light layer deposited on all inside surfaces).

- Boat measured 5-1/8" bow. Straightened walls to 5-1/16" wide with vice.

\section{Cycle \#20}

- Simulant Batch \#4, Boat \#2, Baffle \#1, Coupon Set \#1, 3/4" Ceramic offgas line \#1.

- Re-installed knockout pot. Did not clean before starting cycle. Final DP $=0.50$ in $-\mathrm{H}_{2} \mathrm{O}$.

- Replaced Inconel 690 offgas line \#1 (6") with a 3/4" ceramic tube. Degree of plugging for Inconel 690 offgas line: $39 \%$ reduction in diameter, $63 \%$ reduction in area.

Cycle \#21

- Boat measured 5-1/8" bow. Straightened walls to 5-1/16" wide with vice.

- Simulant Batch \#4 and \#5, Boat \#2, Baffle \#1, Coupon Set \#2, 3/4" Ceramic offgas line \#1.

- $\quad$ Retired Coupon Set \#1.

- Did not clean knockout pot before cycle: Final DP $=2.4$ in $-\mathrm{H}_{2} \mathrm{O}$.

- Boat measured 5-1/8" bow. Straightened walls to 5-1/32" wide with vice.

\section{Cycle \#22}

- Simulant Batch \#5, Boat \#2, Baffle \#1, Coupon Set \#2, 3/4” Ceramic offgas line \#1.

- Cleaned knockout pot before cycle: Final DP $=0.31$ in $-\mathrm{H}_{2} \mathrm{O}$.

- Cleaned ceramic offgas tube (approximately $1 / 2$ plugged).

- Cleaned Inconel 600 offgas line (U-bend). Removed very little material.

- Boat measured 5-1/8" bow. Straightened walls to 5.0" wide with vice.

- Furnace controller unable to hold at $1000^{\circ} \mathrm{C}$. Temperature fluctuated $\pm 2^{\circ} \mathrm{C}$.

Cycle \#23

- Simulant Batch \#5, Boat \#2, Baffle \#1, Coupon Set \#2, 3/4" Ceramic offgas line \#1.

- Did not clean knockout pot before cycle: Final DP $=0.80$ in $-\mathrm{H}_{2} \mathrm{O}$.

- Boat measured 5-1/16" bow.

- Tuned furnace controller up to $500^{\circ} \mathrm{C}$.

\section{Cycle \#24}

- Simulant Batch \#5, Boat \#2, Baffle \#1, Coupon Set \#2, 3/4" Ceramic offgas line \#1.

- $\quad$ Cleaned knockout pot before cycle: Final DP $=0.42$ in $-\mathrm{H}_{2} \mathrm{O}$.

- Boat measured 5-3/32" bow. Straightened walls to 5.0" wide with vice. 
Cycle \#25

- Simulant Batch \#5, Boat \#2, Baffle \#1, Coupon Set \#2, 3/4" Ceramic offgas line \#1.

- Did not clean knockout pot before cycle: Final DP $=0.71$ in $-\mathrm{H}_{2} \mathrm{O}$.

- Cleaned ceramic offgas tube (deposits difficult to remove).

- Boat measured 5-3/32" bow. Straightened walls to 5.0" wide with vice.

Cycle \#26

- Simulant Batch \#5, Boat \#2, Baffle \#1, Coupon Set \#2, 3/4" Ceramic offgas line \#1.

- Cleaned knockout pot before cycle: Final DP $=0.26$ in $-\mathrm{H}_{2} \mathrm{O}$.

Cycle \#27

- Boat measured 5-1/16" bow.

- Simulant Batch \#5 and \#6, Boat \#2, Baffle \#1, Coupon Set \#2, 3/4" Ceramic offgas line \#1.

- Did not clean knockout pot before cycle: Final DP $=0.60$ in $-\mathrm{H}_{2} \mathrm{O}$.

Cycle \#28

- Boat measured 5-3/32" bow. Straightened walls to 4-15/16" wide with vice.

- Simulant Batch \#6, Boat \#2, Baffle \#1, Coupon Set \#2, 3/4" Ceramic offgas line \#1.

- Replaced knockout pot with filter system from Nowata Filtration (purchased from

Filtersource.com). Installed 2 woven glass 10-micron filter cartridges. Final DP $=3.5$ in $-\mathrm{H}_{2} \mathrm{O}$.

- Replaced F-100 with a 0-200 SCFH flowmeter.

- Cleaned ceramic offgas tube.

Cycle \#29

Boat measured 5-3/32" bow. Straightened walls to 4-15/16" wide with vice.

- Simulant Batch \#6, Boat \#2, Baffle \#1, Coupon Set \#2, 3/4" Ceramic offgas line \#1.

- Installed 2 woven glass 20-micron filter cartridges. Final DP $=3.4 \mathrm{in}-\mathrm{H}_{2} \mathrm{O}$.

- Cleaned Inconel 600 offgas line (U-bend).

- Boat measured 5-1/16" bow.

Cycle \#30

- Simulant Batch \#6, Boat \#2, Baffle \#1, Coupon Set \#2, 3/4" Ceramic offgas line \#1.

- Did not replace filter cartridges before cycle: Final DP $=6.5$ in $-\mathrm{H}_{2} \mathrm{O}$.

- Cleaned ceramic offgas tube. End of tube cracked. Cut damaged portion off and re-installed.

- Boat measured 5-1/16" bow.

- Replaced F-100 with a new flowmeter. Range is 0-200 SCFH.

Cycle \#31

- Simulant Batch \#6, Boat \#2, Baffle \#1, Coupon Set \#2, 3/4” I-690 offgas line \#1 (11").

- Replaced 3/4" Ceramic offgas line with 3/4" I-690 offgas line (11" piece of I-690 pipe turned down to $3 / 4 "$ O.D.)

- Modified Nowata Filtration housing to use metal packing and serve as a knockout pot. Loaded $10 \mathrm{~mm}$ nominal Interpack packing. Final $\mathrm{DP}=2.8$ to 5.5 in $-\mathrm{H}_{2} \mathrm{O}$.

- Boat measured 5-3/32" bow. Straightened walls to 5.0" wide with vice.

- Datalogger was not turned on during this cycle.

- It was necessary to strike filter housing to reduce the pressure drop and complete the cycle.

Cycle \#32

- Simulant Batch \#6, Boat \#2, Baffle \#1, Coupon Set \#2, 3/4” I-690 offgas line \#1 (11”).

- Increased simulant loading to $1269 \mathrm{~g}$ per cycle.

- Cleaned knockout pot before cycle. Switched the inlet and outlet ports on the filter housing to reduce the rate of plugging where the offgas enters the filter housing. Final DP $=2.2$ in $-\mathrm{H}_{2} \mathrm{O}$.

- Boat measured 5-1/8" bow. Straightened walls to 5.0" wide with vice. 


\section{Cycle \#33}

- Simulant Batch \#6 and \#7, Boat \#2, Baffle \#1, Coupon Set \#2, 3/4" I-690 offgas line \#1 (11").

- Did not clean knockout pot before cycle: Final DP $=4.0$ to 6.3 in- $\mathrm{H}_{2} \mathrm{O}$.

- Boat measured 5-3/32" bow. Straightened walls to 5.0" wide with vice.

- It was necessary to strike the knockout pot housing several times to reduce the pressure drop and Cycle \#34 complete the cycle.

- Simulant Batch \#7, Boat \#2, Baffle \#1, Coupon Set \#2, 3/4” I-690 offgas line \#1 (11”).

- $\sim 54 \mathrm{~g}$ of the simulant loading was loaded into a crucible, which was placed in the sample boat with the rest of the simulant.

- Cleaned knockout pot and replaced packing before cycle: Final DP = 1.3 in $-\mathrm{H}_{2} \mathrm{O}$.

- Cleaned Inconel 600 offgas line (U-bend).

- Cleaned Inconel 690 offgas line (inside furnace).

- Replaced F-100 with a 0-100 SCFH flowmeter.

- Boat measured 5-3/32" bow. Straightened walls to 5.0" wide with vice.

\section{Cycle \#35}

- Simulant Batch \#7, Boat \#2, Baffle \#1, No coupons, 3/4" I-690 offgas line \#1 (11").

- Did not clean knockout pot before cycle: Final DP $=5.5$ in $-\mathrm{H}_{2} \mathrm{O}$.

- $\sim 54 \mathrm{~g}$ of the simulant loading was loaded into a crucible, which was placed in the sample boat with the rest of the simulant.

- Boat measured 5-3/32" bow. Straightened walls to 5.0" wide with vice.

- It was necessary to strike the knockout pot housing to reduce the pressure drop and complete the cycle.

\section{Cycle \#36}

- Simulant Batch \#7, Boat \#2, Baffle \#1, 3/4" I-690 offgas line \#1 (11").

- Cleaned knockout pot and replaced packing before cycle: Final DP = 3.5 in $-\mathrm{H}_{2} \mathrm{O}$.

- $\quad$ 54 g of the simulant loading was loaded into a crucible, which was placed in the sample boat with the rest of the simulant.

- Boat measured 5-3/32" bow. Straightened walls to 5.0" wide with vice.

- It was necessary to strike the knockout pot housing to reduce the pressure drop and complete the cycle.

- Struck area of offgas line where TC-102 was located. TC-102 immediately began to read a higher temperature. Possible that there were deposits on the thermocouple sheath affecting the temperature reading.

\section{Cycle \#37}

- Simulant Batch \#7, Boat \#2, Baffle \#1, 3/4" I-690 offgas line \#1 (11").

- Did not clean knockout pot before cycle: Final DP = Not Measured in $-\mathrm{H}_{2} \mathrm{O}$.

- $\quad$ 54 g of the simulant loading was loaded into a crucible, which was placed in the sample boat with the rest of the simulant.

- Boat measured 5-1/8" bow. Straightened walls to 5.0" wide with vice.

- Cleaned Inconel 690 offgas line (inside furnace).

- Section of the $3 / 4$ " Inconel 600 offgas line plugged when the furnace was at $975^{\circ} \mathrm{C}$ on the final heating leg of the temperature program. Cycle was aborted and the furnace was allowed to cool. Most of the plugging was located in the elbow closest to the knockout pot and the second elbow downstream of the furnace. 
Cycle \#38

- Simulant Batch \#7 and \#8, Boat \#2, Baffle \#1, 3/4" I-690 offgas line \#1 (11").

- Boat measured 5-3/32" bow. Straightened walls to 5.0" wide with vice.

- Refitted knockout pot to accept cartridge filters from Nowata Filtration (purchased from Filtersource.com). Installed 2 woven glass 50-micron filter cartridges. Final $\mathrm{DP}=3.5 \mathrm{in}-\mathrm{H}_{2} \mathrm{O}$.

- Replaced F-100 with a 0-200 SCFH flowmeter.

- Cleaned Inconel 600 offgas line (U-bend).

- Cleaned Inconel 690 offgas line (inside furnace).

- Replaced section of $1 / 2$ " O.D. stainless tubing between the condenser and TC-103. Tubing had corroded completely through leaving two holes in the tubing.

\section{Cycle \#39}

- Simulant Batch \#8, Boat \#2, Baffle \#1, 3/4” I-690 offgas line \#1 (11").

- Boat measured 5-3/32" bow. Straightened walls to 5.0" wide with vice.

- Did not replace filter cartridges before cycle: Final DP $=7.3$ in $-\mathrm{H}_{2} \mathrm{O}$.

Cycle \#40

- Simulant Batch \#8, Boat \#2, Baffle \#1, 3/4” I-690 offgas line \#1 (11”).

- Installed 2 woven glass 100 -micron filter cartridges. Final DP $=2.8$ in- $\mathrm{H}_{2} \mathrm{O}$.

\section{Cycle \#41}

- Boat measured 5-1/8" bow. Straightened walls to 5.0" wide with vice.

- Simulant Batch \#8, Boat \#2, Baffle \#1, 3/4" I-690 offgas line \#2 (11").

- Replaced 11" long 3/4" I-690 offgas line \#1 with another 11" long piece of 3/4" I-690 turned pipe.

- Cleaned Inconel 600 offgas line (U-bend).

- Boat measured 5-1/8" bow. Straightened walls to 5.0" wide with vice

- Removed 100 micron filter cartridges to demonstrate to PFP pipe fitters how the salts deposited on the filters. Did not clean before reinstalling filter cartridges. Final DP $=4.5$ in- $\mathrm{H}_{2} \mathrm{O}$.

- Thoroughly insulated the I-600 offgas line all the way to TC-102.

Cycle \#42

- Simulant Batch \#8, Boat \#1, Baffle \#1, 3/4" I-690 offgas line \#2 (11").

- Removed 100 micron filter cartridges for weights. Did not clean before reinstalling filter cartridges. Final DP $=6.0$ in $-\mathrm{H}_{2} \mathrm{O}$.

- Boat \#2 measured 5-1/16" bow. Retired Boat \#2. Started using Boat \#1 (widest point is 5.0").

Cycle \#43

- Simulant Batch \#8 and \#9, Boat \#1, Baffle \#1, 3/4” I-690 offgas line \#2 (11”).

- Removed Nowata filter housing and installed Rosedale filter housing. Installed 20 micron filter cartridge (housing holds one 20" long housing). Final DP $=1.2$ in $-\mathrm{H}_{2} \mathrm{O}$.

- Boat measured 5-1/32" bow. Did not straighten.

- Observed a bow in the top heating element.

- Trace of salts penetrated through filter cartridge when the salts began to boil off. Filter was able to collect all salts $\sim 1$ hour after the salts started to boil.

Cycle \#44

- Simulant Batch \#9, Boat \#1, Baffle \#1, 3/4” I-690 offgas line \#2 (11”).

- Cleaned Inconel 600 offgas line (U-bend).

- Boat measured 5-1/16" bow. Did not straighten.

- Did not replace filter cartridges before cycle: Final DP $=2.3$ in $-\mathrm{H}_{2} \mathrm{O}$. 
Cycle \#45

- Simulant Batch \#9, Boat \#1, Baffle \#1, 3/4" I-690 offgas line \#2 (11").

- Did not replace filter cartridges before cycle: Final DP $=3.8$ in $-\mathrm{H}_{2} \mathrm{O}$.

- Boat measured 5-3/32" bow. Straightened to 5-1/16".

Cycle \#46

- Simulant Batch \#9, Boat \#1, Baffle \#1, 3/4" I-690 offgas line \#2 (11”).

- Did not replace filter cartridges before cycle: Final DP $=4.8$ in $-\mathrm{H}_{2} \mathrm{O}$.

Cycle \#47

- Boat measured 5-3/32" bow. Straightened to 5-1/32".

- Simulant Batch \#9, Boat \#1, Baffle \#1, 3/4" I-690 offgas line \#1 (11").

- Reinstalled 3/4" I-690 offgas line \#1 (11"). Line was cleaned by PFP pipefitters before installation.

- Cleaned Inconel 600 offgas line (U-bend).

- Did not replace filter cartridges before cycle: Final DP $=6.5$ in $-\mathrm{H}_{2} \mathrm{O}$.

Cycle \#48

- Boat measured 5-3/32" bow. Straightened to 5-1/16".

- Simulant Batch \#9 and \#10, Boat \#1, Baffle \#1, 3/4" I-690 offgas line \#1 (11").

- Installed Rosedale 10 micron 20" long filter cartridge: Final DP = 1.4 in- $\mathrm{H}_{2} \mathrm{O}$.

- Boat measured 5-3/32" bow. Straightened to 5.0".

- Trace of salts penetrated through filter cartridge when the salts began to boil off. Filter was able to collect all salts $\sim 1$ hour after the salts started to boil.

Cycle \#49

- Simulant Batch \#10, Boat \#1, Baffle \#1, 3/4” I-690 offgas line \#1 (11”).

- Did not replace filter cartridges before cycle: Final DP $=2.2$ in- $\mathrm{H}_{2} \mathrm{O}$.

- Boat measured 5-1/16" bow. Did not straighten.

Cycle \#50

- Simulant Batch \#10, Boat \#1, Baffle \#1, 3/4" I-690 offgas line \#1 (11").

- Did not replace filter cartridges before cycle: Final DP $=3.2$ in $-\mathrm{H}_{2} \mathrm{O}$.

- Boat measured 5-3/32" bow. Straightened to 5-1/32". 


\section{Appendix D}

\section{Analysis of Deposits in Inconel 600 Furnace Offgas Tube (Inside Furnace)}

Two samples were retrieved for analysis when the furnace exhaust tube was removed and scraped to remove deposits following the second cycle. One sample was a hard dark material either deposited or formed in the region where corrosion was the greatest. This material separated from the wall in large flakes with aggressive scraping. It came from a region of the tube inside the furnace wall but near the outside wall surface as shown in Figure D.1. The second sample was a brittle dirty yellow deposit collected downstream from the first deposit. This material, which was chipped off with less aggressive scraping was dark on the side nearest the tube wall. The exact location of both samples was not measured. There was evidence of corrosion of the tube upstream from the dark deposits and nearer to the furnace interior but there was no removable deposit in this region.

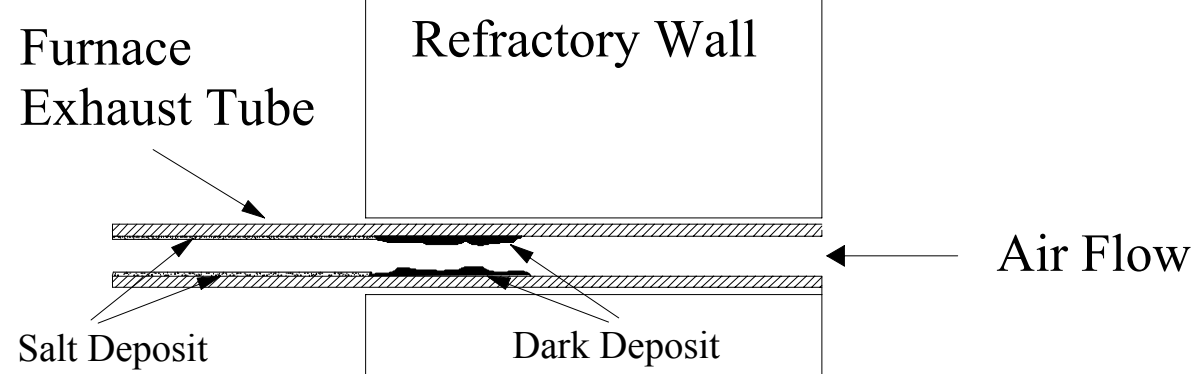

\section{Outside of Furnace}

Furnace Interior

Figure D.1. Schematic of Furnace Wall and Exhaust Tube Showing Approximate Location of the Deposits

Table D.1 shows the average concentrations of elements in the dark deposit based on electron dispersion spectroscopy (EDS) analysis of three locations on a sample. The dark deposit mainly consists of manganese sodium, potassium, chlorine and oxygen. Nickel and sulfur were only detected in one of the analyses at $0.66 \mathrm{wt} \%$ and $0.32 \%$, respectively. Sodium and potassium were present in approximately equal molar concentrations with the sodium molar concentration about 33\% greater than the potassium concentration. The chloride concentration was less than the stoichiometric amount required for sodium and potassium chloride salts. 
Table D.1. Composition of Dark Deposit

in Furnace Exhaust Tube

\begin{tabular}{|l|r|r|}
\hline Element & $\begin{array}{c}\text { Average } \\
\text { Wt \% }\end{array}$ & $\begin{array}{c}\text { Average } \\
\text { Mole\% }\end{array}$ \\
\hline $\mathrm{O}$ & 17.21 & 37.24 \\
\hline $\mathrm{Na}$ & 5.12 & 7.70 \\
\hline $\mathrm{S}$ & 0.11 & 0.12 \\
\hline $\mathrm{Cl}$ & 12.35 & 12.07 \\
\hline $\mathrm{K}$ & 6.53 & 5.79 \\
\hline $\mathrm{Cr}$ & 2.62 & 1.74 \\
\hline $\mathrm{Mn}$ & 49.93 & 31.52 \\
\hline $\mathrm{Fe}$ & 5.93 & 3.65 \\
\hline $\mathrm{Ni}$ & 0.22 & 0.13 \\
\hline
\end{tabular}

The high concentration of manganese is unexpected because it only comprises about $1 \%$ of the Inconel 600 (see Table D.2). Similarly it was surprising that there was essentially no nickel in the deposit even though Inconel 600 is typically $75 \%$ nickel. One possible explanation is that manganese and chromium are reacted with the chloride and leached out of the host metal as a deposit.

Table D.3 shows the average concentrations of elements on the yellow side of the yellow deposit based on electron dispersion spectroscopy (EDS) analysis of three locations on a sample. Only sodium, potassium, chromium, oxygen, and chloride were present in the deposit. Sodium and potassium were not found in approximately equal molar quantities even though the salts were in equimolar concentrations in the calcined solids. Instead the alkali salt mixture in the deposit consisted of approximately 70 mole $\%$ potassium chloride.

Table D.2. Composition of Inconel 600

\begin{tabular}{|l|l|}
\hline Element & Concentration Range \\
\hline $\mathrm{Ni}$ & $72.0 \%$ minimum \\
\hline $\mathrm{Cr}$ & $14.0 \%$ to $17.0 \%$ \\
\hline $\mathrm{Fe}$ & $6.0 \%-10.0 \%$ \\
\hline $\mathrm{Mn}$ & $1.0 \%$ maximum \\
\hline $\mathrm{Cu}$ & $0.5 \%$ maximum \\
\hline $\mathrm{Si}$ & $0.5 \%$ maximum \\
\hline $\mathrm{C}$ & $0.15 \%$ maximum \\
\hline $\mathrm{S}$ & $0.015 \%$ maximum \\
\hline
\end{tabular}


Table D.3. Composition of the Yellow Deposit

in Furnace Exhaust Tube

\begin{tabular}{|c|c|c|}
\hline Element & $\begin{array}{c}\text { Average } \\
\text { Wt \% }\end{array}$ & $\begin{array}{c}\text { Average } \\
\text { Mole\% }\end{array}$ \\
\hline $\mathrm{O}$ & 6.48 & 12.95 \\
\hline $\mathrm{Na}$ & 11.65 & 16.21 \\
\hline $\mathrm{K}$ & 29.66 & 39.06 \\
\hline $\mathrm{Cl}$ & 50.43 & 43.69 \\
\hline $\mathrm{Cr}$ & 1.78 & 1.47 \\
\hline
\end{tabular}

The presence of a small quantity of chromium in the deposit could suggest that a volatile chromium chloride salt was deposited. $\mathrm{CrCl}_{2}$ and $\mathrm{CrCl}_{3}$ have melting points of $824^{\circ} \mathrm{C}$ and $1150^{\circ} \mathrm{C}$, respectively. It is also possible that it is chrome in the tube underneath the deposit dissolved into the salt deposit, which would be consistent with the dark color of the deposit on the side nearest the tube, and the appearance of molten material in the salt deposits as shown in Figure D.2.

The appearance of molten material interspersed within a delicate solids deposit as shown in Figure D.2 suggests that the deposit was below the melting point of the salt mixture, but it was trapping molten droplets of salt entrained in the gas. The alkali salt mixture composition would have a melting point of about $720^{\circ} \mathrm{C}$ assuming that the presence of chromium (or possible alkali oxides based on the deficiency of chloride and the presence of oxygen) did not depress the melting point of the alkali salt mixture. The dark deposit sample appearance was more like that of corrosion products, consistent with the relatively high concentration of oxygen in the deposit (37 mole \%). Figure D. 3 suggests that the dark deposit did not have a delicate open structure as did the yellow deposit. However, the presence of a significant concentration of alkali salt suggests that the salts were depositing but probably as molten material that interacted with the metal tube. The fact that the deposit was from a higher temperature region of the tube would be consistent with this hypothesis.

The chemical analysis and electron images suggest that molten salt deposition on the tube occurred in the zone within the furnace wall near the outside wall of the furnace. This resulted in aggressive corrosion of the inconel 600 tube. Upstream of this zone, there was no significant deposition and tube corrosion occurred due to chloride in the vapor phase (possibly due to the presence of $\mathrm{HCl}$ ), but the corrosion was not as severe. Downstream of this zone, a mixture of solid and molten particles of salt deposited on the tube surface but solidified due to the cooler tube wall temperature. Consequently corrosion that occurred underneath the deposit was less severe than that under the molten salts further upstream. 


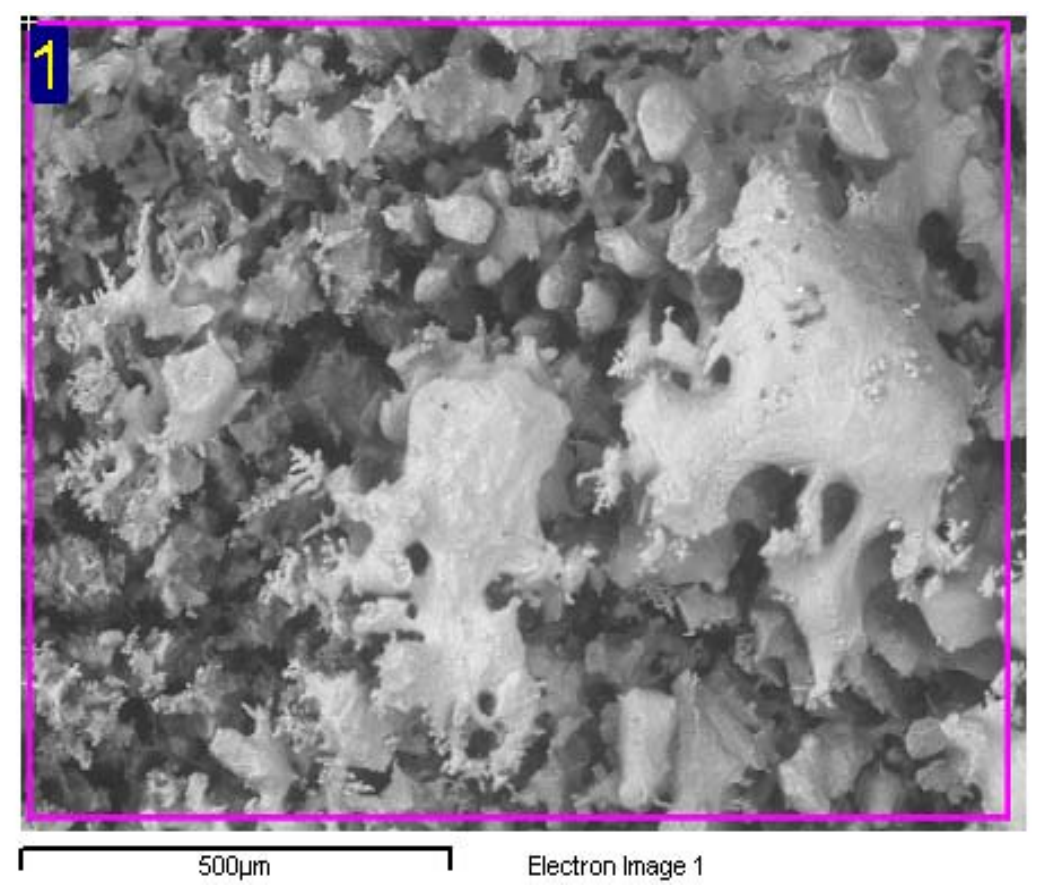

Figure D.2. Electron Image of Yellow Deposit

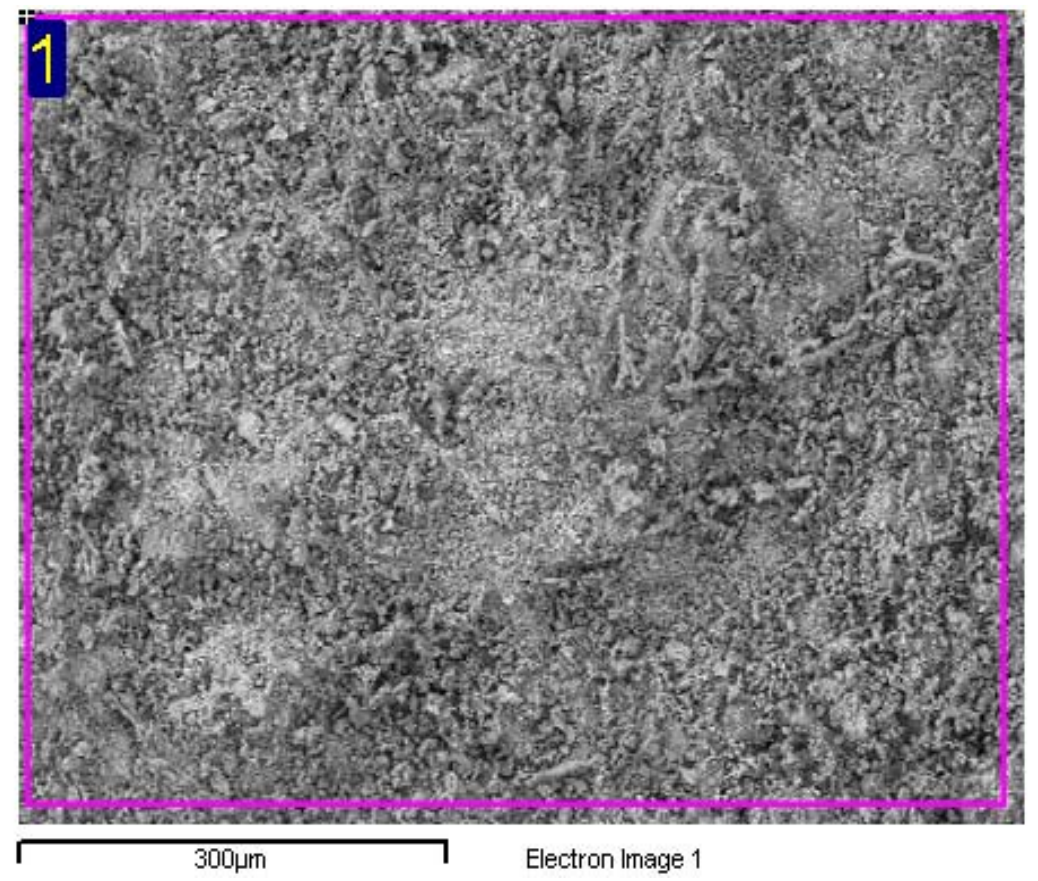

Figure D.3. Electron Image of Dark Deposit 